\title{
Prototype Testing of a Modified Poroelastic Matric Suction Sensor
}

\section{Prabodha Jayasinghe}

Thesis submitted to the Faculty of Graduate and Postdoctoral Affairs in partial fulfillment of the requirements for the degree of

\author{
Master of Applied Science \\ In \\ Environmental Engineering \\ Carleton University \\ Ottawa, Ontario \\ (C) 2013 \\ Prabodha Jayasinghe
}


The undersigned recommend to

The Faculty of Graduate and Postdoctoral Affairs

acceptance of the thesis

\title{
Prototype Testing of a Modified Poroelastic Matric Suction Sensor
}

\author{
Submitted by \\ Prabodha Jayasinghe, B.Eng. \\ in partial fulfillment of the requirements for the degree of \\ Master of Applied Science in Environmental Engineering \\ Dr. Paul Simms \\ Thesis Supervisor \\ Dr. Paul J. Van Geel \\ Chair of the Department \\ Carleton University
}

2013 


\begin{abstract}
The matric suction is one of the stress state variables used in the interpretation of the engineering behaviour of soils. There are many methods available to measure matric suction. This thesis documents development of a Poroelastic Matric Suction Sensor (PE sensor). The advantage of this sensor is that it is a direct method with a relatively large range of suction measurement (up to $8 \mathrm{MPa}$ ), without any cavitation. Modifications of the sensor were carried out to increase accuracy. The modified sensor was then evaluated by comparison with total suction measurements made in artificial silt and in fine grained material. In addition, the behaviour of the sensor when using oil sand tailings was also monitored and compared. The experimental results showed that the suction range of the sensor is about $8 \mathrm{MPa}$, with a mean relative uncertainty of $0.5 \mathrm{MPa}$, a standard deviation of $0.5 \mathrm{MPa}$ compared to the results obtained from the WP4T PotentiaMeter Device. The behaviour of the sensor at temperatures below $0^{0} \mathrm{C}$ was also investigated, and must be further evaluated to obtain reliable results.
\end{abstract}




\section{ACKNOWLEDGMENTS}

I would like to thank my Supervisor Professor Paul Simms for guidance, advice and the support he has given me throughout the time I have worked under him and accepting me in to his excellent group of masters students.

I would also like to thank all the members at Carleton University Stanley Conley, Marie Tudoret Chow, Jason Arnott, Pierre Trudel and Ken McMartin who helped me with the experimental set-ups and all the heavy lifting throughout my studies at the institute.

I am very grateful to have met an excellent set of group members that work under the supervision of Professor Paul Simms who are very helpful, and I would like to especially thank Tessa Innocent Bernard for the help and the self confidence she has given me to succeed in my future endeavours. I wish to thank all my friends for being there during the hard times and encouraging me to pursue further studies.

I would like to thank my family, especially my mother and my father for coming to Canada to give us a better education and being there every step of the way. I want to thank my sister for being my role model, teaching me and supporting me in every single way possible. 


\section{TABLE OF CONTENTS}

ABSTRACT i

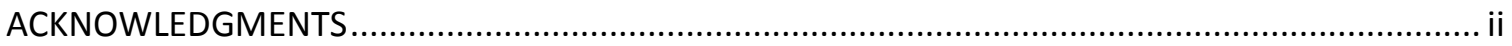

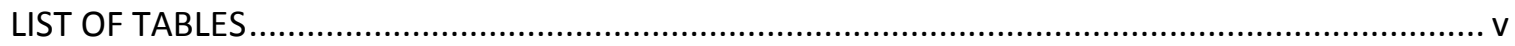

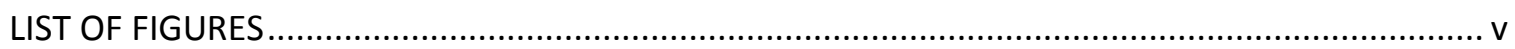

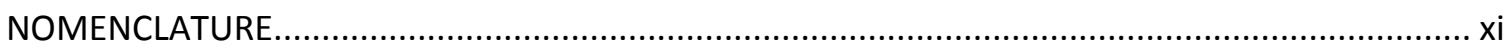

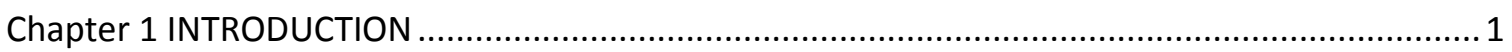

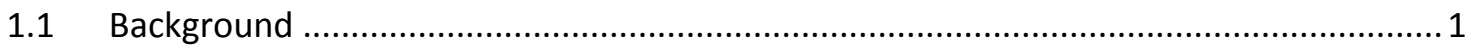

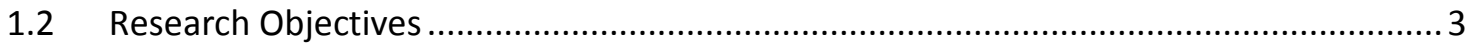

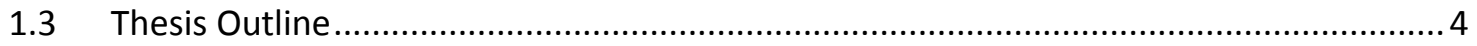

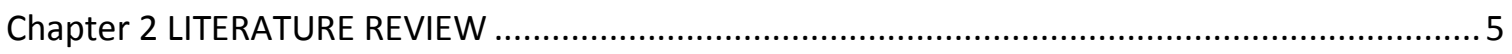

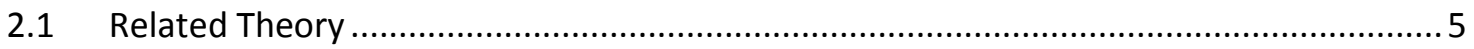

2.1.1 Unsaturated Soils ........................................................................................... 5

2.1.2 Soil Water Characteristic Curve (SWCC) ….......................................................... 5

2.1.3 Hydraulic Conductivity of Unsaturated Soil ........................................................ 8

2.1.4 Matric, Osmotic and Total Suction …............................................................... 11

2.1.5 Matric Suction in Unsaturated Soils: Hysteresis. ............................................... 12

2.1.6 Equation of the Flow in Unsaturated Soil ........................................................... 14

2.1.7 Matric Suction Measurement Techniques........................................................... 17

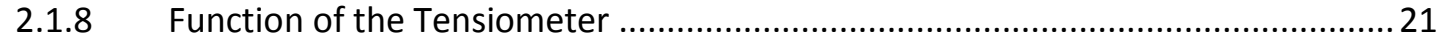

2.1.9 Function of the Heat Dissipation Sensor............................................................... 22

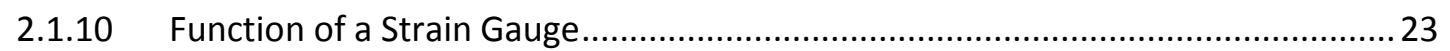

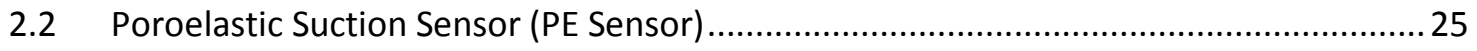

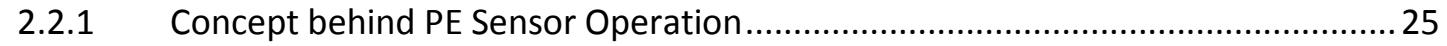

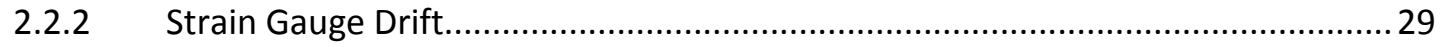

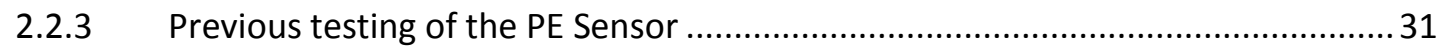

Test Results Conducted by Apking (2010) ……................................................................. 33 
2.2.4 Factors Affecting the Performance of the PE Sensor..........................................59

2.2.5 Phase Transformation of Water in Porous Glass ................................................. 60

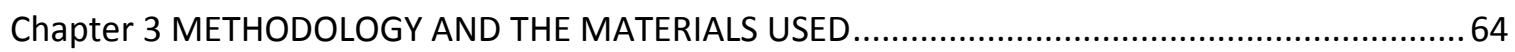

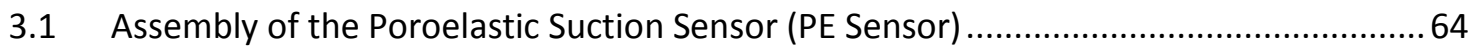

3.1.1 Materials Employed in the Construction of the Poroelastic Suction Sensor .........65

3.2 Saturation Test of the Poroelastic Suction Sensor ..................................................... 79

3.3 Comparison of Total Suction and PE Sensor Using Silt under Drying Conditions ........... 80

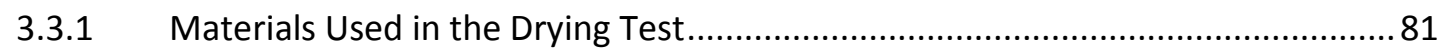

3.3.2 Procedure for the Drying Test Experiment ......................................................... 81

3.4 Wetting and drying of the Silt in the Freezing Conditions ........................................... 83

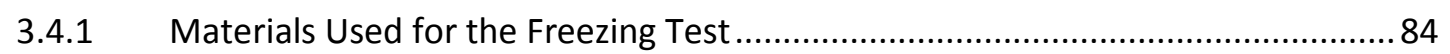

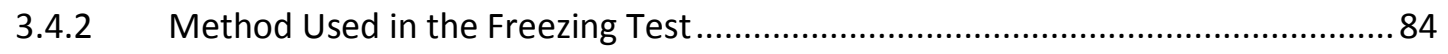

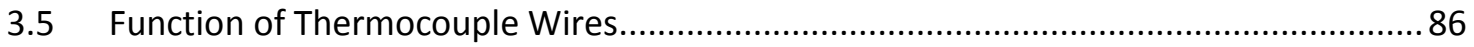

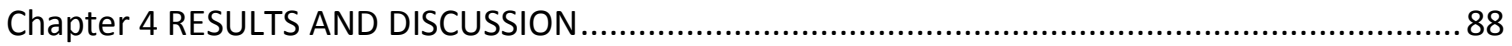

4.1 Saturation Test and Drying of the PE Sensor in Water .............................................. 88

4.2 Comparison Test of the Old and the New PE Sensor in a Wetting Test.........................90

4.3 New PE Sensor Results with the Two Strain Gauges................................................. 91

4.4 Comparison of Suction Readings of WPT4 Hygrometer to the PE Sensor ......................92

4.5 PE Sensor Testing in the Total E\&P Pilot Plant Thickened Tailings, Alberta ................... 98

4.6 PE Sensor in Saturated and Dry Condition in the Freezing Conditions ......................... 100

4.6.1 Dry PE Sensor in the Freezing Temperatures of $0,-10,-20$ and $-30^{\circ} \mathrm{C} \ldots \ldots \ldots \ldots \ldots \ldots . . . . . . .100$

4.6.2 Saturated PE Sensor in the Freezing Temperatures of $0,-10,-20$ and $-30{ }^{\circ} \mathrm{C} \ldots \ldots . . .101$

4.6.3 PE Sensor in Freezing Conditions in Silt at Saturation .......................................... 103

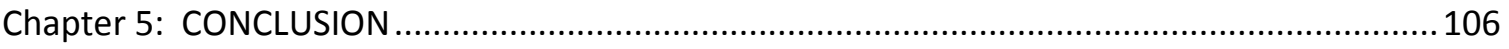

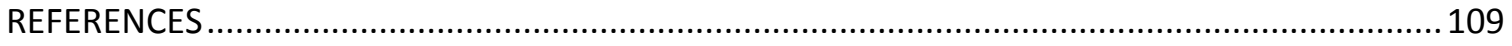

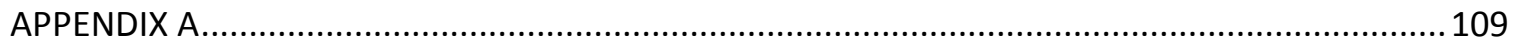




\section{LIST OF TABLES}

Table 2-1: Summary of Equations Derived to Measure the Unsaturated Hydraulic

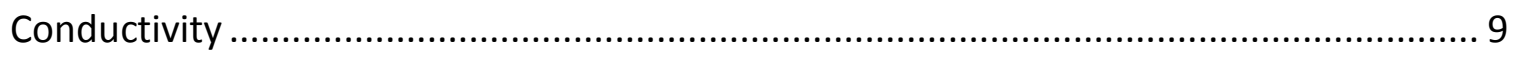

Table 2-2: Summary of Suction Measurement Techniques ........................................ 19

Table 2-3: Variation of Total Suction with the Depth in Artificial Silt............................. 50

Table 2-4: Comparison of Matric Suction from SWCC Curve of Clay for the PE Sensor ... 57

Table 2-5: Summary of the Best fit Modulus for the Apking Results ............................ 58

Table 4-1: Alberta, Total E\&P Thickened Tailings Properties .................................... 98

Table 4-2: Total Suction and the Water Content Results after the Freezing Conditions PE

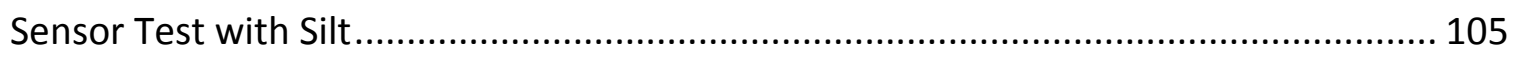

\section{LIST OF FIGURES}

Figure 2-1: Soil Water Characteristic Curve for Degree of Saturation versus Suction ( $\mathrm{kPa})$

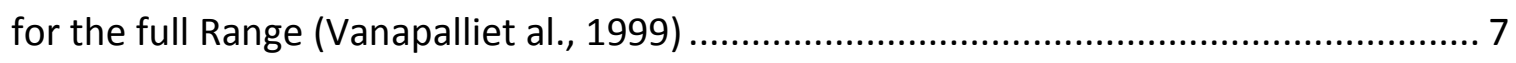

Figure 2-2: Typical Soil Water Characteristic Curve for Soil showing the hysteresis effect

Figure 2-3: Volume of soil representing the continuity of flow .................................. 14

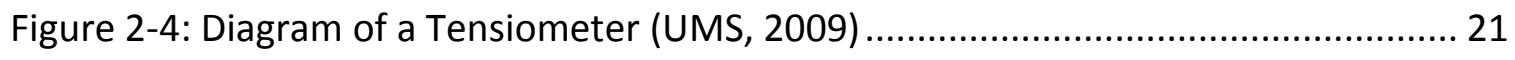

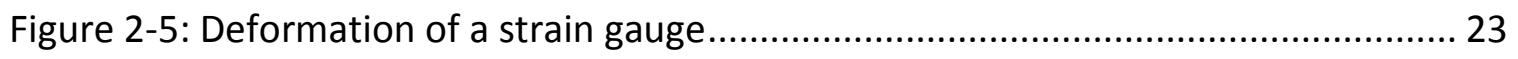

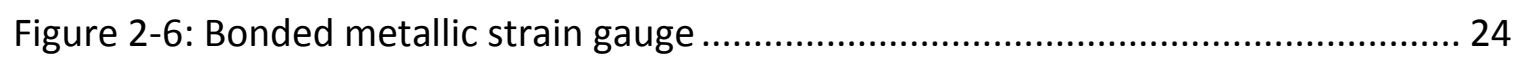


Figure 2-7: Main Components of the PE sensor 26

Figure 2-8: SWCC to Compare PE Sensor and Relative Humidity Sensor in Silt (Dunmola et al., 2009) 32

Figure 2-9: Results Comparing the PE Sensor and Tensiometer in Silt (Dunmola et al., 2009) 33

Figure 2-10: Saturation Test of the PE Sensor for 3 Days (PE Sensor 1) 34

Figure 2-11: Saturation Test of the PE Sensor for 3 Days (PE Sensor 2)...... 34

Figure 2-12: Ambient Temperature versus Time at the Time of Saturation of PE Sensor 2 35

Figure 2-13: Ambient Relative Humidity versus Time at the time of Saturation of PE Sensor 2 37

Figure 2-14: PE Sensor Measured and Corrected Strain Comparison for Drying and Wetting Test in Silt......... 39

Figure 2-15: PE Sensor Measured and Corrected Strain Comparison for Drying and Wetting Test in Clay 40

Figure 2-16: Matric Suction ( $\mathrm{kPa}$ ) during Wetting and Drying Cycles in Silt (K=42.9MPa)

Figure 2-17: Matric Suction (kPa) during Wetting and Drying Cycles in Silt (K=1.77GPa)

Figure 2-18: Matric Suction ( $\mathrm{kPa}$ ) During Wetting and Drying Cycles in Clay ( $\mathrm{K}=42.9 \mathrm{GPa})$ 
Figure 2-19: Matric Suction ( $\mathrm{kPa}$ ) During Wetting and Drying Cycles in Clay ( $\mathrm{K}=1.77 \mathrm{GPa})$

Figure 2-20: Comparison Test of Drying and Wetting Cycles of Poroelastic Sensor 1 in Artificial Silt 49

Figure 2-21: Comparison Test of Drying and Wetting Cycles of Poroelastic Sensors 1 and 7 in Kaolin Clay 53

Figure 2-22: SWCC Obtained for PE Sensors 1 and 7 (Clay Test) .................................. 56

Figure 2-23: SWCC for the Regina Clay (Vu et al., 2007) ........................................... 57

Figure 2-24: Porous Glass Saturation with Respect to Water with Varying Temperature (Antoniou, 1964) 61

Figure 3-1: Previously Constructed Sensor (left, (Dunmola et al., 2009)), Added Strain Gauge (Middle), Newly Modified PE Sensor with Outer Cover (Right) ..... 64

Figure 3-2: Illustration of the Materials Used to Construct the PE Sensor 67

Figure 3-3: Horizontal Placement of the Porous Rod on a Flat Surface 67

Figure 3-4: Obtaining Isopropyl Alcohol into Gauze, Applying the Isopropyl Alcohol on the Porous Rod in One Direction. 68

Figure 3-5: Application of the M-Prep Conditioner on to the Porous Rod and Wiping the Rod with Gauze in One Direction. 69

Figure 3-6: Neutralizer Application to Restore the Porous rod to its Neutral pH. 69

Figure 3-7: Placement of the Strain Gauge on to the Plexiglass and Pealing the Strain Gauge Face up Onto the PCT - 2M Installation Tape. 70 
Figure 3-8: Placement of the Strain Gauge onto the Porous rod and pealing the Tape off so that the Bottom of the Strain Gauge was exposed.

Figure 3-9: Careful Application of the M-Bond Catalyst to the Back of the Strain Gauge.

Figure 3-10: Application of the Adhesive on to the Strain Gauge and Mounting the

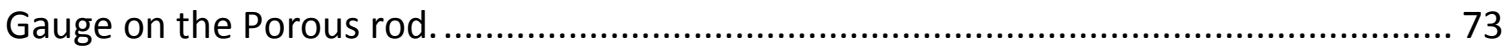

Figure 3-11: Affixing the Bondable Terminals to the Sensor cap ................................ 74

Figure 3-12: Materials Used to Apply the Protective Casing of the Sensor (Left: HDPE

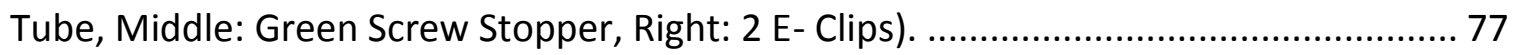

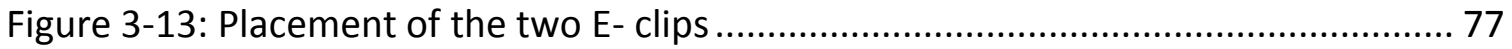

Figure 3-14: Finally Constructed PE Sensor Ready to be Tested and Used in Experiments.

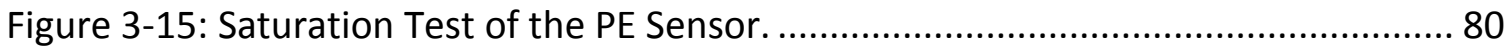

Figure 3-16: 1-D Columns Used in the PE Sensor Freezing with Silt Test ....................... 84

Figure 3-17: Experimental Setup of the Freezing Test of PE Sensor with Silt ................. 86

Figure 4-1: Wetting and Drying Test of the PE Sensor in Water .................................. 89

Figure 4-2: Comparison of the Old and the New PE Sensors during Saturation in Water. 90

Figure 4-3: Representation of the Strain Values Obtained Using the two Strain Gauges

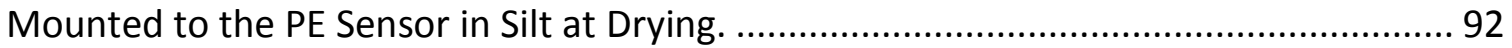

Figure 4-4: Total Suction Results for Drying Tests Presented as SWCC......................... 94 
Figure 4-5: PE Sensor Results from Drying Test Presented as SWCC, Compared to Best fit SWCC Obtained by Fitting Total Suction Data in Figure 4-4 95

Figure 4-6: The Range of Suction from 0 - 1MPa for Both PE Sensor Results and the WP4T Device 96

Figure 4-7: The Range of Suction from 0 - 10MPa for Both PE Sensor Results and the WP4T Device 96

Figure 4-8: Suction Comparison of the WP4T PotentiaMeter Results to the PE Sensor Results versus the Time in Hours 97

Figure 4-9: Comparison of Total Suction (WP4 Device) vz. Matric Suction (PE sensor) in Oil Sand Tailings 99

Figure 4-10: Behaviour of the dry PE Sensor in Freezing Conditions 101

Figure 4-11: Saturated PE Sensor at Temperatures 0, -10, -20 and -30 Degree Centigrade 102

Figure 4-12: Freezing of Silt at 0, -10, -20 and -30 Degrees Centigrade 104

Figure A -1: Comparison Results of Total Suction Machine Results vs. PE sensor Results in SWCC1 - Test1 113

Figure A -2: Comparison Results of Total Suction Machine Results vs. PE sensor Results in SWCC2 - Test2 113

Figure A-3: Comparison Results of Total Suction Machine Results vs. PE sensor Results in SWCC3 - Test3 114

Figure A-4: Comparison Results of Total Suction Machine Results vs. PE sensor Results in SWCC4 - Test4 115 
Figure A-5: Photograph of the PE Sensor Inserted into the Drying box of the oil Sand

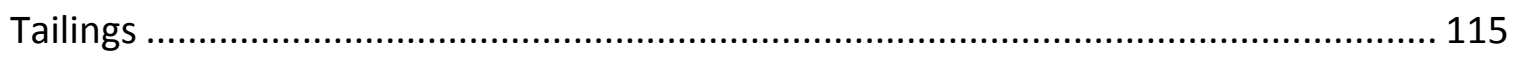

Figure A-6: Temperature, RH versus Time Plot for the oil Sand Tailings....................... 116

Figure A-7: Evaporation Rates of the oil Sand Tailings with and without Cracked Surface 


\section{NOMENCLATURE}

AEV: Air Entry Value

n: Porosity

DAS: Data Acquisition System

$\mathrm{E}_{\mathrm{s}}$ : Young's Modulus

emf: Electro Motive Force

$\mathrm{G}_{\mathrm{s}}:$ Shear Modulus

H: Hydraulic Head (m)

HD Sensor: Heat Dissipation Sensor

$\mathrm{h}_{\mathrm{c}}$ : Capillary Height

HDPE: High Density Polyethylene

K, k: Hydraulic Conductivity (m/d)

$\mathrm{k}_{\mathrm{w}}$ : Unsaturated Coefficient of Permeability

K: Bulk Modulus of the Porous Solid

$\mathrm{K}_{s}$ : Bulk Modulus of Solid Backbone of Porous Material

PE Sensor: Poroelastic Suction Sensor

$q_{x}, q_{y}, q_{z}$ : Fluxes in $x, y$ and $z$ direction $(m / s)$

q: Discharge Per Unit Area Flux Density (m/d)

RH: Relative Humidity

$\mathrm{R}_{\mathrm{s}}$ : Radius of Curvature

SWCC: Soil Water Characteristic Curve

$\mathrm{S}_{\mathrm{A}-\mathrm{B}}$ : Seebeck Coefficient 
S: Saturation

$S_{\text {eff: }}$ Effective Saturation

$\mathrm{S}_{\mathrm{wr}}$ : Irreducible Water Content

$t_{c}$ : Cumulative time (hour)

$\mathrm{T}_{\mathrm{s}}$ : Surface Tension

U: Matric Suction

$\mathrm{u}_{\mathrm{v}}$ : Partial Pressure of Pore Water Vapour

$\mathrm{u}_{\mathrm{v}, 0}$ : Vapour Pressure of Water

$\mathrm{u}_{\mathrm{w}}$ : Pore Water Pressure

$\mathrm{u}_{\mathrm{a}}$ : Pore Air Pressure

$\mu$ : Possions Ratio

$\mathrm{V}_{\mathrm{v}}$ : Volume of Void

$\mathrm{V}_{\mathrm{T}}$ : Total or Bulk Volume

wc: Water Content

$\Psi$ : Total Suction

$\pi$ : Osmotic Suction

$\theta_{\mathrm{w}}$ : Volumetric Water Content

$\theta_{r}:$ Residual Volumetric Water Content

$\theta_{s}:$ Saturated Volumetric Water Content

$\rho:$ Density of Water $\left(\mathrm{Kg} / \mathrm{m}^{3}\right)$

$\nabla$ : Gradient $\left(\nabla=\frac{d}{d x}+\frac{d}{d y}+\frac{d}{-d z}\right)$.

$\varepsilon:$ Strain $(\mu \varepsilon)$

$\Omega: \mathrm{Ohm}$

$\varepsilon_{\text {corrected }}$ : Corrected Strain Value 
$\varepsilon_{\text {measured }}:$ Measured Strain Value

$\frac{d \epsilon}{d t}:$ Rate of Change of Saturated Strain 


\section{Chapter 1 INTRODUCTION}

\subsection{Background}

Matric suction in is one of the key stress state variables used in the interpretation of the engineering behaviour of unsaturated soils. Applications that require either prediction or measurement of matric suction include irrigation control, cover design for waste isolation, and shallow foundation design in arid climates, to name just a few.

Matric suction can be defined as the difference between the pore air pressure and the pore-water pressure $\left(u_{a}-u_{w}\right)$, when the pore-water pressure decreases below atmospheric pressure.

There are many methods developed to measure matric suction in soil. These methods can be divided into two categories:

- Direct Methods

- Indirect Methods

The direct methods involve measuring how the negative pore-water pressure in soil acts on a component of a sensor, such as the length of deformation membrane directly in contact with soil-water. Indirect methods measure other soil parameters and correlate these with matric suction. Such parameters include relative humidity, water content, electromagnetic properties, or thermal conductivity. 
However, none of the commonly used methods are capable of measuring matric suction of the full range of suction from fully saturated state of $100 \%$ saturation to the lowest point of saturation of approximately $0 \%$ saturation. Also, most methods have additional drawbacks apart from their range that limit their accuracy.

The most accurate method is probably the tensiometer, which directly measures porewater pressure in a reservoir inside the sensor body. The measured, negative porewater pressure is numerically equal to the matric suction when the pore-air pressure is at atmospheric pressure (Fredlund and Rahardjo 1988). However, the range of the tensiometer is generally limited by cavitation in the reservoir. This generally limits the range to less than $100 \mathrm{kPa}$, though some commercial sensors can have their range temporarily extended up to $300 \mathrm{kPa}$. Some experimental tensiometers developed at research facilities have been reported temporarily extended ranges up to $1 \mathrm{MPa}$.

A new matric suction measuring device prototype, the Poroelastic Suction Sensor (PE sensor) was developed by Dunmola et al. (2010) to eliminate the problem of cavitation, while still retaining the characteristic of direct suction measurement. The principle of measurement is to measure deformation of a porous material of high air-entry value (AEV). A prototype was designed and tested by Dunmola et al. (2010); however, the prototype was not sufficiently robust to be used as a reliable sensor. The aim of this thesis is to improve upon the design of the sensor and to test it in varied conditions. This includes evaluating the performance of the sensor during freezing of soils, where 
the small pore-size of the sensor material is expected to suppress the freezing point, and hence allow for suction measurement in freezing conditions.

\section{$1.2 \quad$ Research Objectives}

The objectives of this research are as follows:

- To redesign the Poroelastic Matric Suction Sensor (PE Sensor) to eliminate the problem of drift. Upon attaining the saturation of the porous rod, the deformation should be ceased due to the achievement of maximum expansion. However, in the previous design of the PE sensor an abrupt increase in the strain was observed even after achieving the maximum rate of saturation of the PE sensor causing a drift in the results obtained.

- To test the sensor in the freezing conditions to determine if the PE sensor is capable of obtaining matric suction in the below zero temperature ranging from $0^{\circ} \mathrm{C}$ to $-30^{\circ} \mathrm{C}$. This is thought to be possible since the porous rod that is been used in the PE sensor has very small pores which results in a higher freezing point depression prolonging the time it takes for the water in the porous rod to freeze.

- To test the PE sensor in new materials, such as fine grained tailings. The sensor has been previously tested in silt, clay, and silt-sized mine tailings. 
The performance of the sensor was mainly evaluated by measuring total suction using a chilled mirror hygrometer (WP4T PotentiaMeter from Decagon Devices). This was done as the high values of matric suction were required to be measured (> $1 \mathrm{MPa})$, and the hygrometer is a quick and accurate method to measure total suction in that range. Most tests were done using an artificial silt prepared using deionised water to eliminate osmotic suction.

\subsection{Thesis Outline}

Chapter 1 gives an introduction of the research with a background, the purpose and the outline of the thesis.

Chapter 2 gives a detailed explanation of the theory related to the PE sensor and a review of matric suction measurement techniques.

Chapter 3 describes the materials and the method of preparation of the PE sensor and the methodology of experiments that were conducted using the PE sensor.

Chapter 4 presents the results and discussion of the conducted experiments.

Chapter 5 summarizes the results and presents the conclusions of the study, and presents recommendations to better improve the functionality and the accuracy of the sensor. 


\section{Chapter 2 LITERATURE REVIEW}

\section{$2.1 \quad$ Related Theory}

\subsubsection{Unsaturated Soils}

The water table can be defined as the point where water pressure becomes atmospheric, such that it can connect with the free-surface of surface water. Soil has the ability to retain water at less than atmospheric pressure above the water table. In soil, or other porous media, water can be retained above the water table and / or under negative (gauge) pressures due to capillary action within the pores. The capillary action arises from two forces, both the cohesion of water molecules, and the strong adhesion of water to the surface of most minerals present in the subsurface (Fredlund \& Rahardjo 1998). The fraction of a soil's porosity that is filled with water at a given value of negative pressure is a function of the sizes and distribution of the individual pores, and is described by a soil's water-retention curve or Soil Water Characteristic Curve (SWCC).

\subsubsection{Soil Water Characteristic Curve (SWCC)}

The soil water characteristic curve is a function that relates water content (gravimetric or volumetric) or degree of saturation and matric suction (Fredlund \& Xing 1994) for a porous material. The SWCC is unique only for a given initial state of the porous medium, and also depends on whether the soil is drying or wetting. Initial state may be affected by compaction variables, stress state, or stress history (Vanapalli et al. 2000). 
A typical soil water characteristic curve is presented Figure 2-1. The air entry value is the matric suction value where air enters the largest pores in the soil. This is the point at which the desaturation of soil starts to occur. It is often defined by the intersection of lines tangent to the boundary and desaturation zones of the SWCC. The AEV should only be defined in saturation versus suction space; otherwise volume change can lead to underestimation of the AEV.

The residual water content is represented to show the area where a large amount of suction is necessary to remove the remaining pore-water in the soil, since the water present at this stage does not contribute to liquid flow, and is assumed to represent a point where the water phase becomes discontinuous. 


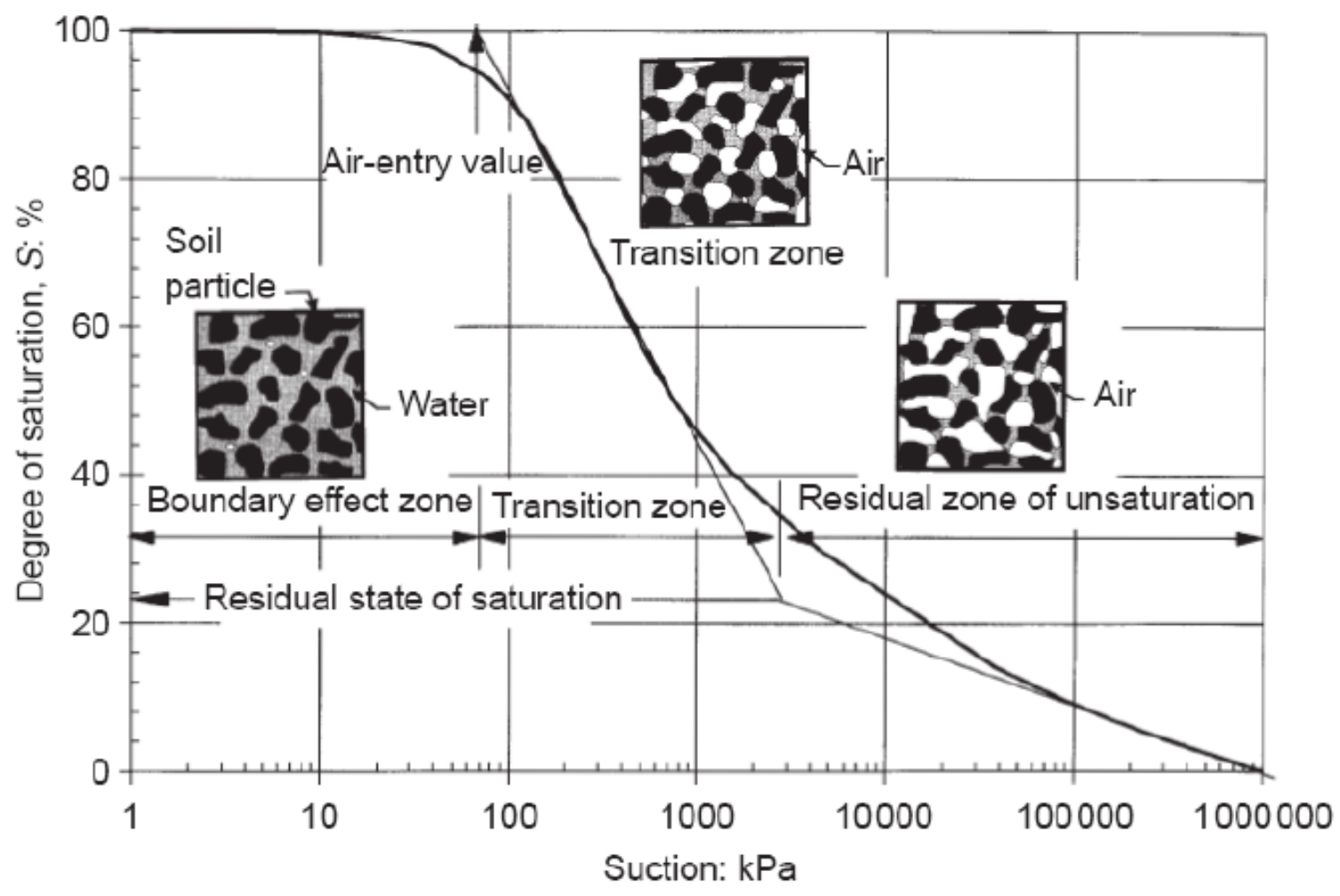

Figure 2-1: Soil Water Characteristic Curve for Degree of Saturation versus Suction (kPa) for the full Range (Vanapalli et al. 1999)

Figure 2-1 is a representation of the SWCC for the full range of suction from 0kPa to $1,000,000 \mathrm{kPa}$ for the degree of saturation versus suction $(\mathrm{kPa})$. The boundary effect zone as shown in Figure 2-1 represents when the soil is fully saturated and all the pores in the soil are almost filled with water. Hence the saturation at this point is close to $100 \%$. The transition zone is bounded by the AEV and the residual water content. The greatest rate of water content change with suction occurs in this zone. After the soil reaches residual water content, the soil desaturates at a slower rate increasing suction. The water content theoretically reaches $0 \%$ at 1,000,000kPa (Vanapalli \& Fredlund 2000). 
The SWCC changes depending on the type of soil. The key difference in the characteristics of the SWCC for sand and clay is the AEV for the two curves. The reason for this difference is that in clay, the pores are smaller due to the high fines content of the soil. Therefore, the AEV is higher for the clay compared to sand where the soil particles are larger and the pores are larger, which allows the air to enter at lower values of matric suction. As a result, sand has a smaller AEV.

\subsubsection{Hydraulic Conductivity of Unsaturated Soil}

Hydraulic conductivity is mainly affected by the void ratio and the saturation of the soil. The saturated hydraulic conductivity can be represented using the following equation by (Darcy 1856),

$$
Q=K A \frac{h_{1}-h_{2}}{L}
$$

$A$ is the cross-sectional area $\left(\mathrm{m}^{2}\right), L$ is the length of the soil sample $(\mathrm{m}), Q$ is the flow rate $\left(\mathrm{m}^{3} /\right.$ day), $K$ is the hydraulic conductivity ( $\mathrm{m} /$ day) and $h_{1}$ and $h_{2}$ are the total heads at the entrance and the exit of the soil sample (m) (Chin 2006). Hydraulic conductivity of the saturated soil remains a constant for a constant volume, whereas in unsaturated soil it varies.

In an unsaturated soil, the water in the soil leaves the pores and replaced by air reaching the AEV. This mechanism is expressed by the soil water characteristic curve, which was discussed in more detail in Section 2.1.2. As the pore water leaves the soil the matric suction increases and the air-water interface is drawn closer to the soil grains. 
Therefore the hydraulic conductivity of soil decreases as the pore space available for flow decreases and the average wetted pore-size decreases.

The SWCC can be used as a tool to estimate unsaturated hydraulic conductivity. This assumes that the volumetric water content at a given value of suction can be represented by both the cross sectional area available for the flow and the effective diameter of the fluid filled pores (Childs and Collis-George, 1950; Millington and Quirk, 1961; Green and Corey 1971). These empirical equations can be derived by a number of procedures such as Brooks \& Corey (1964), Green \& Corey (1972), Gardner (1958) and van Genuchten (1980) and Fredlund and Xing (1994). Fredlund et al. (1994) predicts the permeability function over the entire range of suction from $0-1,000,000 \mathrm{kPa}$.

Unsaturated hydraulic conductivity can be expressed using parameters such as water content (wc), void ratio (e), and degree of saturation (S) which are interrelated with each other. The relationship among the parameters can be expressed as $k_{w}=f(e, w c) ; k_{w}$ $=f(S, e) ; k_{w}=f(S, w c)$ etc. (Fredlundet al. 2001). Following is a summary of equations derived by researchers to predict the unsaturated hydraulic conductivity,

Table 2-1: Summary of Equations Derived to Measure the Unsaturated Hydraulic Conductivity

\begin{tabular}{|l|l|l|l|}
\hline Researchers & $\begin{array}{l}\text { Empirical Equations } \\
\text { for predicted k }\end{array}$ & $\begin{array}{l}\text { Fitted Equation for } \\
\text { swCC }\end{array}$ & Symbols \\
\hline \multirow{3}{*}{ Gardner (1958) } & $k_{w}=k_{s} e^{-\alpha U}$, & $\begin{array}{l}S_{e}(h)= \\
{\left[e^{-0.5 \alpha h}(1+\right.} \\
0.5 \alpha h)]^{-2 /(l+2)} \\
\mathrm{S}_{\mathrm{e}}=\left(\theta_{\mathrm{w}}-\theta_{\mathrm{r}} / \theta_{\mathrm{s}}-\theta_{\mathrm{r}}\right)\end{array}$ & $\begin{array}{l}a, b=\text { constants } \\
k_{w}=\text { unsaturated } \\
\text { coefficient of } \\
\text { permeability, }\end{array}$ \\
\hline
\end{tabular}




\begin{tabular}{|c|c|c|c|}
\hline $\begin{array}{l}\text { Cambell (1973), } \\
\text { Ahuja (1974) }\end{array}$ & $\begin{array}{l}k_{w}=k_{s}\left(\frac{\theta_{w}}{\theta_{s}}\right)^{2 \mathrm{~b}+3} \\
\text { and } b=\frac{\Delta \log (U)}{\Delta \log \left(\theta_{w}\right)}\end{array}$ & & \multirow{4}{*}{$\begin{array}{l}U=\text { Matric } \\
\text { suction } \\
\text { Subscript 's' }= \\
\text { saturated } \\
\theta_{w}=\text { volumetric } \\
\text { water content. } \\
\theta_{\mathrm{r}}=\text { residual } \\
\text { volumetric water } \\
\text { content, } \\
\theta_{\mathrm{s}}=\text { saturated } \\
\text { volumetric water } \\
\text { content }\end{array}$} \\
\hline $\begin{array}{l}\text { Davidson et al., } \\
(1969), \\
\text { Dane and Klute } \\
(1977)\end{array}$ & $\begin{aligned} k_{w}=k_{s} \exp [ & b\left(\theta_{w}\right. \\
& \left.\left.-\theta_{s}\right)\right]\end{aligned}$ & & \\
\hline Richards (1931) & $k_{w}=a+b U$ & & \\
\hline $\begin{array}{l}\text { Wind (1955), Weeks } \\
\text { and Richards (1967) }\end{array}$ & $k_{w}=a U^{-\mathrm{b}}$ & & \\
\hline $\begin{array}{l}\text { Brooks and Corey } \\
\text { (1964) }\end{array}$ & $\begin{array}{l}\text { Water in unsaturated } \\
\text { zone, wetting fluid: } \\
k_{w}=\left(S_{\text {eff }}\right)^{\frac{2+3 \lambda}{\lambda}} \text { Air } \\
\text { in unsaturated zone, } \\
\text { non-wetting fluid: } \\
k_{w}=(1- \\
\left.S_{e f f}\right)\left(S_{e f f}\right)^{\frac{2+\lambda}{\lambda}}\end{array}$ & $\begin{array}{l}S_{e f f}=\frac{S_{w}-S_{w r}}{1.0-S_{w r}} \\
=\left(U / U_{b}\right)^{-\lambda}\end{array}$ & $\begin{array}{l}\mathrm{S}_{\mathrm{eff}}=\text { Effective } \\
\text { Saturation } \\
\mathrm{S}_{\mathrm{wr}}=\text { irreducible } \\
\text { water saturation } \\
\lambda=\text { fitting } \\
\text { parameter }\end{array}$ \\
\hline $\begin{array}{l}\text { van Genuchten } \\
(1980)\end{array}$ & $\begin{array}{l}\text { Water in unsaturated } \\
\text { zone, wetting fluid: } \\
k_{w}=\left(S_{\text {eff }}\right)^{\frac{1}{2}}[1- \\
\left.\left(1-S_{\text {weff }}{ }^{1 / m}\right)\right]^{2} \\
\text { Air in unsaturated } \\
\text { zone, non- wetting } \\
\text { fluid: } \\
\quad \begin{array}{l}k_{w} \\
\quad=\left(1-S_{e f f}\right)^{\frac{1}{2}}[1 \\
-(1 \\
\left.\left.\quad-S_{e f f}^{1 / m}\right)\right]^{2 m}\end{array}\end{array}$ & $\begin{array}{l}S_{e f f} \\
=[1 \\
\left.+\left(\alpha P U_{c}\right)^{n}\right]^{-m}\end{array}$ & $\begin{array}{l}\alpha, n \text { and } m \text { are } \\
\text { fitting } \\
\text { parameters often } \\
m=1-1 / n\end{array}$ \\
\hline
\end{tabular}




\subsubsection{Matric, Osmotic and Total Suction}

Total suction of a solid or a liquid can be measured by relating the sample water potential to the vapour pressure in air in equilibrium with the sample (Krahn \& Fredlund 1972). This can be shown using the equation (Equation 2) below,

$$
\Psi=\frac{R T}{v_{w 0} \omega_{v}} \cdot \ln R H
$$

$\Psi$ is the total suction, $\mathrm{RH}$ is the relative humidity, $\mathrm{T}$ is the temperature of the sample (Kelvin), $R$ is the universal gas constant $(8.31 \mathrm{~J} / \mathrm{mol} \mathrm{K}), \omega_{\mathrm{v}}$ is the molecular mass of water $\operatorname{vapour}(18.016 \mathrm{~kg} / \mathrm{kmol})$ and $\mathrm{v}_{\mathrm{wo}}$ is the specific volume of water $\left(1 / \rho_{w}, \mathrm{~m}^{3} / \mathrm{kg}\right)$. When the $\mathrm{RH}$ is $100 \%$ in a given soil, the suction of that soil is said to be zero (Fredlund \& Rahardjo 1988). Relative humidity is defined by the following equation (Equation 3),

$$
R H=\left(\hat{u}_{v} / \hat{u}_{v 0}\right) \times 100 \%
$$

$\mathrm{RH}$ is relative humidity, $\hat{\mathrm{u}}_{\mathrm{v}}$ is Partial pressure of pore-water vapour $(\mathrm{kPa})$ and $\hat{\mathrm{u}}_{\mathrm{v}, 0}$ is vapour pressure of water.

As per Equation 2, the total soil suction is dependent on the $\mathrm{RH}$ of the soil. Total suction is comprised of matric and osmotic suction:

$$
\Psi=\left(u_{a}-u_{w}\right)+\pi
$$

$\left(u_{a}-u_{w}\right)$ is the pore air pressure $\left(u_{a}\right)$ minus the pore water pressure $\left(u_{w}\right)$ which is the matric suction, and $\pi$ represents the osmotic suction. 
Matric suction is the component of water potential due to capillary forces in soil. It is a measure of the decrease in $\mathrm{RH}$ due to the decrease in radius of curvature in a soil pore when compared to a free surface of water.

Osmotic suction is represented using the symbol $\pi$. This can also be defined as a measure of the decrease in $\mathrm{RH}$ of pore-air due to the presence of dissolved mass in the pore waters of the soil.

\subsubsection{Matric Suction in Unsaturated Soils: Hysteresis.}

Matric suction is related to the capillary effect due to the surface tension of water in small pores of the soil. The matric suction required to desaturate a pore of a certain size can be expressed using the following equation, Young-Laplace (Equation 5), which is derived from the radius of the curvature,

$$
\mathrm{u}_{\mathrm{a}}-\mathrm{u}_{\mathrm{w}}=\frac{2 \mathrm{~T}_{\mathrm{s}}}{\mathrm{R}_{\mathrm{s}}}
$$

$T_{S}$ is the surface tension, and $R_{s}$ is the radius of curvature of the air water interface. This equation assumes perfect wetting of the water to the soil, that is, the contact angle is 180 degrees.

As the pore size decreases the matric suction required to desaturate the pore increases. Therefore the grain size distribution influences in capillary rise in soil and the SWCC. 
The matric suction of the soil at given water content also depends on whether the soil is drying or wetting. This phenomenon is called hysteresis and is shown in the Figure 2-2 below,

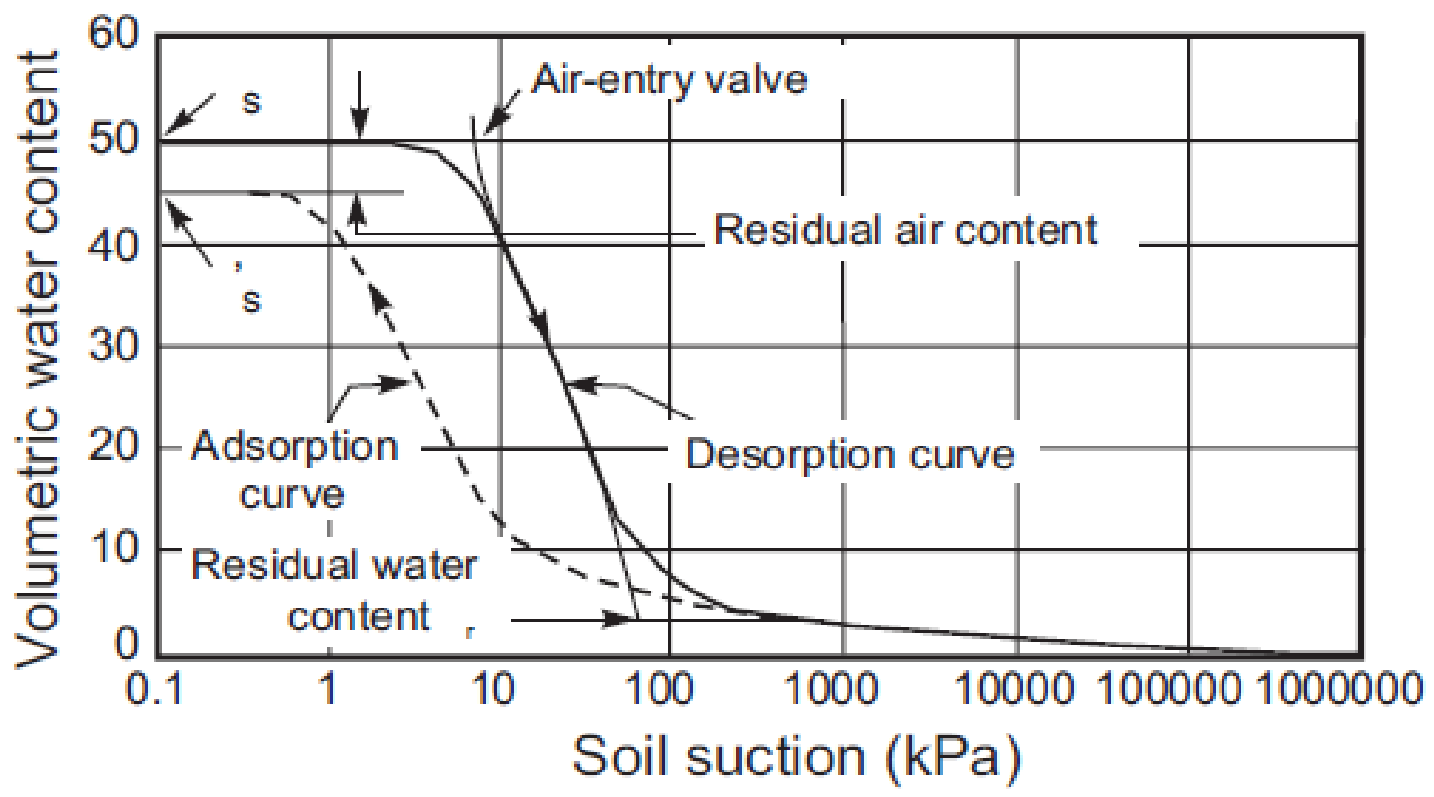

Figure 2-2: Typical Soil Water Characteristic Curve for Soil showing the hysteresis effect

It can be seen in Figure 2-2, at a given matric suction and the soil water content during wetting and drying process are different. Due to air entrapment in the soil, the end point of the adsorption curve may differ from the starting point of the desorption curve (Drying curve). The hysteresis effect in the SWCC is in part due to the non uniform pore size distribution in the soil. The difference between the contact angle of the wetting process, drying process and entrapped air in the soil also contribute to hysteresis. 
Factors such as stress history of the soil can also affect the soil water characteristic curve. The SWCC is a function of the initial density and stress history (Vanapalli \& Fredlund 2000).

\subsubsection{Equation of the Flow in Unsaturated Soil}

A cubical dimensional figure can be used to understand the flow in unsaturated soil (Fredlund \& Morgenstern 1977). Where, conservation of mass is applied, to represent that the total flux in and out of the system are equal. The following Figure 2-3 represents the system where conservation of mass is applied to a soil element in order to understand the flow in unsaturated soil.

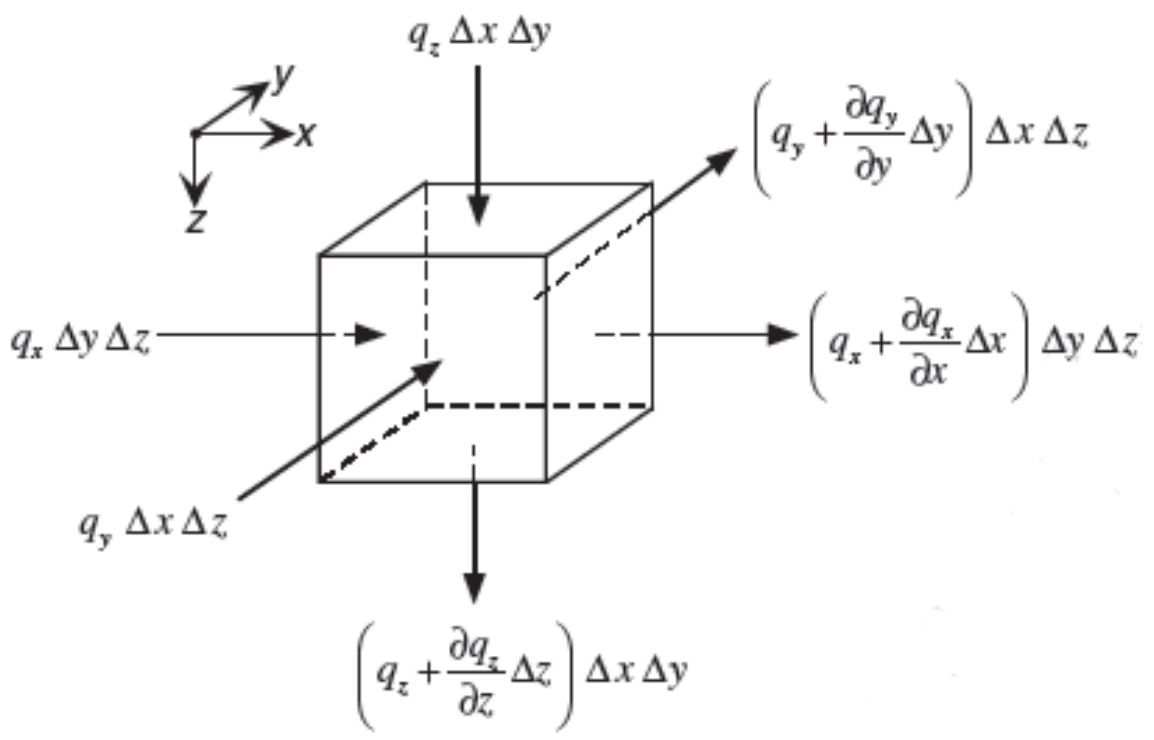

Figure 2-3: Volume of soil representing the Continuity of Flow 
The following set of equations represents the flow in unsaturated soil in $x, y$ and $z$ directions. $\theta$ is the water content and inflow is represented by the arrows going into the positive coordinate direction in Figure 2-3

$$
\begin{gathered}
q_{\text {in }}=\rho\left(q_{x} \Delta y \Delta z+q_{y} \Delta x \Delta z+q_{z} \Delta x \Delta y\right) \\
q_{\text {out }}=\rho\left[\left(q_{x}+\frac{\partial q_{x}}{\partial x} \Delta x\right) \Delta y \Delta z+\left(q_{y}+\frac{\partial q_{y}}{\partial y} \Delta y\right) \Delta x \Delta z+\left(q_{z}+\frac{\partial q_{z}}{\partial z} \Delta z\right) \Delta x \Delta y\right]
\end{gathered}
$$

$\rho$ is the density of water in $\mathrm{kg} / \mathrm{m}^{3}$ and $\mathrm{q}_{\mathrm{x}}, \mathrm{q}_{\mathrm{y}}$ and $\mathrm{q}_{\mathrm{z}}$ are the fluxes in $\mathrm{x}, \mathrm{y}$, and $\mathrm{z}$ directions respectively $(\mathrm{m} / \mathrm{s})$.

Conservation of mass equation in terms of water content (also known as the storage term) can be represented as shown below:

$$
\frac{\partial(\rho \theta)}{\partial t} \Delta x \Delta y \Delta z
$$

Therefore the equation can be written using the storage term as follows,

$$
-\rho\left(\frac{\partial q_{x}}{\partial x} \Delta x \Delta y \Delta z+\frac{\partial q_{y}}{\partial y} \Delta y \Delta x \Delta z+\frac{\partial q_{z}}{\partial z} \Delta z \Delta x \Delta y\right)=\frac{\partial(\rho \theta)}{\partial t} \Delta x \Delta y \Delta z
$$

This can be simplified further, and is used as the governing equation for transient flow and is applied in saturated and unsaturated soil conditions as follows, 


$$
q_{\text {in }}-q_{\text {out }}=-\rho\left(\frac{\partial q_{x}}{\partial x}+\frac{\partial q_{y}}{\partial y}+\frac{\partial q_{z}}{\partial z}\right)=\frac{\partial(\rho \theta)}{\partial t}
$$

In unsaturated soil conditions the coefficient of permeability is not constant, but it is a function of the water content or matric suction. These conditions are stated in the following equations in three-dimensions,

$q_{x}=-k_{x}(U) \frac{\partial h}{\partial x} \quad q_{y}=-k_{x y}(U) \frac{\partial h}{\partial y} \quad q_{z}=-k_{z}(U) \frac{\partial h}{\partial z}$

$U$ is the matric suction head, and the term $k(U)$ is the unsaturated hydraulic conductivity function (Richards 1931). To illustrated the equation further z-direction is considered and used in the following derivations,

Obtaining equation 10 and substituting it into the equation 9 in z-direction the following equation can be derived which is called the Richard's equation (Richards 1931) as follows,

$$
\frac{\partial \theta}{\partial t}=\frac{\partial}{\partial z}\left[k(U)\left(\frac{\partial \Psi}{\partial z}+1\right)\right]
$$

The water content can be expressed in terms of matric suction by using chain rule to the left side of equation 11 as follows,

$$
\frac{\partial \theta}{\partial t}=\frac{\partial \theta}{\partial \Psi} \frac{\partial U}{\partial t}
$$


The slope of the SWCC is the specific moisture capacity which is indicated in equation 12 as $\frac{\partial \theta}{\partial U}$. The slope of the SWCC is non linear therefore the specific moisture capacity can be expressed as a function of suction as,

$$
C(\Psi)=\frac{\partial \theta}{\partial U}
$$

Therefore, Richard's equation can be expressed in terms of matric suction head as follows,

$$
C(U) \frac{\partial U}{\partial t}=\frac{\partial}{\partial z}\left[k(U)\left(\frac{\partial U}{\partial z}+1\right)\right]
$$

\subsubsection{Matric Suction Measurement Techniques}

Measurement of suction can be divided into two categories: direct method and indirect method. The direct method measures matric suction by separating air phase and the water phase by using a ceramic disk, to facilitate detection of the water pressure by the sensor. The indirect methods use measurement of other parameters such as the water content and the relative humidity to obtain a suction measurement. Several reviews of suction measurement techniques exist in the literature, including (Ridley \& Wray 1995), (Tarantino \& Yu-Jin 2009).

Three methods are described in detail in the literature review: tensiometers, thermal conductivity sensors, and the chilled mirror hygrometer. Tensiometers and thermal 
conductivity sensors are among the most common techniques employed in the direct and indirect categories respectively. The chilled mirror hygrometer is used in the experimental program of this thesis. Table 2-2 summarizes the major techniques. 
Table 2-2: Summary of Suction Measurement Techniques

\begin{tabular}{|c|c|c|c|c|c|}
\hline \multicolumn{3}{|c|}{ Technique (Method) } & \multirow{2}{*}{$\begin{array}{c}\begin{array}{c}\text { Suction } \\
\text { Range (kPa) }\end{array} \\
0-1500\end{array}$} & \multirow{2}{*}{$\begin{array}{c}\text { Equilibrium } \\
\text { time } \\
\text { Hours }\end{array}$} & \multirow[b]{2}{*}{$\begin{array}{l}\text { ir entry disk, entrapped air } \\
\text { discontinuous. Need sample } \\
\text { situ) (Vanapalli et at. 2005) }\end{array}$} \\
\hline $\begin{array}{l}\text { Direct suction } \\
\text { Measurement }\end{array}$ & $\begin{array}{l}\text { Matric } \\
\text { suction }\end{array}$ & $\begin{array}{l}\text { Axis - } \\
\text { translation } \\
\text { technique }\end{array}$ & & & \\
\hline & & Tensiometer & $0-150$ & Seconds & $\begin{array}{l}\text { Cavitation occurs easily; Time consuming to bring the } \\
\text { tensiometer back to working condition. In situ measurements. } \\
\text { Accuracy } \pm 0.5 \mathrm{kPa} \text {. Not for dry soil, in field application requires } \\
\text { impact protection. }\end{array}$ \\
\hline & & $\begin{array}{l}\text { High capacity } \\
\text { tensiometer }\end{array}$ & $0-1500$ & Minutes & $\begin{array}{l}\text { Suction is limited to the air entry value of the ceramic disk. In } \\
\text { situ measurements (Ridley \& Burland 1999). eventual cavitation }\end{array}$ \\
\hline \multirow[t]{2}{*}{$\begin{array}{l}\text { Indirect } \\
\text { suction } \\
\text { measurement }\end{array}$} & $\begin{array}{l}\text { Matric } \\
\text { suction }\end{array}$ & $\begin{array}{l}\text { Time domain } \\
\text { reflectometry }\end{array}$ & $0-1500$ & Hours & $\begin{array}{l}\text { Needs a precise determination of the SWCC of the soil of } \\
\text { interest. Requires a sophisticated electronic device (Pan et al. } \\
\text { 2010). }\end{array}$ \\
\hline & & $\begin{array}{l}\text { Electrical } \\
\text { conductivity } \\
\text { sensor }\end{array}$ & $50-1500$ & $6-50$ hours & $\begin{array}{l}\text { Sensitivity of the sensor becomes very low when the matric } \\
\text { suction exceeds } 300 \mathrm{kPa} \text {. Electric resistance of the porous block } \\
\text { depend on the salt concentration of the soil solution and not a } \\
\text { direct indication of the moisture content of the porous block. } \\
\text { Non in situ. Accuracy is } \pm 10 \% \text { (Pan et al. 2010). }\end{array}$ \\
\hline
\end{tabular}




\begin{tabular}{|c|c|c|c|c|c|}
\hline \multicolumn{3}{|c|}{ Technique (Method) } & \multirow{2}{*}{\begin{tabular}{c|}
$\begin{array}{c}\text { Suction } \\
\text { Range (kPa) }\end{array}$ \\
$0-1500$
\end{tabular}} & \multirow{2}{*}{$\begin{array}{c}\text { Equilibrium } \\
\text { Time } \\
\text { Hours - } \\
\text { Days }\end{array}$} & \multirow{2}{*}{$\begin{array}{l}\text { Limitations } \\
\text { Low strength and poor durability of the ceramic tip. Insensitive } \\
\text { and inaccurate results of higher suction. Poor stability of the } \\
\text { electronic signal. Each sensor needs a separate calibration curve. } \\
\text { In situ measurement. Accuracy }< \pm 5 \% \text {. (Pan et al. 2010). }\end{array}$} \\
\hline \multirow[t]{7}{*}{$\begin{array}{l}\text { Indirect } \\
\text { suction } \\
\text { measurement }\end{array}$} & \multirow[t]{2}{*}{$\begin{array}{l}\text { Matric } \\
\text { suction }\end{array}$} & $\begin{array}{l}\text { Thermal } \\
\text { conductivity } \\
\text { sensor }\end{array}$ & & & \\
\hline & & $\begin{array}{l}\text { In-contact } \\
\text { filter paper }\end{array}$ & all & 7-14 days & $\begin{array}{l}\text { Long response time (7-14 days). Filter may not make good } \\
\text { contact with the soil (Pan, et al. 2010). Non In situ }\end{array}$ \\
\hline & $\begin{array}{l}\text { Osmotic } \\
\text { suction }\end{array}$ & $\begin{array}{l}\text { Squeezing } \\
\text { technique }\end{array}$ & $0-1500$ & days & $\begin{array}{l}\text { Measurements affected by the magnitude of the extraction } \\
\text { pressure applied, depending on the type of soil (Pan et al. 2010). } \\
\text { Non In situ }\end{array}$ \\
\hline & $\begin{array}{c}\text { Total } \\
\text { suction }\end{array}$ & $\begin{array}{l}\text { Psychrometer } \\
\text { technique }\end{array}$ & $100-10000$ & $1 \mathrm{~h}$ & $\begin{array}{l}\text { Larger total suction values need longer equilibrium time. } \\
\text { Accuracy is }< \pm 0.05 p F, \pm 0.01 p F \text { (repeatability)(Cardoso et al. } \\
2007 \text { ),(Agus \& Schanz 2005). In situ. }\end{array}$ \\
\hline & & $\begin{array}{l}\text { Relative } \\
\text { humidity } \\
\text { sensor }\end{array}$ & $100-8000$ & Hours-days & $\begin{array}{l}\text { Specimen chamber must be open for a while in between } \\
\text { measurements. Accuracy is } \pm 1.5 \% \text { (Agus \& Schanz 2005). In situ } \\
\text { measurements }\end{array}$ \\
\hline & & $\begin{array}{l}\text { Chilled-mirror } \\
\text { hygrometer }\end{array}$ & $\begin{array}{c}100- \\
600000\end{array}$ & 10 minutes & $\begin{array}{l}\text { Not accurate when measuring low suction values, needs sample } \\
\text { extraction to be measured (non in situ). Temperature fluctuates } \\
\text { between } \pm 5^{\circ \mathrm{C}} \text {. Measurements vary } \pm 0.5 \mathrm{MPa} \text { for dry samples. } \\
\pm 0.1 \mathrm{MPa} \text { from } 1 \text { to } 10 \mathrm{MPa} \text { and } \pm 1 \% \text { from } 10 \text { to } 60 \mathrm{MPa} \\
\text { (Tarantino et al. 2009). }\end{array}$ \\
\hline & & $\begin{array}{l}\text { Non-contact } \\
\text { filter paper }\end{array}$ & All & $7-14$ days & $\begin{array}{l}\text { Long equilibrium time and a strict protocol are needed during } \\
\text { the experiment (Pan et al. 2010). Non in situ }\end{array}$ \\
\hline
\end{tabular}




\subsubsection{Function of the Tensiometer}

A typical tensiometer is represented in Figure 2-4 below:

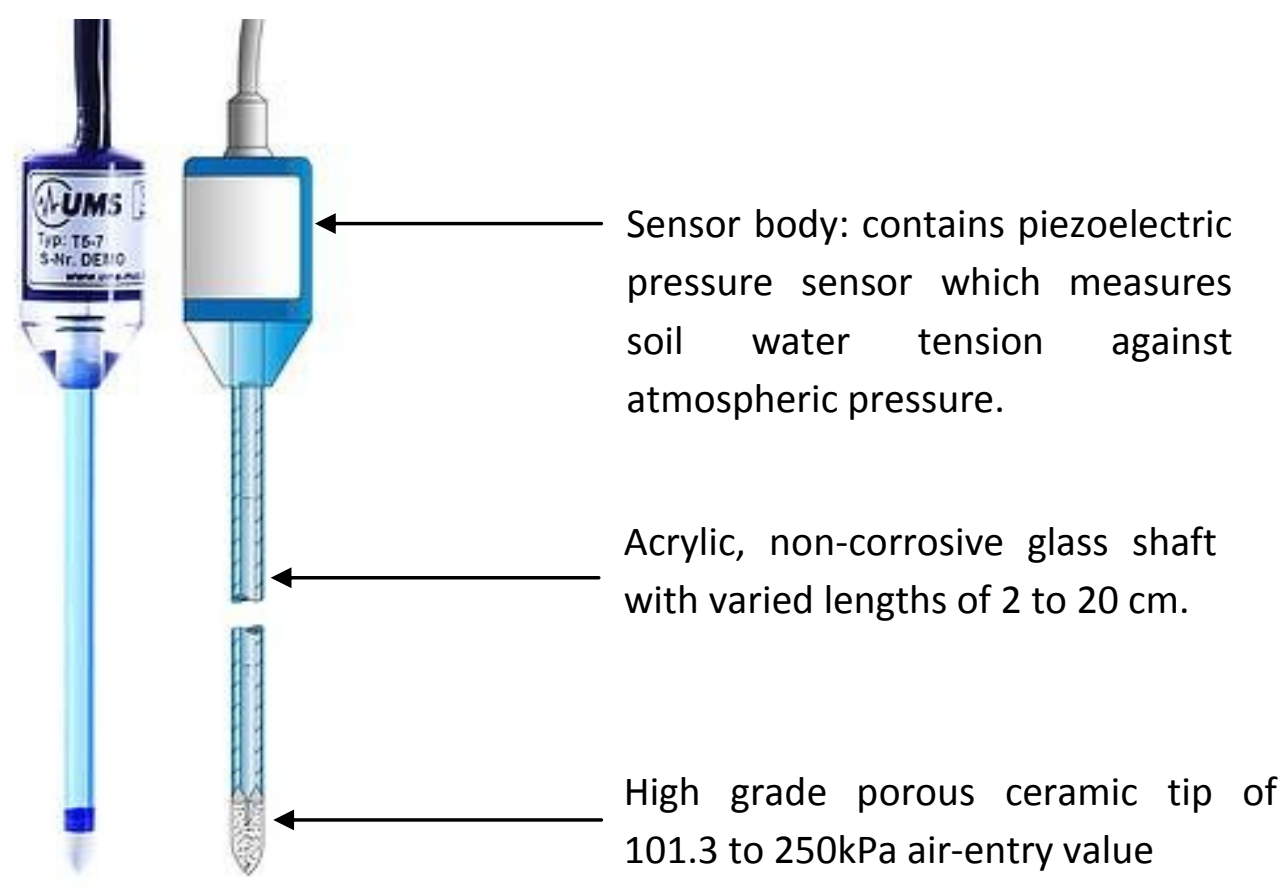

Figure 2-4: Diagram of a Tensiometer (UMS 2009)

Tensiometers are designed to measure the negative pore water pressure in the soil. A tensiometer consists of a water reservoir that is connected to the soil-water through a saturated porous ceramic tip with a high AEV. The water pressure in the reservoir, presumed to be in equilibrium with the soil-water, is measured using a vacuum gauge or a flexible pressure membrane (Fredlund \& Rahardjo 1988).

Pore water pressure measurement by a tensiometer is generally limited to around $90 \mathrm{kPa}$ due to the effect of cavitation in the tensiometer. As shown by Guan and Fredlund (1993), this limit can be temporarily exceeded by applying cycles of positive 
and negative pressure to the reservoir water, so as to eliminate cavitation nuclei (air bubbles). Eventually, air will diffuse back into the reservoir through the porous tip. In all cases, matric suction values greater than the AEV of the ceramic cup cannot be measured. The osmotic component of the soil cannot be measured using a tensiometer since the soluble salts can freely move through the pores in the tip.

\subsubsection{Function of the Heat Dissipation Sensor}

The Heat Dissipation Sensors (HD Sensors) measure the thermal conductivity of a porous material of known SWCC, placed in contact with soil. Thermal conductivity is a function of water content, which can then be correlated with matric suction if the SWCC is known (Wilson et al. 1999). The HD sensor has two parts, a heating and heat sensing device (thermistor) enclosed in a porous block. The heater and the sensing devices are embedded within a small porous ceramic.

The heat dissipation sensor operates by measuring the temperature using the thermistor before and after activation of a pulse from the heater. These temperature readings are then used to calculate thermal conductivity. The double correlation with water content and suction is then applied. This double correlation is usually obtained by calibration of the sensor in an axis-translation device.

The heat dissipation sensor cannot measure suctions below the AEV of the porous material, since the thermal conductivity will not change for those suctions. These sensors are also restricted by the validity of the double correlation, which are valid for only one path on the SWCC, e.g., drying from saturation, but not rewetting from 
residual or any other intermediate water content. In other words, the matric suction value measured by the HD sensor depends on whether the ceramic is saturating or desaturating, therefore ideally the sensor should be calibrated during each process.

\subsubsection{Function of a Strain Gauge}

In this thesis, the deformation of the sensor is monitored by using strain gauges. A brief review of strain gauge technology is presented. The strain as measured by a gauge can be illustrated using the following equation (Equation 12),

$$
\varepsilon=\frac{\Delta L}{L}
$$

The fractional change in length can be represented using Figure 2-5,

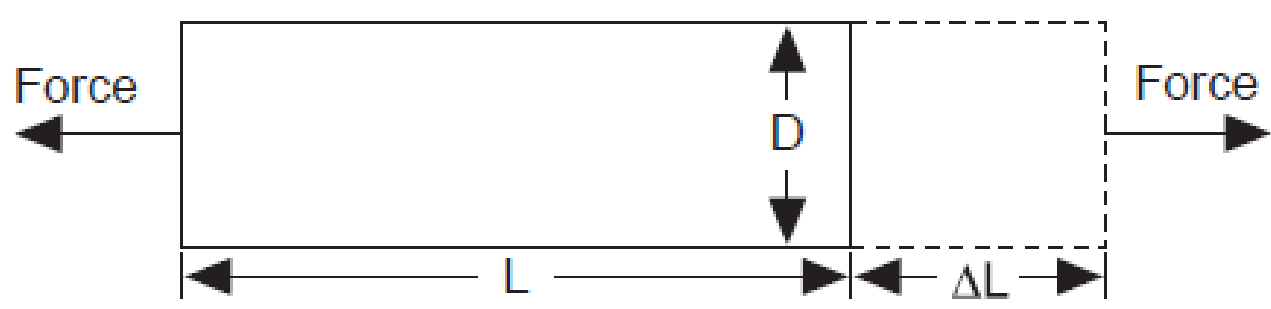

Figure 2-5: Deformation of a strain gauge

The strain can be represented as either tensile (positive) or compressive (negative). The unit for strain is generally expressed in microstrain $(\mu \varepsilon)$ due to its small magnitude of measurement. 
The strain gauge has fine wire or metallic foil arranged in a grid pattern which maximizes the metallic wire that is subjected to strain in the parallel direction. The grid is bonded in a thin backing called the carrier which is attached directly to the specimen. When a strain gauge is attached to a test specimen the deformation of the system can be measured by the strain gauge which responds with a linear change in electrical resistance. The most common strain gauges are 120, 350 and $1000 \Omega$, although the entire range is from 30 to $3000 \Omega$. Figure 2-6 represents a diagram of a bonded strain gauge.

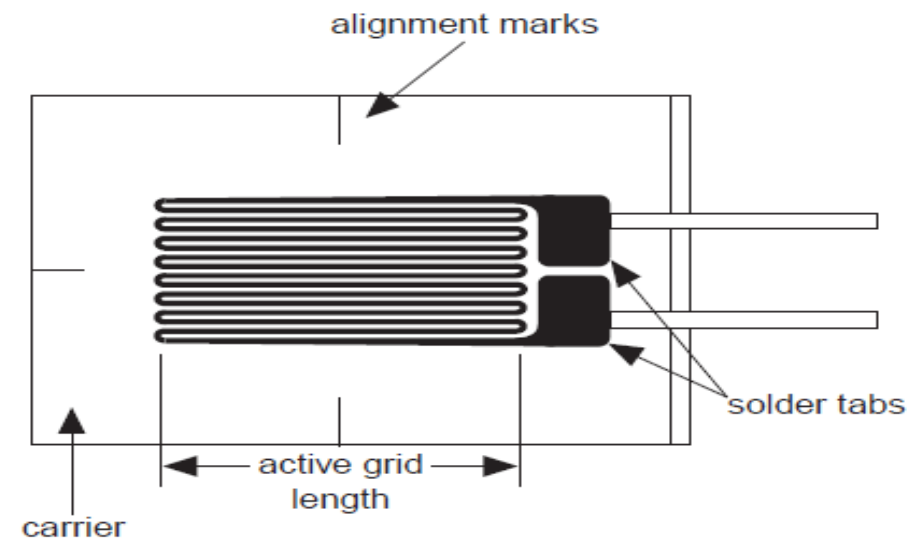

Figure 2-6: Bonded metallic strain gauge

Although strain gauges provide many favourable features, they have some limitations. Each strain gauge's performance depends on two factors such as the temperature, the environment that it is applied in (Tokyo Sokki Kenkyujo Co.Ltd).

Apart from the limitations, the strain gauges carry many favourable features, such as the simple construction of the strain gauge allowing it to not interfere with the stresses 
on the specimen of interest. Strain gauges have a short distance between the measuring points for localized evaluation, good frequency response for tracking rapid fluctuations in stress and allowing simultaneous measurements to be recorded at multiple points (Tokyo Sokki Kenkyujo Co.Ltd).

The strain gauge that is been used to construct the PE sensor was a series EA strain gauge (Micro-Measurment Division). These types of strain gauges are used for general purpose, experimental stress analysis. This particular type of strain gauge was constructed with a $0.03 \mathrm{~mm}$ tough, flexible polyimide film support. The temperature range of the strain gauge is $-75^{\circ} \mathrm{C}$ to $175^{\circ} \mathrm{C}$, with a short-term exposure temperature range of $-195^{\circ} \mathrm{C}$ to $205^{\circ} \mathrm{C}$. The gauge life depends on the gauge length and the method of cycling. For $10^{8}$ cycles, the strain is $\pm 1200 \mu \varepsilon$ and $10^{6}$ cycles is at $\pm 1500 \mu \varepsilon$.

\subsection{Poroelastic Suction Sensor (PE Sensor)}

This section presents a description of the construction and operation of the PE sensor. In addition, it presents previous testing that was conducted by other researches on the sensor.

\subsubsection{Concept behind PE Sensor Operation}

The PE sensor has three parts: namely the top cap, the strain gauges ( 2 strain gauges) and the porous rod. The main importance of the PE sensor lies in its porous rod (or its poroelastic behaviour). A diagram of the PE sensor is shown in Figure 2-7. 


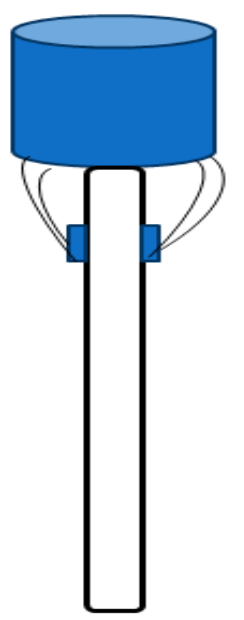

Figure 2-7: Main Components of the PE sensor

The poroelastic material in this case responds to matric suction by through volume change that will result due to the change in pore water pressure. The change in volume measured by the poroelastic material is measured as strain over the longitudinal axis, which then can be converted to pore-water pressure using Biot theory (Dunmola et al. 2009).

The Biot theory can be used to explain the behaviour associated with the poroelastic rod used in the PE sensor by using two equations (Patzek 2005). The first equation shown below (Equation 13) represents the fractional volume change yielded by the change in applied stress and pore water pressure and the second equation (Equation 14) shows that the changes in pore water pressure and applied stress requires fluid to be added or removed from storage in the pore space.

$$
\varepsilon=a_{11} \sigma+a_{12} p
$$




$$
\zeta=a_{21} \sigma+a_{22} p
$$

The terms in the above equations are as follows, $\sigma$ is the isotropic stress field, $\varepsilon$ is the volumetric strain based on the bulk volume (which shows a positive value for expansion and a negative value for contraction), $\zeta$ represents the increment of fluid content (i.e. the fluid added to the control volume represented as positive) and $p$ is the pore water pressure (if the value is above the atmospheric pressure, $p$ is positive, otherwise negative). According to the aforementioned equations, in a condition where a uniform change in the fluid mass or pore pressure exists, a uniform strain can be seen in the bulk porous rod. This concept was used in the poroelastic rod in the PE sensor provided that no external force has been applied to the rod.

The volumetric strain measured by the porous rod of the PE sensor must be converted to the pore-water pressure $\left(u_{w}\right)$ in order to determine matric suction $\left(u_{a}-u_{w}\right)$. A formula assuming fully saturated porous medium and assuming a linearly elastic solid frame is shown in the following equation (Equation 15) (Bentz et al. 1998),

$$
\epsilon=\frac{S p_{c a p}}{3}\left(\frac{1}{K}-\frac{1}{K_{S}}\right)
$$

$p_{c a p}$ is the pressure in the pore fluid, $\mathrm{S}$ is the degree of saturation, $\mathrm{K}$ is the bulk modulus of the porous solid, $\mathrm{K}_{\mathrm{s}}$ is the bulk modulus of the solid frame of the porous solid and $\epsilon$ is the linear strain (Bentz et al. 1998). The above equation is valid only for scenarios where the degree of saturation is $80 \%$ or above hence the accuracy of the equation tends to decrease as the degree of saturated drops below $80 \%$. Equation 15 therefore 
should give results that are accurate for the strain below the suction of the AEV for the poroelastic rod (Dunmola et al. 2009).

The bulk modulus $\left(K_{s}\right)$ in the previous equation (Equation 15) can be obtained using the following equation (Equation 16),

$$
K_{s}=\frac{E_{S}}{3(1-2 u)}
$$

$E_{s}$ is the young's modulus of the porous rod's solid phase (or frame), and $\mu$ is the Poisson ratio (Dunmola et al. 2009). The relationship between the bulk modulus of the solid frame and the bulk modulus of the porous material can be expressed using the following equation (Equation 17),

$$
\frac{K}{K_{S}}=1-\frac{\left(3 K_{S}+4 G_{S}\right) n}{4 G_{S}}
$$

$\mathrm{n}$ is the porosity of the material and $G_{s}$ is the shear modulus (Bentz et al. 1998). The shear modulus can be obtained using the following equation represented below,

$$
G_{s}=\frac{E_{S}}{2(1+u)}
$$

According to the tests conducted by Dunmola et al. (2009), it was determined that the internal surface area of the porous material is $250 \mathrm{~m}^{2} / \mathrm{g}$, the specific gravity is 1.5 , the porosity is 0.34 and the average pore diameter is 4 nanometres. The AEV of the porous rod was determined to be approximately $8000 \mathrm{kPa}$ using the young-Laplace equation. 
From literature, the backbone material has an elastic modulus of 65GPa and a Poisson ratio of 0.24 (Dunmola et al. 2010).

The fact that the porous rod used in the poroelastic suction sensor (PE sensor) has a high AEV (contains micro pores), eliminates the issue of cavitation. Also, if the material is linearly elastic, hysteresis will also not be a concern.

The volume change of the PE sensor is monitored by the strain gauges mounted on to the porous rod. Specifics as to the construction of the sensor are provided in sections 3.1. This volume change is measured by the data logger as microstrain, which can then be converted to matric suction.

\subsubsection{Strain Gauge Drift}

Depending on the strain gauge type, there could be strain associated drift for some strain gauges. The drift in values can be expressed when the change in strain with respect to time does not become zero, even after attaining its maximum rate of deformation. For an instance a strain gauge attached to a saturated porous glass rod should constantly give the same value of strain with time, showing that the porous rod has reached its maximum rate of expansion. However, in some cases the strain gauge results tend to give increasing values with time even after the maximum deformation has attained, showing a drift in the results.

This drift can be due to various factors that influence the strain gauge to deform; one such factor can be the temperature difference around the strain gauge. The 
temperature can influence the strain values by causing the strain gauge to expand or contract, if the strain gauge is in an area of warmer temperature or lower temperature respectively. Most strain gauges are manufactured such that it works in a specific range of temperatures.

Other potential sources that could cause a drift in the strain gauge results are $\mathrm{RH}$ and heat transfer. The $\mathrm{RH}$ can change the moisture content around the strain gauge deforming the strain gauge causing the values to show a drift in the results. In addition, the strain values can change due to the heat induced by electricity passing through the strain gauges causing a deformation in the gauge, resulting in a drift. A good example of this would be, if the strain gauge is attached to a poor heat conductor (such as the PE sensor porous rod) that causes the current passing through the strain gauge to be affected by the heat conduction causing a deformation.

In addition, another factor that could contribute to drift is the potential of creep. The creep is the tendency of material to deform under mechanical stresses. This can be further explained by imagining a sudden load being applied to the test element (PE sensor); there is a possibility of the strain-gauge bridge output to decrease with time from an initial value. This state of decrease in value can be relatively large for the first few seconds and decreases giving an output of a constant value. The creep can also happen in the opposite direction because of the back material on the strain gauge. However, the most strain gauges are designed to compensate for the creep factors. The 
adhesives used in the strain gauges are also manufactured to have minimal creep effects and elevated temperature curing.

The following section illustrates the tests that were done using the poroelastic suction sensor (PE sensor) by previous researchers (Dunmola et al. 2010 and Apking 2010).

\subsubsection{Previous testing of the PE Sensor}

The first set of wetting and drying tests were done to determine the SWCC for the porous glass. Wetting and drying cycles were repeated and the results were plotted as suction versus gravimetric moisture (water) content of the porous medium. The results obtained show no evidence of hysteretic behaviour up to a suction level of at least 4MPa (Dunmola et al. 2009).

The PE sensor was also tested using silt and gold mine tailings, where the tests results were compared with the results obtained by tensiometer, axis translation technique, and psychrometer during the drying of the soil. The SWCC of the (drying cycle) was plotted (Figure 2-8) comparing the PE sensor and the relative humidity sensor. Both sets of values show a high correlation with an $R^{2}$ value of 0.977 (Dunmola et al. 2009). 


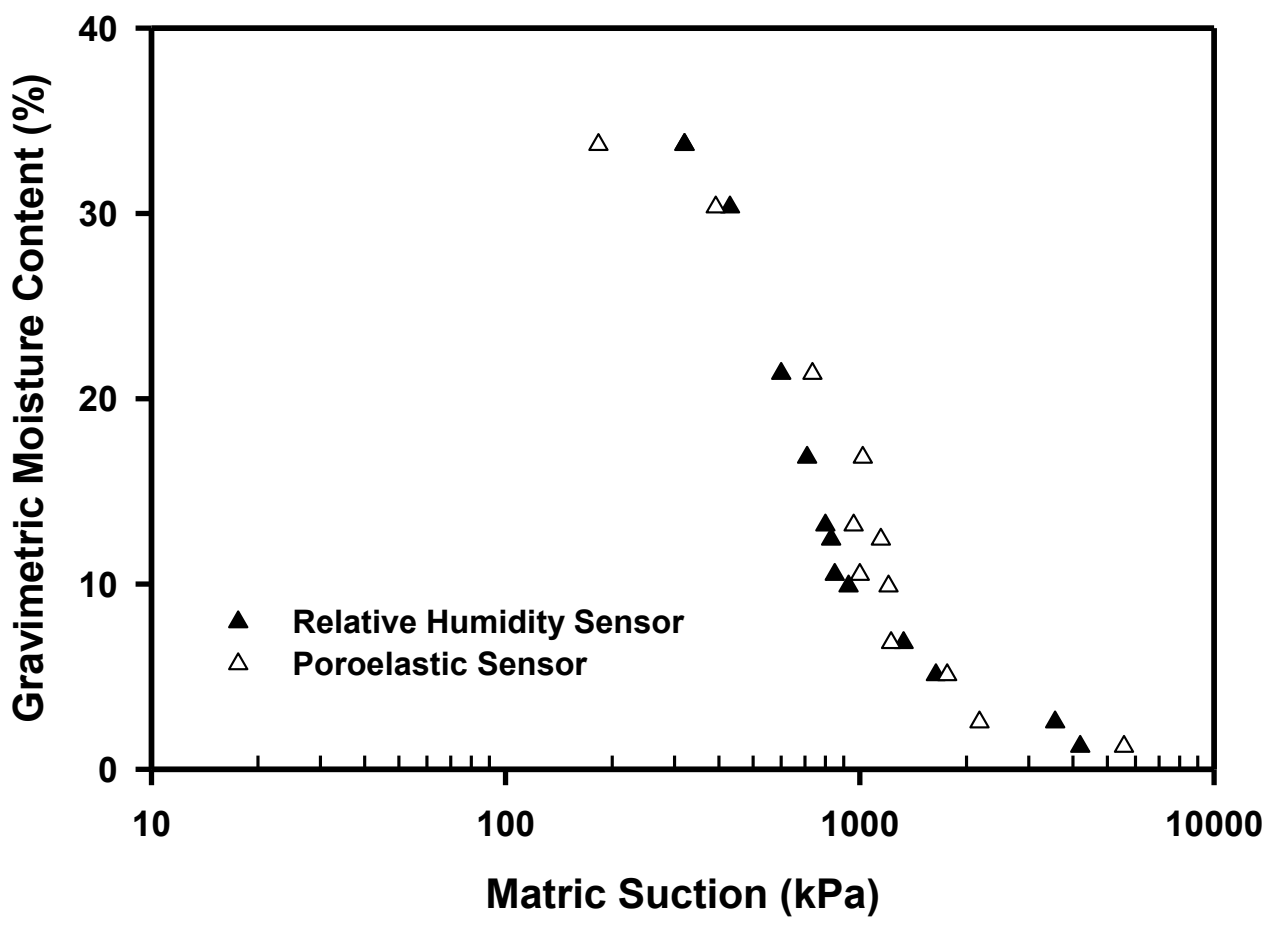

Figure 2-8: SWCC to Compare PE Sensor and Relative Humidity Sensor in Silt (Dunmola et al. 2009)

Also matric suction versus time was plotted for the PE sensor results and the tensiometer results. The following plot (Figure 2-9) presents the results, which shows a high correlation between the results with a $\mathrm{R}^{2}$ value of 0.977 . 


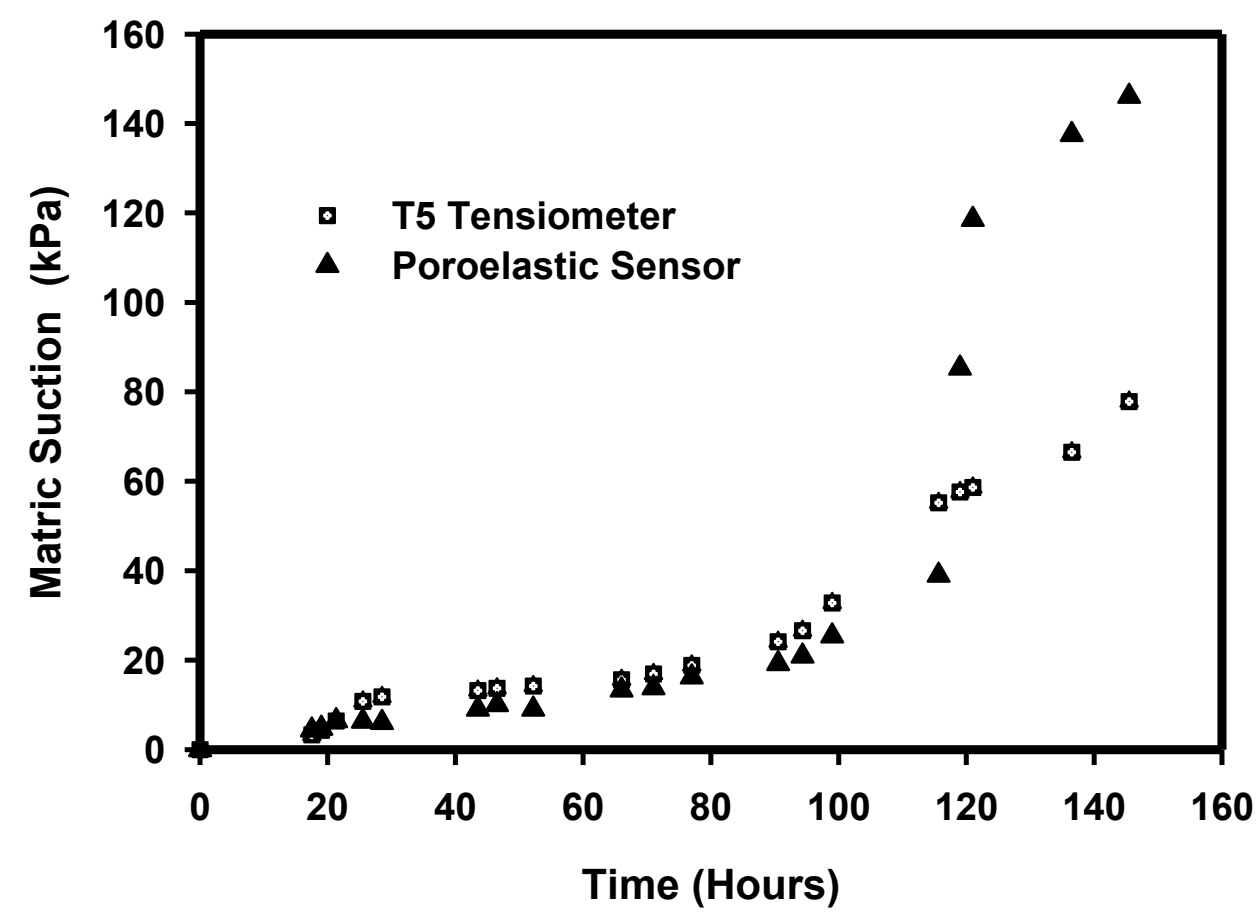

Figure 2-9: Results Comparing the PE Sensor and Tensiometer in Silt (Dunmola et al. 2009)

\section{Test Results Conducted by Apking (2010)}

After preparing a new PE sensor, a saturation test must be done to saturate the sensor and to ensure that the sensor is working properly, before it is tested in soil. During saturation, the water enters the porous part of the sensor and a rapid increase of strain was observed at the beginning of the procedure. After the saturation was obtained (the saturation strain typically varies in the range of $2000-3500 \mu \varepsilon)$, the strain does not reach a constant value. Instead, a drift was observed in the results obtained for both sensors, captured in the following figures, 


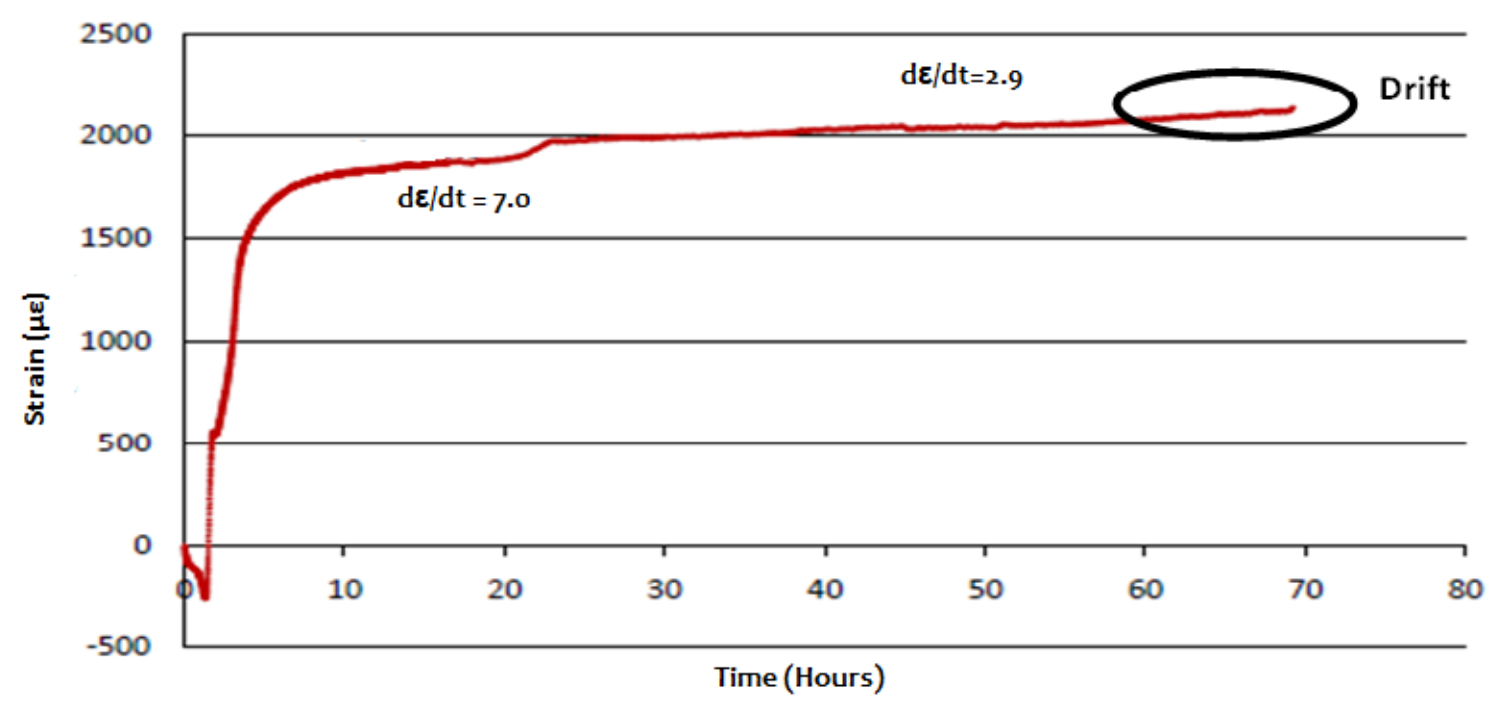

Figure 2-10: Saturation Test of the PE Sensor for 3 Days (PE Sensor 1)

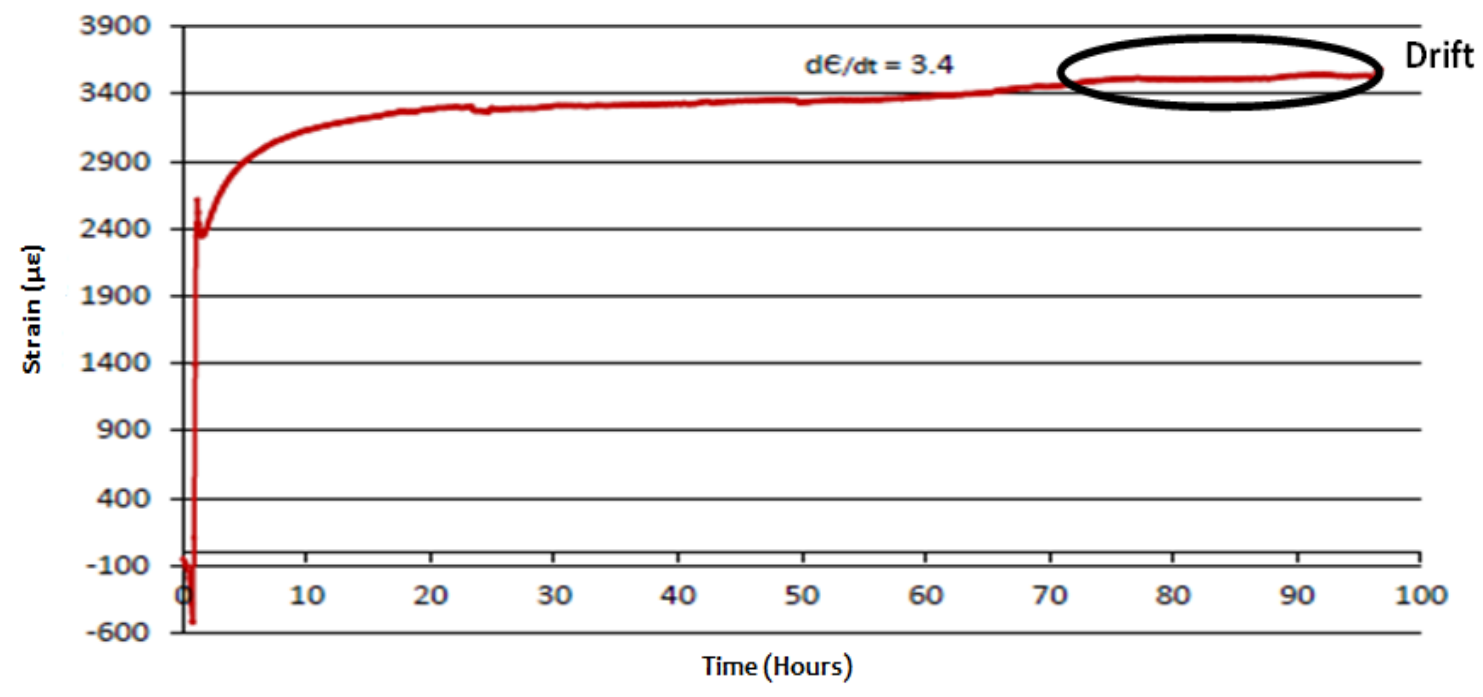

Figure 2-11: Saturation Test of the PE Sensor for 3 Days (PE Sensor 2) 
It was also determined that the drift observed at repeated tests tend to be different, but follows a similar range. Therefore Apking (2010) was able to make two important statements about the PE sensor.

1. The drift in strain is always positive (tension)

2. Drift remains fairly linear over significant duration of time

The drift was thought to be caused by the temperatures of the surrounding environment, or by heating induced due to the strain gauge itself. However these test results suggest that the trend observed for the temperature change is not similar to the drift observed by the PE sensor results. It was further observed that an increase in temperature does not have a significant effect (thermal strain) on the PE sensor. The temperature testing was done at the same time as the PE sensor 2 test for saturation. The following Figure 2-12 shows the temperature versus time period plot,

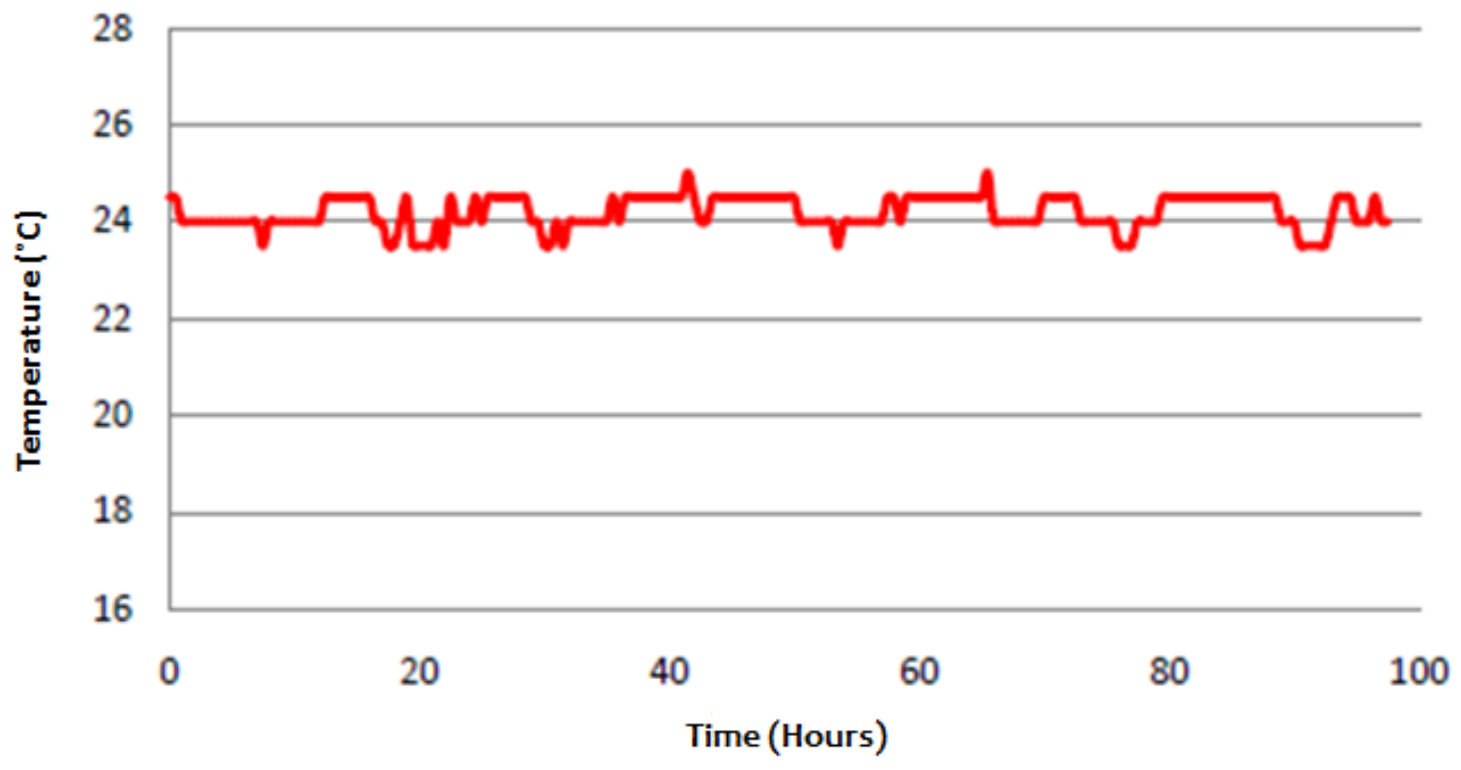

Figure 2-12: Ambient Temperature versus Time at the Time of Saturation of PE Sensor 2 
From Figure 2-12, it was observed that the temperature variations were only about \pm $0.5^{\circ} \mathrm{C}$, and the temperature variation and the drift of the sensor do not tend to correlate with each other. The same test was conducted for the other PE sensors to further validate that the temperature difference was not the cause for the drift of strain in the PE sensors.

In addition to the temperature testing, relative humidity (RH) test results were also compared to the saturation test results that were both conducted on PE sensor 2. If a change exists, a gradual deformation of the sensor material should be observed with the variation of $\mathrm{RH}$. However, the trend of the $\mathrm{RH}$ test results does not show a correlation between the behaviour of the trend of the PE sensor saturation test results. The variation of the $\mathrm{RH}$ during the test period was determined to be approximately $13 \%$ $16 \%$ between $25-60$ hours. After conducting identical tests with the other sensors, it was evident that the $\mathrm{RH}$ is also not the cause of the drift observed in the saturation tests. The RH tests results are presented in the following Figure 2-13, 


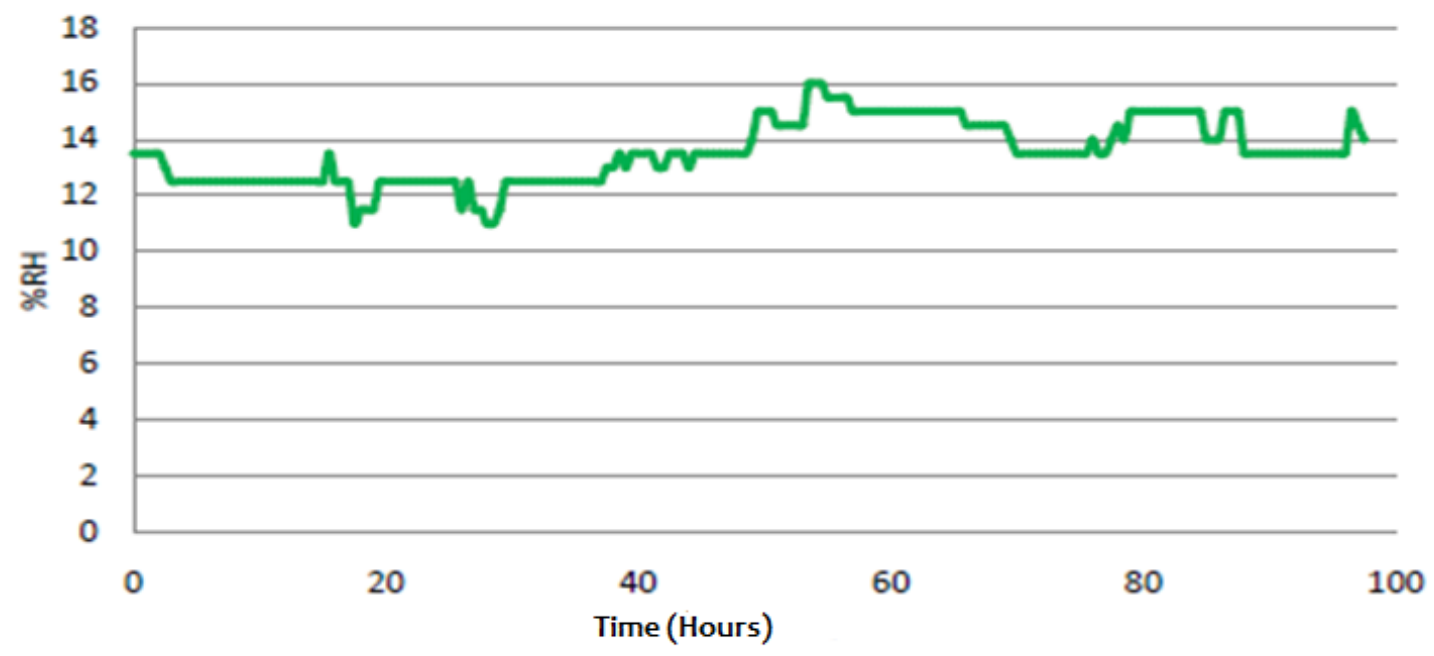

Figure 2-13: Ambient Relative Humidity versus Time at the time of Saturation of PE Sensor 2

From the tests that were presented above, Apking (2010) was unable to determine the actual cause of the drift observed on the PE sensors. However, the drift observed on the newly prepared sensors tended to decrease after using the sensors for extended period of time.

Apking (2010) postulated that the drift variation was due to the possibility of the energy that is being dissipated by the strain gauge used in the PE sensor; causing a thermal expansion of the gauge yielding the observed results. Since the porous material is a poor conductor of heat and electricity, the expansion of the strain gauge can be directly observed from the results obtained, for saturation in each PE sensor. Although this can be a possibility, he performed no tests to prove the validity of the theory. 
To minimize the effect of drift that was observed by the PE sensor, Apking (2010) calculated the slope of the strain values as shown in the Figure 2-10 and Figure 2-11. The inability of the sensor to obtain a constant datum renders the inaccuracy of the sensor values, therefore there suction values were considered unreliable. Without a set datum of the strain values, the deformation over a significant time period observed on the sensor cannot follow the true deformation. Therefore, correction of the strain values were determined by using the equation (Equation 19) for the soil tests,

$$
\epsilon_{\text {corrected }}=\left(\epsilon_{\text {measured }}\right)-\left(t_{c} \times \frac{d \epsilon}{d t}\right)
$$

$\epsilon_{\text {corrected }}$ represents the corrected strain value from the measured strain $\epsilon_{\text {measured }}$ values, $t_{c}$ is the cumulative time in hours, and $\frac{d \epsilon}{d t}$ is the rate of change of saturated strain values with time for each sensor. The Figure 2-14 compares the measured strain results to the corrected strain results. 


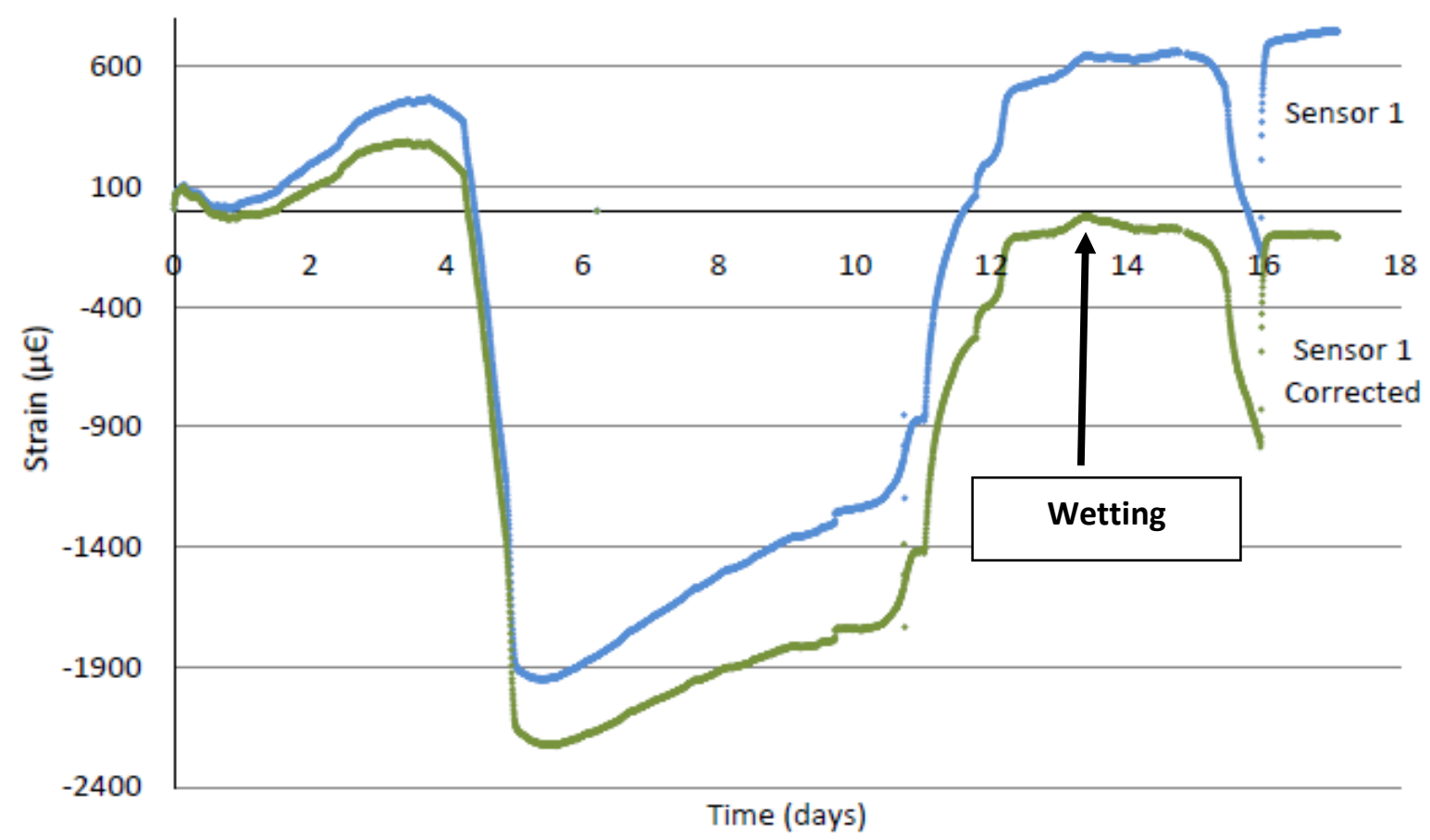

Figure 2-14: PE Sensor Measured and Corrected Strain Comparison for Drying and

\section{Wetting Test in Silt}

From Figure 2-14, it can be seen that the initial strain values of the sensor is zero, since at the beginning of the test the PE sensor is at its full saturation $(S \approx 100 \%)$. As the time passes the soil starts to dry and the matric suction of the soil starts to increase. This can be seen after day 5 in Figure 2-14 as the strain starts to become negative. As a result, the porous rod of the sensor deforms under compression due to the presence of negative pore water pressure. The corrected strain shows a greater deformation than that of the measured strain after day 5 since the drift of strain in the positive direction counteracts with the actual strain of deformation of the sensor. Therefore, the application of the correction $\frac{d \epsilon}{d t}=50 \mu \varepsilon /$ day tends to show a controlled trend of drift, 
which also agrees with the strain reading observed by the PE sensor when the strain reaches zero upon the initiation of the wetting cycle at day 13 . Therefore, at day 13 the clay should be at $100 \%$ saturation giving a strain value of zero, corresponding to a suction value of zero.

After testing the sensor on silt, experiments were performed for the wetting and drying cycles of the sensor on Clay sample. The clay sample measured strain data was then compared with the corrected strain values as shown in Figure 2-15,

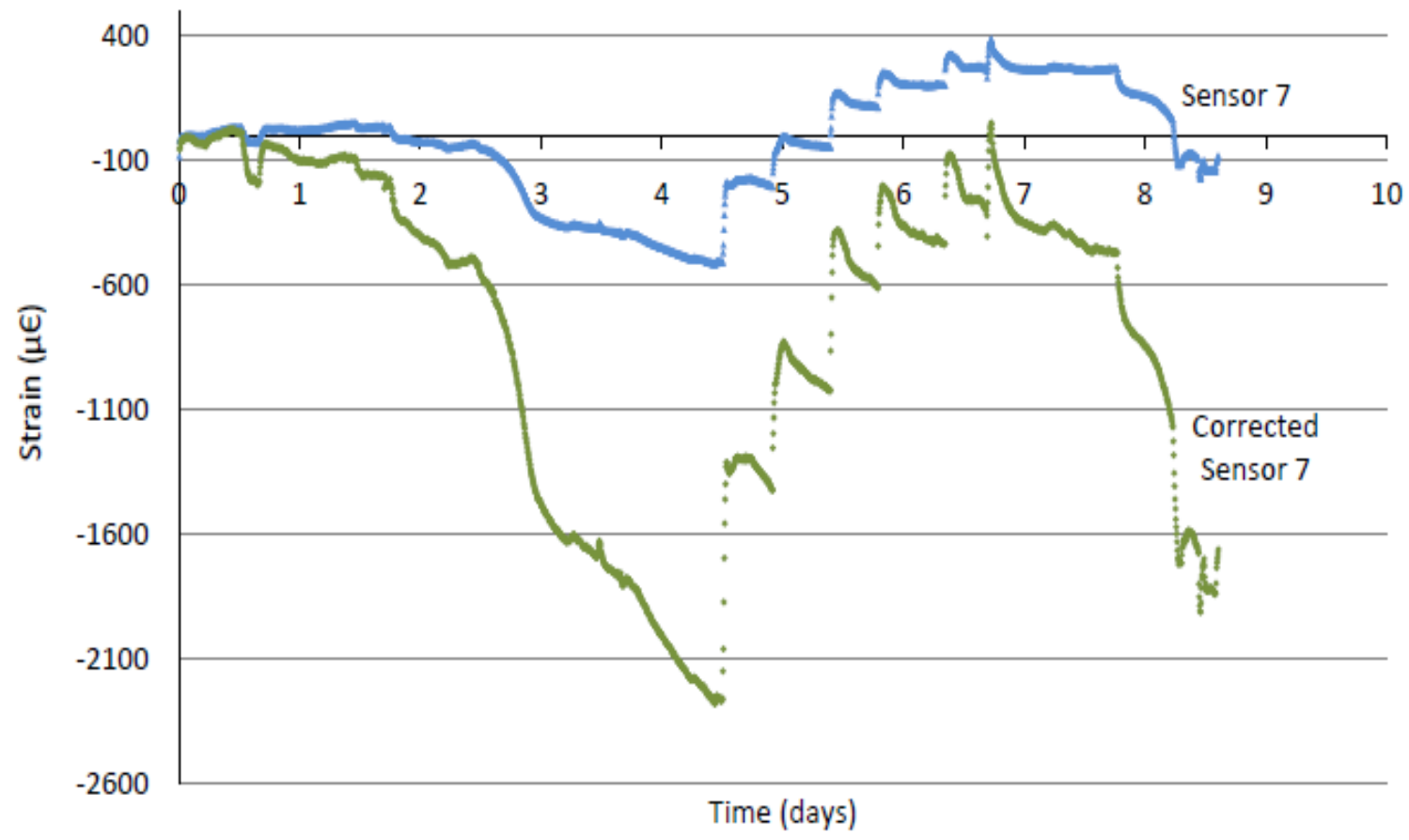

Figure 2-15: PE Sensor Measured and Corrected Strain Comparison for Drying and Wetting Test in Clay 
As shown in Figure 2-15, a strain correction of $\frac{d \epsilon}{d t}=55 \mu \varepsilon /$ day was applied to the measured strain values obtained from the PE sensor. The value used for clay is similar to the values used for the saturation test, giving a reliable assumption of the corrected strain values. This can be seen by observing the Figure $2-15$, where the strain value returns to the original value of $\varepsilon=0$ indicating a very low value of suction in the soil (approximately $\approx 5 \mathrm{kPa}$ ) after the soil has been re-saturated to a high degree of saturation. The corrected values were then obtained from the suction measurements from the PE sensor soil test results. This procedure was followed to minimize the effect of drift observed from the sensor test results.

The strain values obtained from the PE sensor tests must be converted to matric suction values in $\mathrm{kPa}$ through a linear relation between the strain and matric suction of the porous material using the following equation obtained through substitution of Equation 15 ,

$$
P=\frac{3 \epsilon}{S\left(\frac{1}{K}-\frac{1}{K_{S}}\right)}
$$

$\mathrm{K}$ represents the bulk modulus of the porous solid composite, $\mathrm{K}_{\mathrm{s}}$ represents the bulk modulus of the solid backbone of the porous material. Equation 20, represents the suction value in $\mathrm{KPa}$, assuming that the saturation of the material is at $100 \%$ (material is fully saturated, $S=1$ ). Full saturation of the sensor was assumed, since the porous material should be in saturation without de-saturating until it reaches the AEV value of the material which is approximately $8000 \mathrm{kPa}$, based on tests conducted by Apking 
(2010). In order to determine $\mathrm{K}$ and the $\mathrm{K}_{\mathrm{s}}$, the modulus of elasticity and the Poisson's ratio of the sensor material must be determined.

The modulus of elasticity $\left(E_{s}\right)$ of the porous rod used for the PE sensor was obtained to be 65GPa from the previous experiments by Bentz et al. (1998). The Poisson's ratio $(\mu)$ for the backbone of the material used by Dunmola et al. (2009) was 0.24 and the same value was used by Apking (2010) in his calculations since the same material was employed. Equation 16 was used to determine the bulk modulus of the solid backbone material $\left(\mathrm{K}_{\mathrm{s}}\right)$, which was calculated to be $41.7 \mathrm{GPa}$.

Equation 16 was used to obtain the bulk modulus (K) of the composite porous material relating the modulus of elasticity and Poisson's ratio since it provides more accurate values than Equation 17 which is based on the calculated bulk modulus of the solid backbone material $\left(\mathrm{K}_{\mathrm{s}}\right)$ (Dunmola et al. 2009). Various modulus of elasticity values were obtained with constant Poisson's ratio of $\mu=0.17$ in Equation 16 (Dunmola et al. 2009). From these results, several bulk modulus values were obtained for the actual porous material, which can be used in order to obtain the matric suction values using Equation 20 for the entire soil test. When using Equation 20 to obtain the matric suction values the bulk modulus of the backbone $\left(\mathrm{K}_{\mathrm{s}}\right)$ value was kept constant.

Bulk Modulus variation with the Silt Test Measurements by Apking (2010)

Original bulk modulus value used by Dunmola et al. (2009) to calculate the matric suction values for drying and wetting tests in the silt was $42.9 \mathrm{MPa}$. However ( $\mathrm{K}=$ 
42.9MPa), when used in silt, gave matric suction values lower than $300 \mathrm{kPa}$ shown in the Figure 2-16,

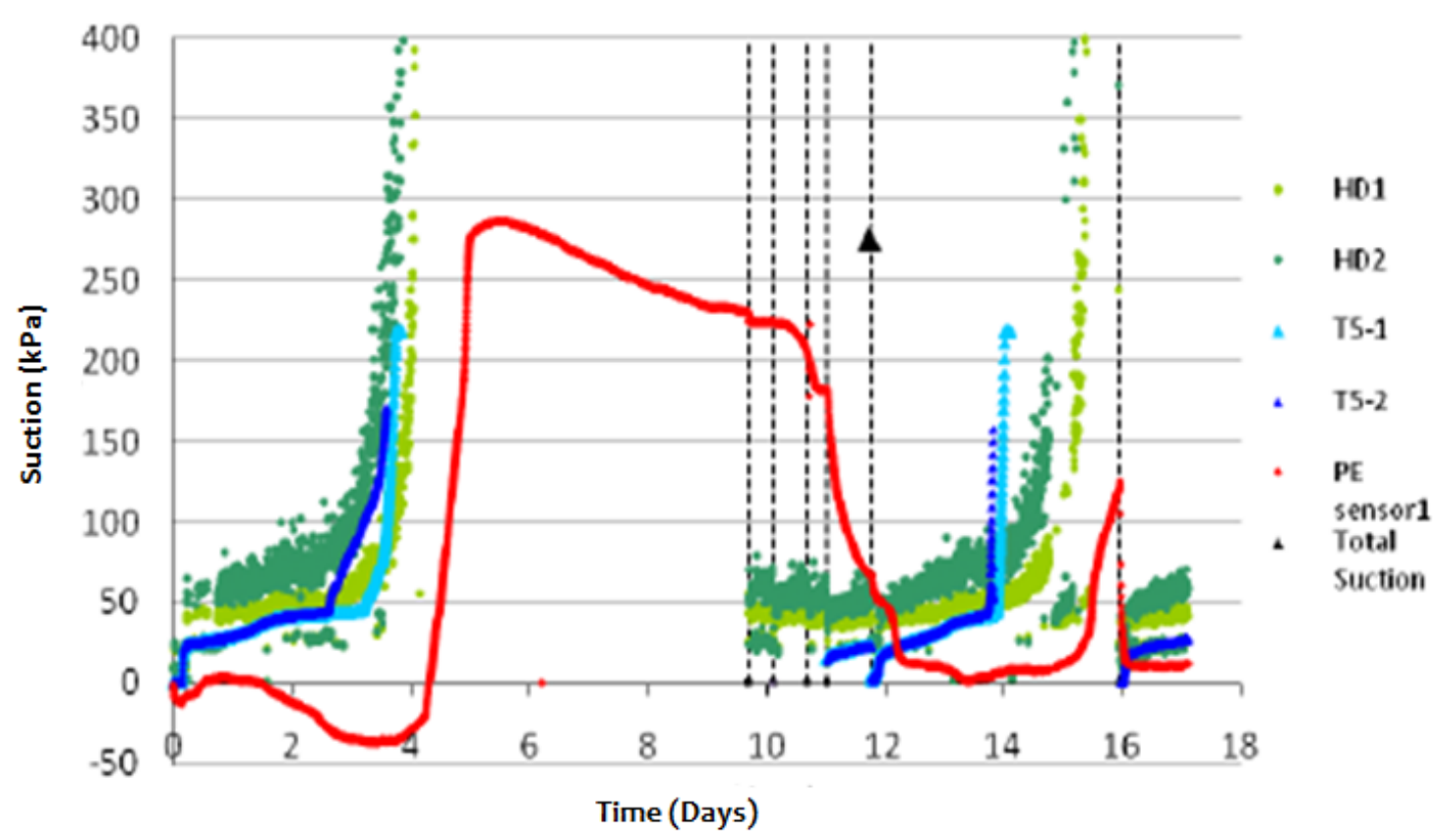

Figure 2-16: Matric Suction ( $\mathrm{kPa}$ ) during Wetting and Drying Cycles in Silt ( $\mathrm{K}=42.9 \mathrm{MPa})$

According to Figure $2-16$, if the $\mathrm{K}$ value was taken to be $42.9 \mathrm{MPa}$, the PE sensor values severely under predicts the suction values compared to those obtained for tensiometers and HD sensors. However, the trend of the matric suction values obtained shows an agreement with these results. On the other hand, strain values obtained from previous tests carried out in silt (Figure 2-14), provide evidence that the PE sensor responded well to the deformation due to high matric suction values. Therefore, it was determined that the $\mathrm{K}$ value used in the calculations in the Figure 2-16 does not accurately represent 
the volumetric deformation of the porous rod of the sensor to the stress applied; hence other values were used to properly compare the matric suction values to the acceptable methods (tensiometer and HD sensor values).

A more suitable $\mathrm{K}$ value of $1.77 \mathrm{GPa}$ was obtained by using the elasticity modulus of 3.5GPa. $\mathrm{K}=1.77 \mathrm{GPa}$ yielded a maximum matric suction value of $12,000 \mathrm{kPa}$, as measured previously for the deformation of the PE sensor during wetting and drying cycles in silt. After adjusting the K value, the PE sensor results and the HD sensor results show good correlations to each other (days 13 -16, Figure 2-17).

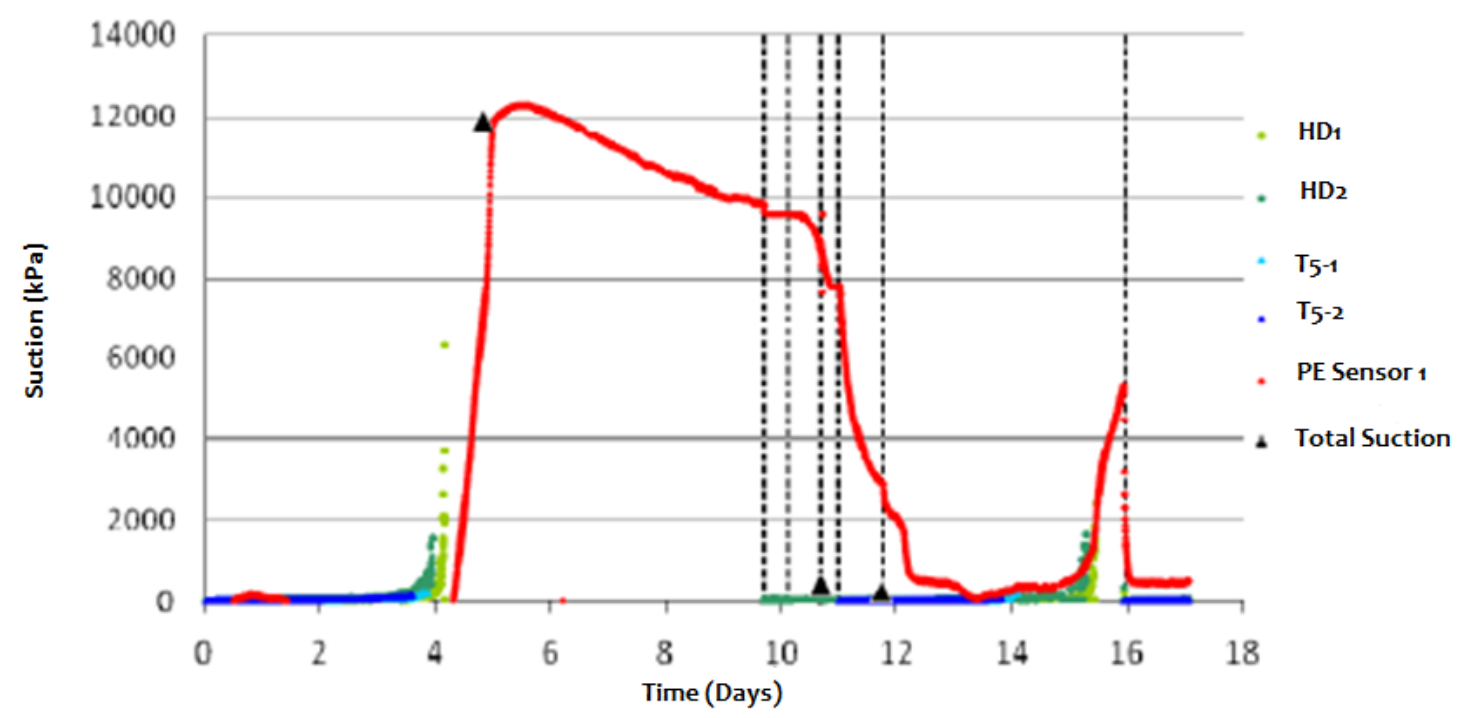

Figure 2-17: Matric Suction $(\mathrm{kPa})$ during Wetting and Drying Cycles in Silt $(\mathrm{K}=1.77 \mathrm{GPa})$

After day 4 , the total suction measurements were determined to be a value of $11,905 \mathrm{kPa}$ in the silt, taken from the same approximate depth of the PE sensor tip. In Figure 2-17, it is apparent that the values obtained for the PE sensor and for the total suction measurements tend to agree well with each other. However, since the AEV 
value of the PE sensor only extends up to $8000 \mathrm{kPa}$, values greater than the AEV cannot be measured by the PE sensor.

Furthermore in Figure 2-17, the results obtained after day 4 cannot be accurate since the equation that has been used for the determination of the matric suction values from the strain values obtained from the PE sensor, needs saturation closer to $100 \%$ ( $\mathrm{S} \geq$ $0.8)$.

From the Figure 2-17 it was shown that a poor correlation exists between the PE sensor results and the tensiometer results when the suction values are less than $1000 \mathrm{kPa}$, when the bulk modulus was used to be $1.77 \mathrm{GPa}$. Therefore, from the results it was concluded that the determination of a constant bulk modulus for the suction values obtained from the experimental range of matric suction measurements will not be reasonable. This can be elaborated by the porous material straining beyond a linear relationship between the applied stress and strain (proportionality limit), where the bulk modulus must be obtained as a function of deformation to applied stress. In Figure $2-17$, the bulk modulus value was selected to show the correlation of the PE sensor data at a matric suction range above the value of $1000 \mathrm{kPa}$. Therefore, for the silt tests, the modulus of elasticity was determined to be $\mathrm{E}=2.8 \mathrm{GPa}$, with a bulk modulus of $\mathrm{K}$ $=1.4 \mathrm{GPa}$.

Bulk Modulus variation with the Clay Test Measurements by Apking (2010)

Similar to experiments done in silt, when using clay, the same method of utilizing bulk modulus values were used to determine the matric suction from the strain 
measurements of the PE sensor. Initially, the bulk modulus was set at 42.9MPa, which produced a maximum matric suction value of about $100 \mathrm{kPa}$ as predicted by the PE sensor. The values obtained using $\mathrm{K}=42.9 \mathrm{MPa}$ shows an agreement with the HD sensor and the tensiometers values. The HD sensor suction values exceed $100 \mathrm{kPa}$ at day 2 , indicating that the bulk modulus used for the PE sensor was inaccurate when considering the porous rod deformation of the sensor to applied stress as shown in Figure 2-18,

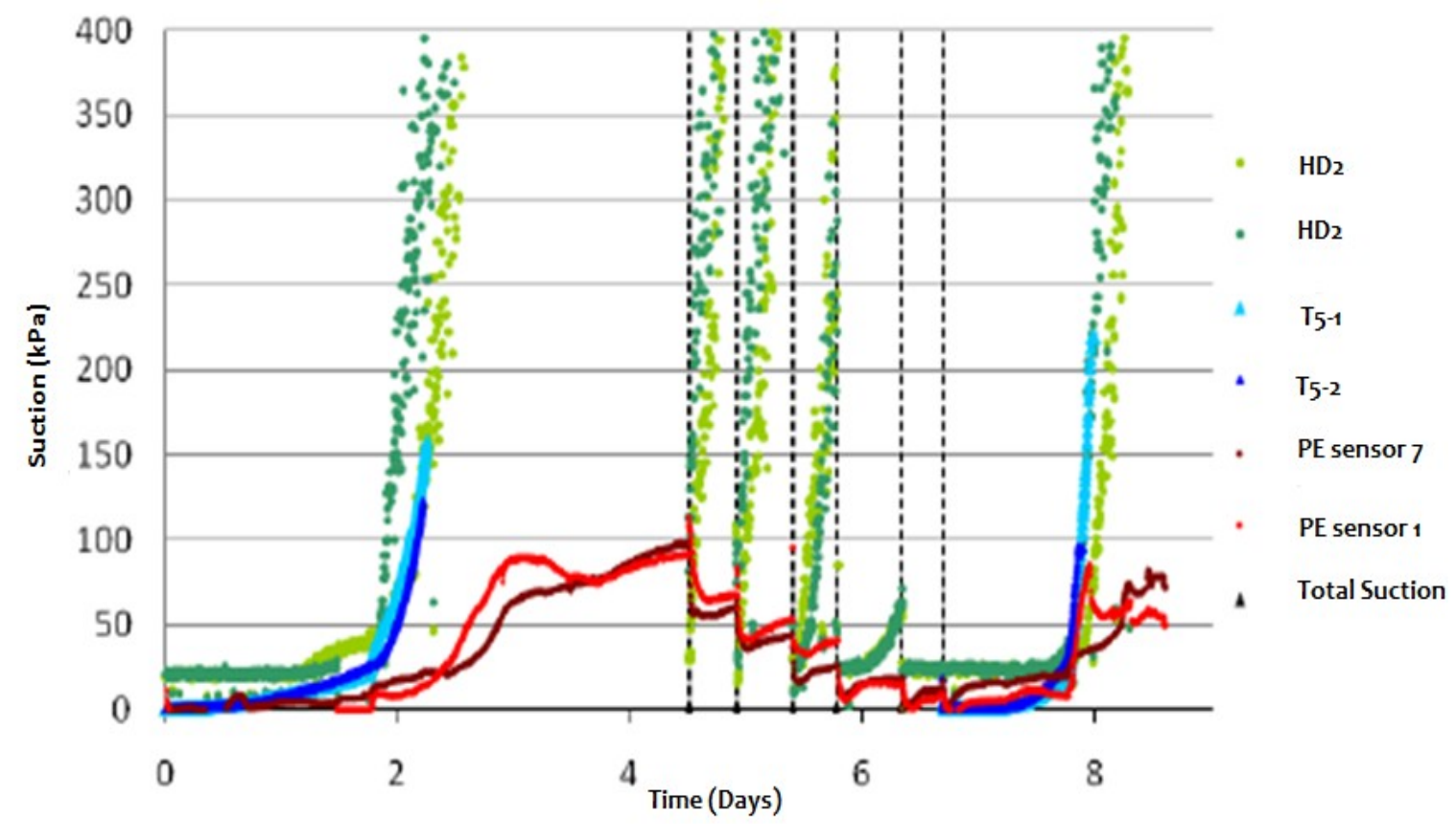

Figure 2-18: Matric Suction ( $\mathrm{kPa}$ ) During Wetting and Drying Cycles in Clay ( $\mathrm{K}=42.9 \mathrm{GPa})$

In order to obtain a better fit for the trends of the other suction methods (such as, the HD sensor and the tensiometer), a bulk modulus of 1.77G Pa was used for the clay test to obtain the matric suction values as shown in the Figure 2-19. It should also be noted that the same modulus of elasticity as for silt was used here. 


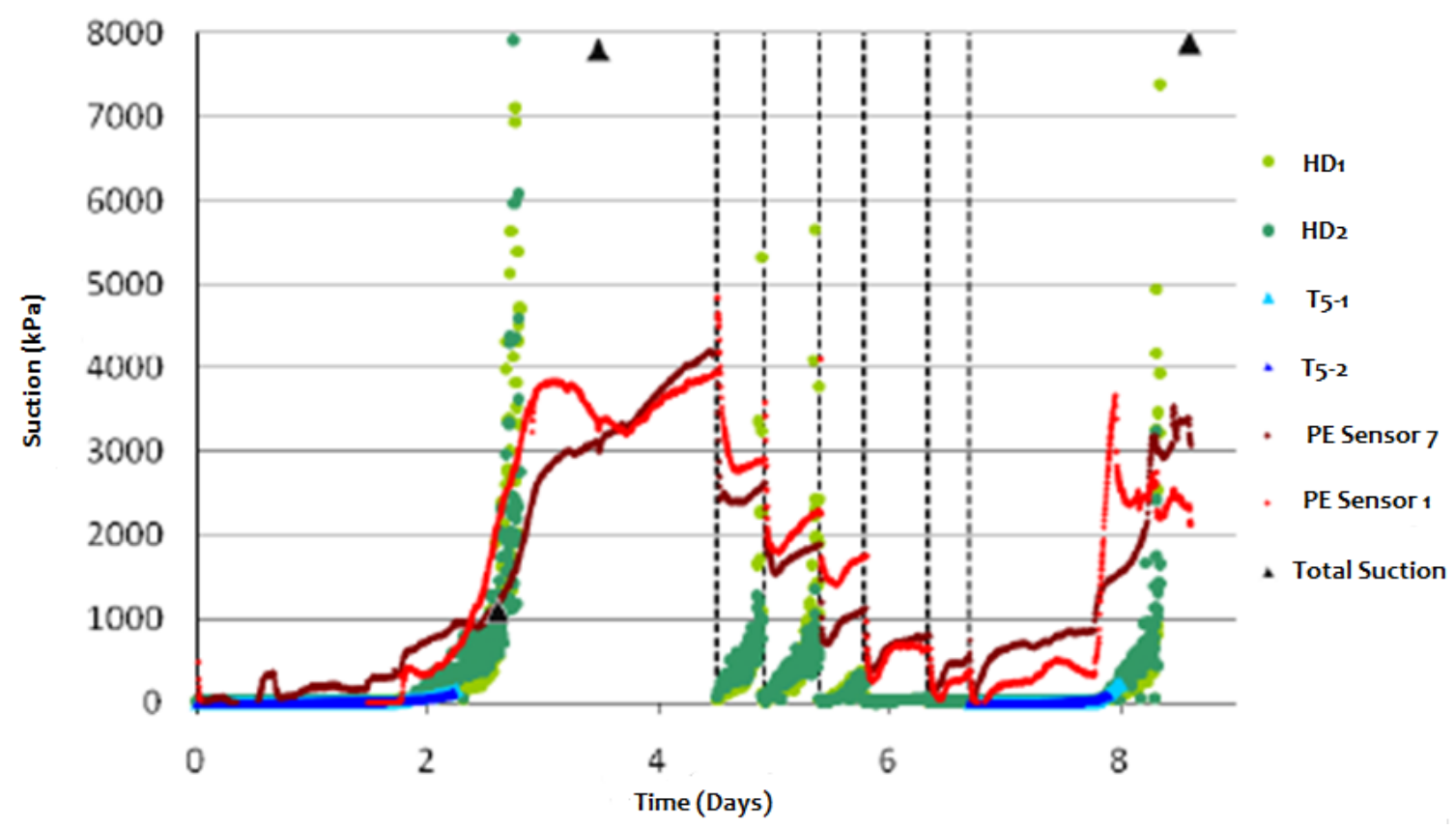

Figure 2-19: Matric Suction (kPa) During Wetting and Drying Cycles in Clay ( $\mathrm{K}=1.77 \mathrm{GPa})$

When the bulk modulus is higher, the matric suction tends to be higher for the same strain when compared to Figure 2-18. This shows that the deformation of the porous material was produced by higher pore pressure, since clay was assumed to be stiffer than silt. The results obtained from the new $\mathrm{K}$ value of $1.77 \mathrm{GPa}$ did not show accurate results for matric suction values lower than $1000 \mathrm{kPa}$. These results also show that the higher matric suction values of the PE sensor do not show a strong correlation with the values from HD sensors and tensiometers. Although the AEV value of the PE sensor is $8000 \mathrm{kPa}$, the values obtained above $4000 \mathrm{kPa}$ by the other methods, are under predicted by the PE sensor as shown in Figure 2-19.

The experiments conducted by Dunmola et al. (2009) showed that the modulus of elasticity measured for the composite material was approximately 5 - 9GPa. However it 
will be reasonable to use a higher modulus of elasticity. Therefore, a modulus of elasticity of 6.9GPa was applied to obtain the $\mathrm{K}$ value using equation 16 , resulting in a bulk modulus of $3.48 \mathrm{GPa}$. This value was used to obtain the matric suction of the clay test data, since it apparent that the best relationship between stress and deformation can be obtained using a bulk modulus of 3.48G Pa.

Silt Test Results with the Adjusted Bulk modulus by Apking (2010)

After adjusting the bulk modulus, a comparison test was conducted by converting the PE sensor strain values to matric suction using the new bulk modulus. The comparison test consists of tensiometers, HD sensors and WP4T Dewpoint PotentiaMeter (Total suction machine) for the wetting and drying of the artificial silt. The comparison results obtained are shown in Figure 2-20.

The gravimetric water content of the silt was prepared for $25 \%$ with a high saturation (S $\geq 0.95)$. When compared to the other methods, the PE sensor shows a high correlation between the suction measured during the drying test. However, at lower suction values ranging from $0-500 \mathrm{kPa}$, the matric suction values show a poor correlation compared to the other methods, due to bulk modulus of $\mathrm{K}=1.41 \mathrm{GPa}$. This can be seen in Figure $2-20$, the matric suction values tend to be quite low until day 3 , followed by a sudden increase in suction from $-1220 \mathrm{kPa}$ to $9300 \mathrm{kPa}$ within 29 hours. 


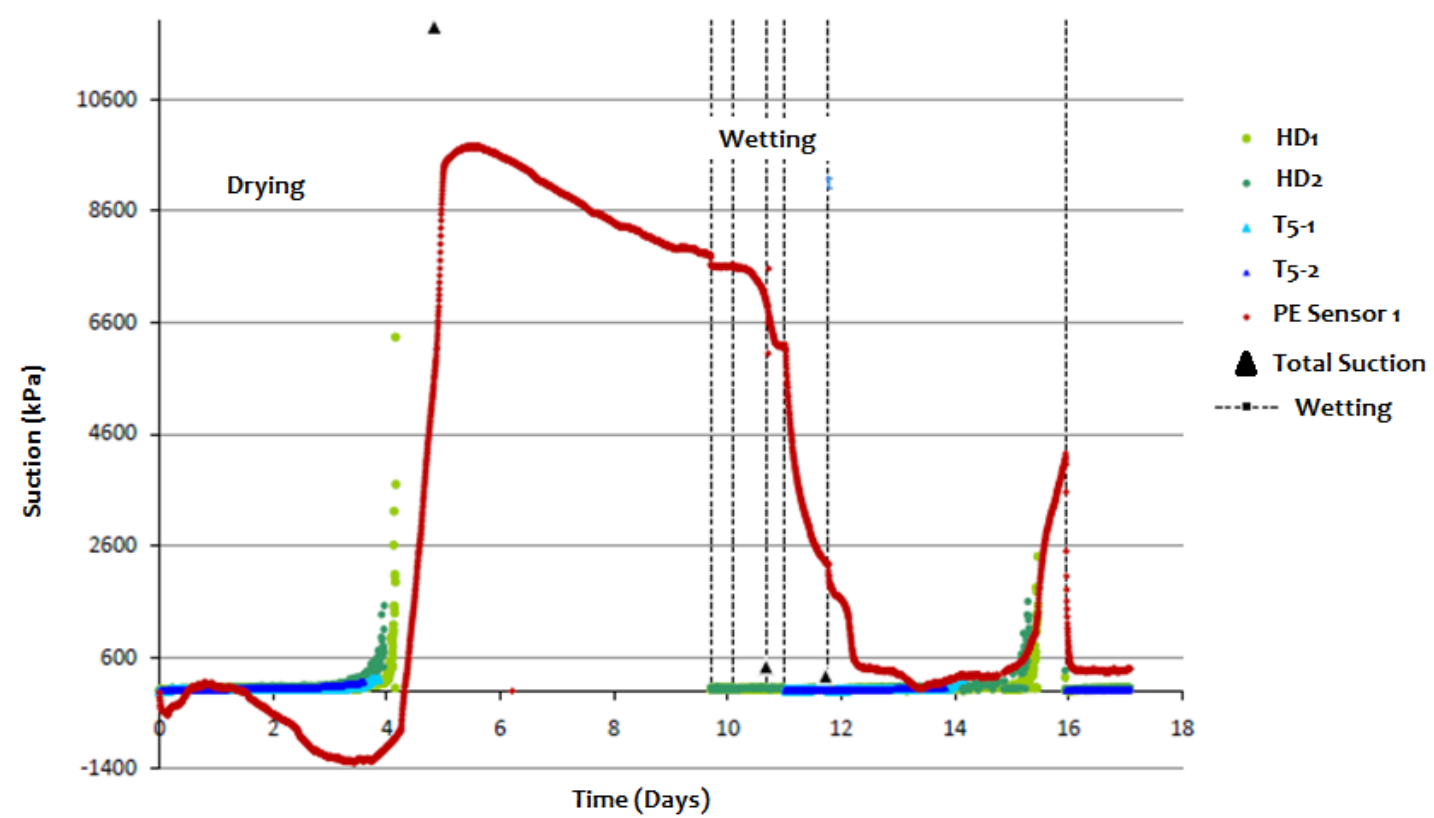

Figure 2-20: Comparison Test of Drying and Wetting Cycles of Poroelastic Sensor 1 in Artificial Silt

At this point, the results obtained from the HD sensor and the tensiometer tends to agree with the PE sensor matric suction values. The PE sensor suction values tend to increase to a closer value of $11,900 \mathrm{kPa}$ which was obtained by the total suction machine, prior to PE sensor desaturation that occurs at matric suction values higher than the AEV $(8000 \mathrm{kPa})$ of the porous rod. After the maximum matric suction of the PE sensor was reached, the PE sensor matric suction values start to decrease as the strain increase. According to Figure 2-20, the sensor continues to deform until the initiation of wetting cycles, showing a decrease in matric suction.

It should be noted that even a slight movement of any of the sensors and a depth variation can drastically change the matric suction values. The total suction values 
obtained at different depths of drying in silt is shown in Table 2-3. Therefore, it is necessary to carry out the experiments with extreme caution.

Table 2-3: Variation of Total Suction with the Depth in Artificial Silt.

\begin{tabular}{|c|c|}
\hline Depth from Soil Surface $(\mathbf{c m})$ & Total Suction $(\mathbf{k P a})$ \\
\hline $0.5-1.0$ & 226610 \\
\hline $1.0-1.5$ & 222850 \\
\hline $1.5-2.0$ & 240760 \\
\hline $2.0-3.0$ & 18820 \\
\hline $3.0-4.0$ & 4990 \\
\hline
\end{tabular}

The wetting cycles shown in Figure 2-20 were done using a gravimetric water content increment of $5 \%$ which is indicated on the Figure 2-20 using 6 dotted lines. It can be observed that immediately after rewetting the sensor response increases, however no significant change was observed with subsequent wetting cycles. Prior to $3^{\text {rd }}$ and $5^{\text {th }}$ wetting cycles, an average total suction of $447 \mathrm{kPa}$ and $277 \mathrm{kPa}$ was obtained. When the total suction measurements were compared to the HD sensor results and the tensiometer results, the values tend to be similar to each other after day 10 . However, the PE sensor suction obtained during wetting shows inaccuracy when compared to the acceptable matric suction measuring techniques. This can be a result of the porous material of the PE sensor desaturating as the silt reaches very high suction values upon 
drying. The corresponding total suction machine value was $272,770 \mathrm{kPa}$ at day 7 . Therefore, the porous material of the PE sensor was re-saturated after each wetting cycle to ensure that the porous rod was saturated. The saturation of the PE sensor porous rod can be observed from the matric suction results $(60 \mathrm{kPa})$ obtained after day 13.

This inaccuracy of the suction predictions observed in Figure 2-20 may signify that during the re-wetting of the sample, a hysteretic behaviour of the PE sensor material was observed. In addition, it should be noted that the equation 15 used to calculate the matric suction from the strain results obtained from the PE sensor are only valid when the degree of saturation of the material is above 0.8 . When considering the hysteretic effect and the validity of the equation 15, the other acceptable methods of measurements show more accurate results than the PE sensor suction data.

The PE sensor results observed in Figure 2-20 show that the sensor has re-saturated after day 14. The results observed after day 14 tends to follow the acceptable matric suction methods as the silt dries. The suction values observed from the acceptable methods and the PE sensor matric suction data tend to agree with each other until the final wetting was done at day 16 . After day $16, \mathrm{PE}$ sensor results show a quick decrease in matric suction, with a similar trend observed in the other acceptable methods. Therefore, it can be seen that, once the PE sensor is saturated the values of the sensor gives reliable results that agrees well with the other methods (HD sensors and 
Tensiometers). The hysteretic effect is not present for the PE sensor values below its AEV $(8000 \mathrm{kPa})$.

Kaolin Clay Results Comparison to the PE sensor by Apking (2010)

Unlike the silt test, two PE sensors were used to test the Kaolin clay. The test was conducted with very high gravimetric water content of $70 \%$, in order to attain uniform water content throughout the soil with a degree of saturation above 0.95 . As shown in the Figure 2-21 the correction of the drift was applied to PE sensor 7 since it was showing a significant drift during saturation compared to PE sensor 1 . The results of strain obtained from PE sensor 1 and 7 were converted to obtain the matric suction values. The matric suction results obtained for the two PE sensors were then compared to the HD sensors, tensiometers and total suction data. 


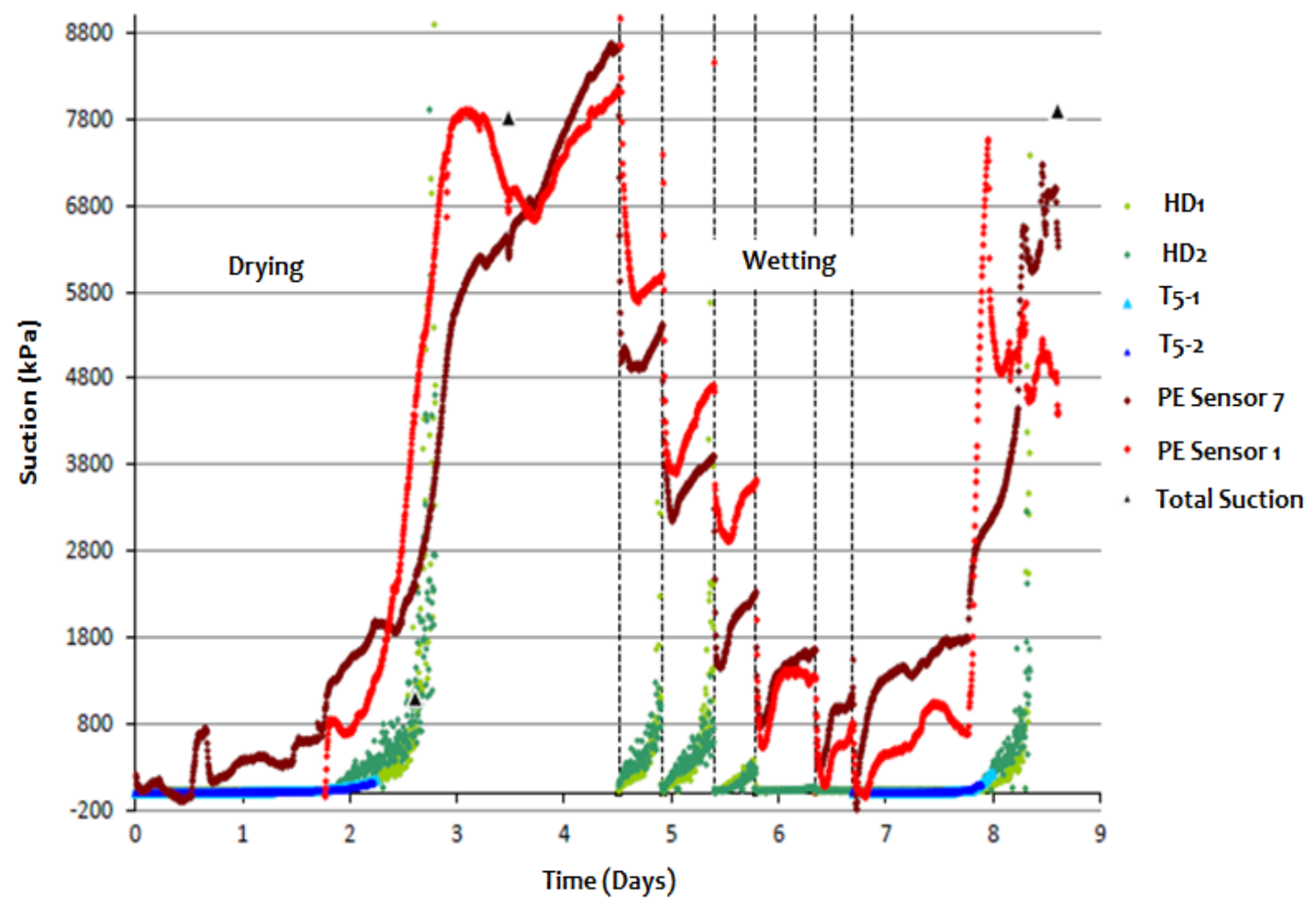

Figure 2-21: Comparison Test of Drying and Wetting Cycles of Poroelastic Sensors 1 and 7 in Kaolin Clay

The drying phase data presented in Figure 2-21 shows an agreement with the values obtained from the comparison results. After day 2, a clear rise in matric suction was noticed with the HD sensors and the tensiometers (until cavitation). During the same period, the suction values obtained from the PE sensor show similar matric suction values.

The gradual slope of the desorption curve observed in Figure 2-21 for clay was not as drastic as the curve observed for the silt in Figure 2-20. 
The matric suction values obtained for clay using the PE sensor results exceed the accuracy for the tensiometer $(\leq 100 \mathrm{kPa})$ and $\mathrm{HD}$ sensor $(\leq 1200 \mathrm{kPa})$ values. However, the PE sensor shows reasonable suction values according to the trend shown in Figure 2-21. A total suction measurement was taken immediately after day 3 with a reading of $7820 \mathrm{kPa}$. The values in the same range as $7820 \mathrm{kPa}$ were obtained by the PE sensor 1 as well, proving that this sensor produces readings up to its AEV. After PE sensor 1 has reached its $A E V$, the matric suction values show a decreasing trend upon reaching the maximum capacity of the porous rod. However, PE sensor 7 shows lower suction values at points where PE sensor 1 reaches almost its AEV, indicating that PE sensor 7 has not developed negative pore water pressure that is equivalent to its $A E V(8000 \mathrm{kPa})$. After 3.5 days, the matric suction value of the PE sensors 1 and 7 tend to increase, showing that the sensors have not completely desaturated.

The deviations observed in the PE sensor matric suction results and the other methods shown in Figure 2-21 during the first 2 days of the drying phase can be due to the soil interactions with the sensors, since a significant amount of cracking on clay was apparent during the first 10 hours of the experiment. The crack size increased in severity during the test period which led to a displacement of the sensors and a decrease in soil-sensor contact. The lack of contact of the soil with the PE sensor affected the accuracy of the matric suction values predicted, since the deformation of the porous material is assumed due to the negative pore water pressure of the soil. The cracking of clay has resulted in questionable accuracy of the results. 
At the end of the drying phase (day 4.5) of the experiments, both PE sensor 1 and 7 measured matric suction values that are $8000 \mathrm{kPa}$ and $8650 \mathrm{kPa}$ respectively. The total suction measurement at day 4.5 was $15,345 \mathrm{kPa}$. The value obtained for the PE sensor 7 shows it has reached a point above its AEV. However, the failure of the PE sensor to measure the value obtained by the total suction machine shows that the range of the PE sensor is limited to approximately $8000 \mathrm{kPa}$. In Figure $2-21$, it can be seen that after 4.5 days, desaturation was commenced.

As shown in Figure 2-21, six wetting cycles were used in this experiment. During the first wetting cycle the PE sensor results did not agree with the HD sensor or the tensiometer results due to the cracking that occurred during the course of the experiment period around the HD sensors. Upon rewetting, water infiltrated the cracks rapidly allowing the suction to drop immediately, and in similar fashion water was lost at a faster rate from the cracks allowing the ceramic sensor body of the HD sensor to desaturate. Therefore, in this case the suction values obtained from the PE sensor show accurate results. To better assess the results, a SWCC was obtained for the two sensors where the water content of the soil was determined based on the amount of water added to each wetting cycle and the evaluation of the approximate evaporation rate. The SWCC's for the two PE sensors (1 and 7) are shown below in Figure 2-22, 


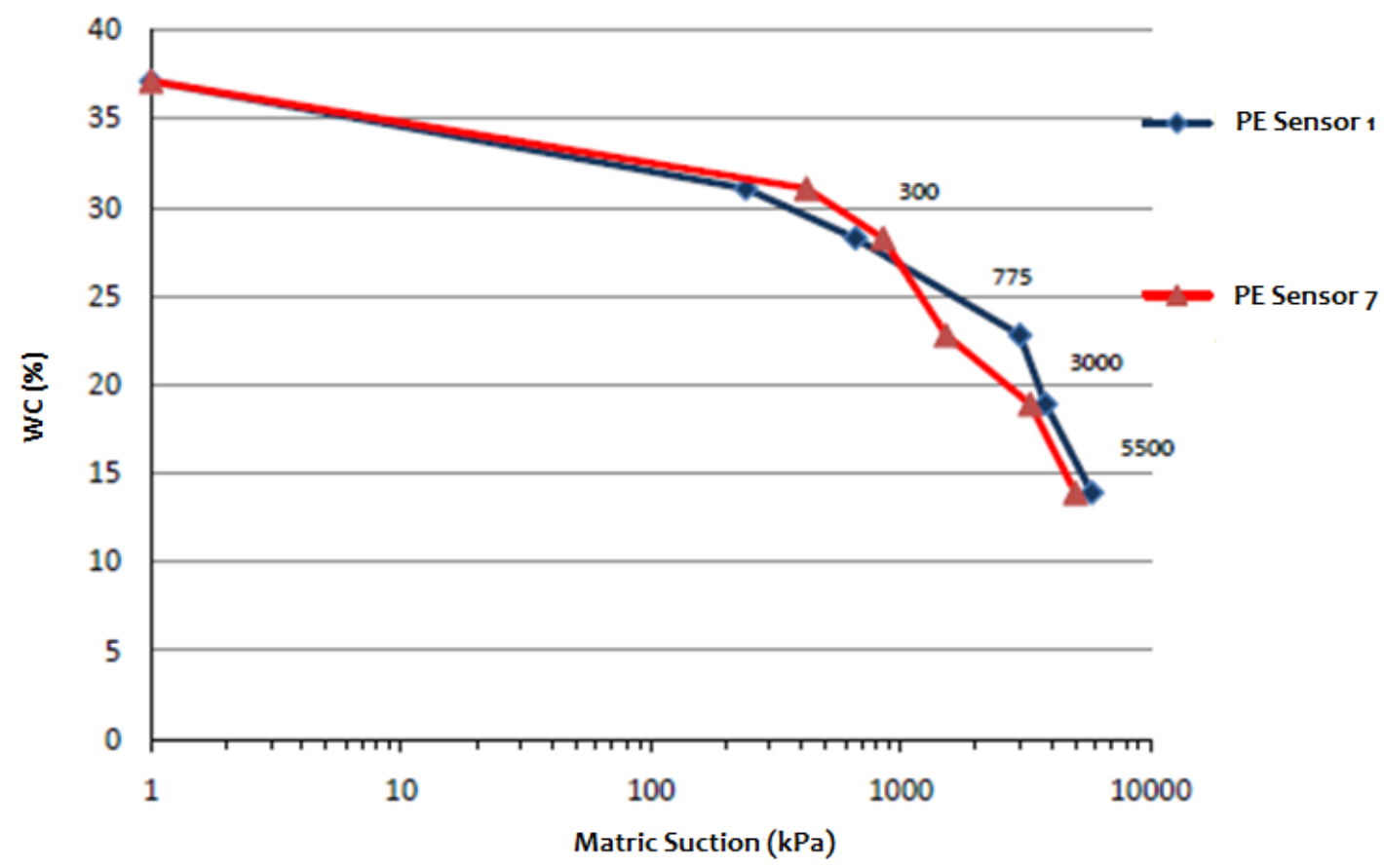

Figure 2-22: SWCC Obtained for PE Sensors 1 and 7 (Clay Test)

In order to validate the results obtained in Figure 2-22, the matric suction values at various gravimetric water contents were compared to the published values of SWCC for Regina clay. Regina clay has similar Atterberg limits to the clay used in this study. After the comparison, it was determined that the PE sensor results strongly agree with the compared data proving that the behaviour of the sensor during the wetting of the clay is favourable. In addition, no hysteretic effect was observed during this process. The direct comparison of the suction values from the published SWCC (theoretical values) presented in Figure 2-23 and the SWCC obtained for the PE sensors is shown in Table $2-4$. 


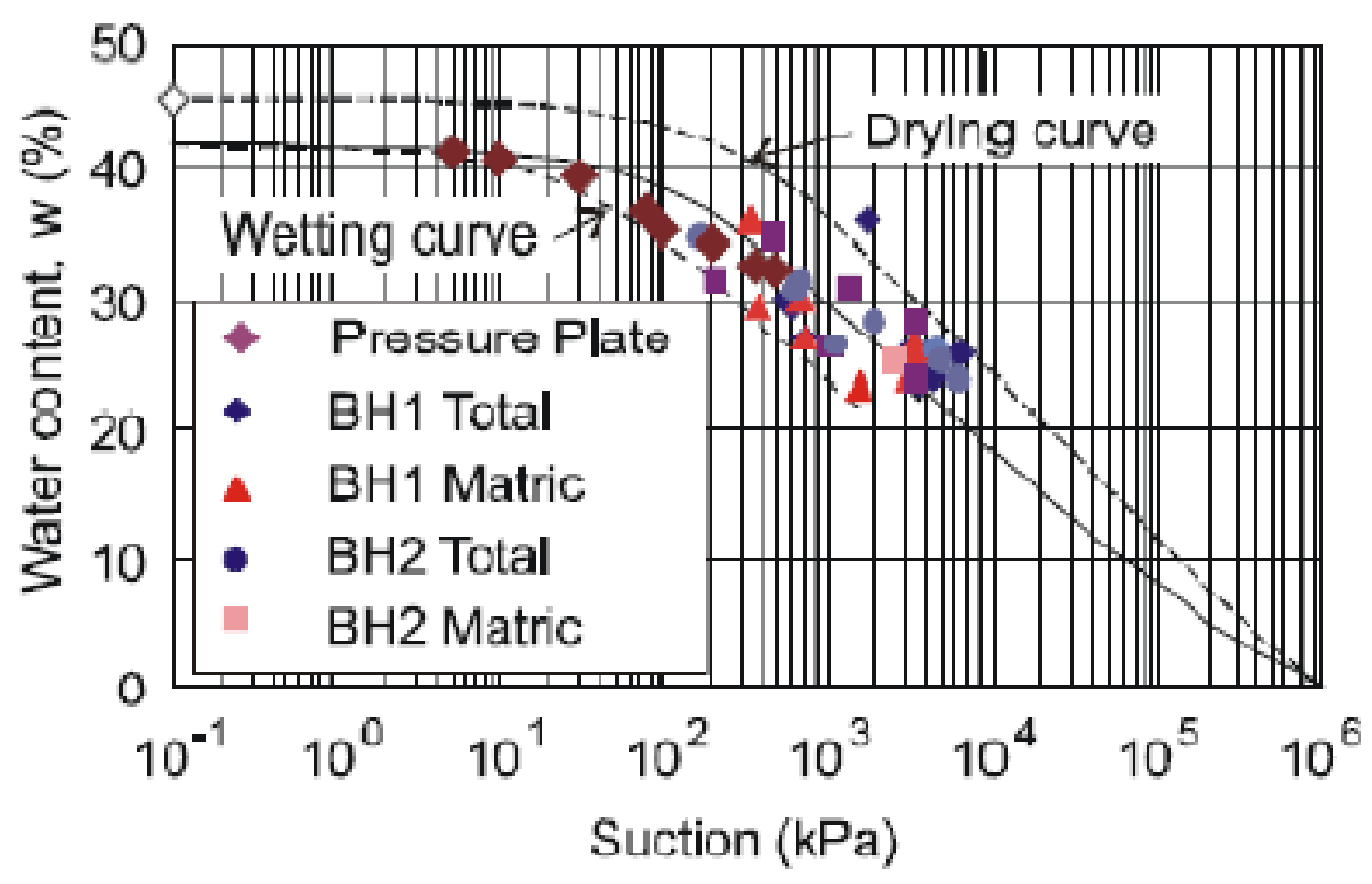

Figure 2-23: SWCC for the Regina Clay (Vu et al. 2007)

Table 2-4: Comparison of Matric Suction from SWCC Curve of Clay for the PE Sensor

\begin{tabular}{|c|c|c|}
\hline W (\%) & Theoretical (kPa) & PE sensor (kPa) \\
\hline 15 & 6000 & 5500 \\
\hline 20 & 2000 & 3000 \\
\hline 25 & 750 & 775 \\
\hline 30 & 300 & 300 \\
\hline
\end{tabular}


After the wetting cycle has completed, the PE sensors showed a low matric suction value (close to zero), which is accurate since the clay is saturated with water. As the drying started to occur the PE sensor matric suction values showed a poor correlation with the data from the HD sensors and the tensiometers, which is likely to be caused by the soil-sensor interaction since the cracking was severe. However, the suction measurements obtained from the PE sensor during the clay test were reasonably similar to the values obtained from the other matric suction methods; however, in some cases it was shown that the PE sensor performance was superior to that of the HD sensors during the wetting cycle. The summary of the best fit modulus values are presented in the Table 2-5 below for the saturation tests, the sensor in silt and clay.

Table 2-5: Summary of the Best fit Modulus for the Apking (2010) Results

\begin{tabular}{|c|c|c|}
\hline Test & Drift & Best fit Modulus \\
\hline Saturated Test Sensor 1 & $\mu \varepsilon / h r=d \varepsilon / d t=3.4$ & \\
\hline Saturated Test Sensor 2 & $\mu \varepsilon / h r=d \varepsilon / d t=2.9$ & \\
\hline $\begin{array}{l}\text { Drying and Wetting Test } \\
\text { in Silt }\end{array}$ & $\begin{array}{l}\text { Correction factor }=\mathrm{d} \varepsilon / \mathrm{dt}= \\
50 \mu \varepsilon / \text { day to get the } \\
\text { saturation strain to zero, } \\
\text { hence } \Psi=0 \text { at saturation. } \\
* * \text { The saturation value } \\
\text { was not zero in the actual } \\
\text { results }\end{array}$ & $\begin{array}{c}\mathrm{E}=2.8 \mathrm{GPa} \text { with } \\
\mathrm{K}=1.4 \mathrm{GPa}\end{array}$ \\
\hline $\begin{array}{l}\text { Drying and Wetting Test } \\
\text { in Clay }\end{array}$ & $\begin{array}{l}\text { Correction factor }=\mathrm{d} \varepsilon / \mathrm{dt}= \\
55 \mu \varepsilon / \text { day to avoid the } \\
\text { drift problem }\end{array}$ & $\begin{array}{c}\mathrm{E}=6.9 \mathrm{GPa} \\
\mathrm{K}=3.48 \mathrm{GPa}\end{array}$ \\
\hline
\end{tabular}




\subsubsection{Factors Affecting the Performance of the PE Sensor}

The performance of the PE sensor can potentially be affected by several factors. One such factor is the hysteresis effect when drying of the PE sensor might not be the same as wetting, especially if the AEV is exceeded. However, the sensor seems to return to the same point after every rewetting, which would imply no air is entrapped, or at least the same degree of saturation is achieved after each wetting phase. This may be due to the small size and uniform distribution of pores in the rod, which would minimize any entrapped air upon rewetting. Also the entrapment of the air depends on the pressure gradient associated; the larger the pressure gradient there is less chances for the presence of air entrapment.

The porous glass that has been used in the PE sensor shows consistent and valid results

within the range of temperatures 20 to $40{ }^{\circ} \mathrm{C}$ (Sotomayor et at. 2001). The density of water and the viscosity remain consistent over the above mentioned range of temperature. However in subzero temperatures the PE vycor porous glass behavior can vary depending on the behavior of the pore water in the porous rod and the variation of densities of water or ice. The increase in density of the porous glass is apparent, at temperatures ranging from 0 to $-33^{\circ} \mathrm{C}$. Li et al. (1991) show that in micro porous materials, this increase in density causes a hysteresis effect upon cooling and warming from subzero temperatures to the ambient temperature.

The linearity of the values of the vycor porous glass was assumed. Micro porous glass was subjected to wetting and drying by Schiller et al. (2008), who found that associated 
volume change in a water vapour atmosphere is a linear function of the reduced pressure except in cases of low or very high air humidity conditions. James (2000) found that the deformation of microporous glass with rewetting after shows a linear trend when a graph was plotted with relaxation time (seconds) versus sample thickness $\left(\mathrm{mm}^{2}\right)$ (James 2000).

Another factor that can affect the performance of the PE sensor is the temperature induced strain in the solid matrix of the porous rod. Thermally induced longitudinal stress on vycor porous glass was tested to see the fracture toughness by Kagawa (1994). The deformations measured were what were expected according the coefficient of thermal expansion. The value of thermal expansion found in Kagawa (1994) for vycor glass was $0.51 \times 10^{-6} / \mathrm{K}$

\subsubsection{Phase Transformation of Water in Porous Glass}

One of the potential applications of the PE sensor is for suction measurement in freezing conditions, as it was hoped that the small pore-size would suppress ice crystal nucleation. The transformation of water in porous glass varies greatly with temperature below the normal freezing point of water. The degree of saturation, and the range in temperature at which water transforms from one state to another, affects the performance of the porous glass (Antoniou 1964). 
The porous glass that was used by Antoniou (1964) was vycor brand No.7930 manufactured by the Corning Glass Works. The chemical composition of the glass was $96 \% \mathrm{SiO}_{2}$ with $3 \% \mathrm{~B}_{2} \mathrm{O}_{3}$. Before the experiment, the glass was treated by evacuating in a gravimetric apparatus to a pressure of $1 \times 10^{-4} \mathrm{~mm}$, and was exposed to oxygen at about $300^{\circ} \mathrm{C}$ to clean the organic contaminants. The dimensions used in this experiment were $8 \mathrm{~cm} \times 1 \mathrm{~cm} \times 0.5 \mathrm{~cm}$. Distilled water was used as the absorbent.

The following Figure 2-24 represents the relationship between the porous glass saturation with respect to water, and its change in length. Where "•" represents data obtained during cooling and " $O$ " represents data obtained during warming.

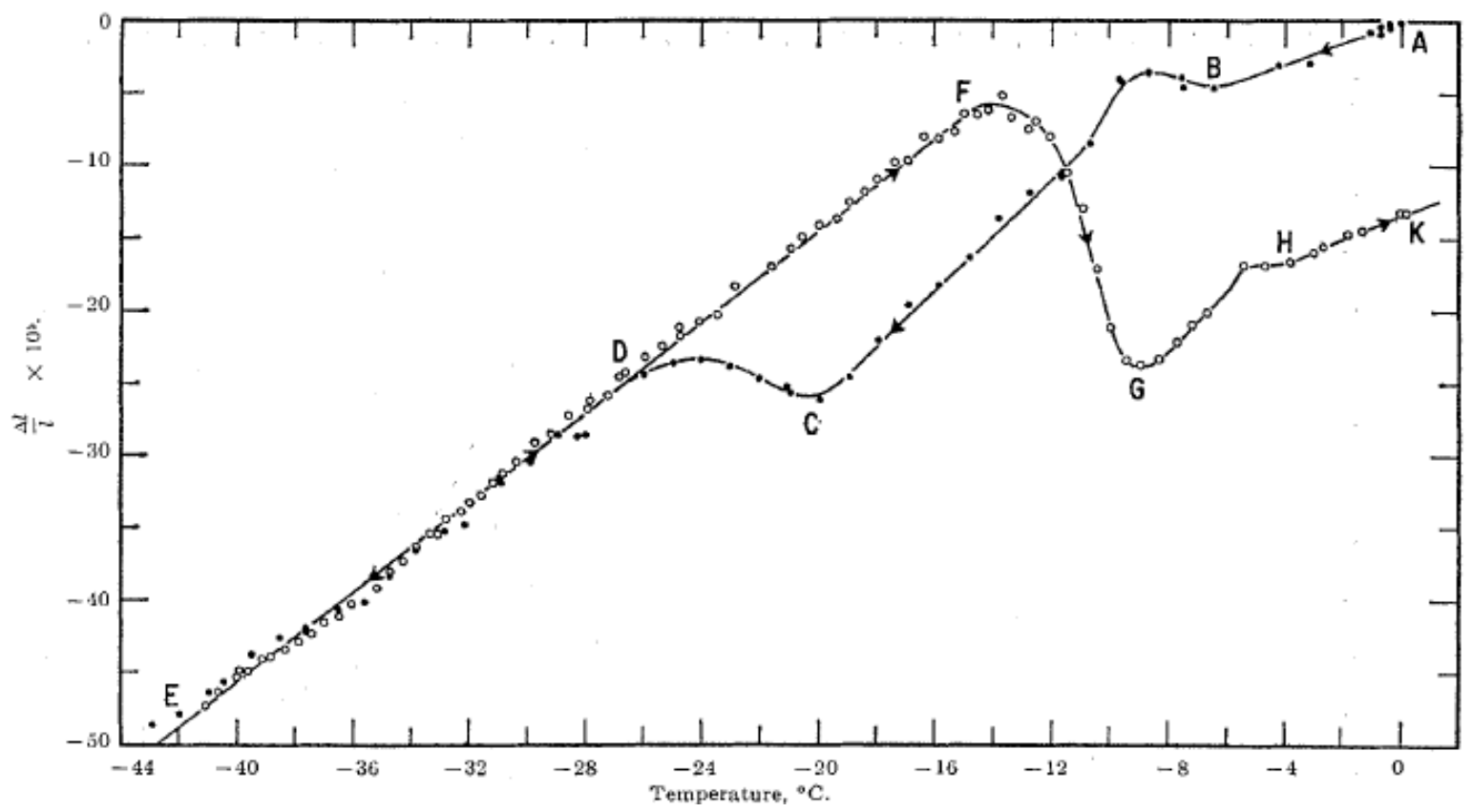

Figure 2-24: Porous Glass Saturation with Respect to Water with Varying Temperature (Antoniou 1964) 
In the figure above each section behaviour is represented as follows,

Section A-B: contracts with a linear thermal coefficient of $7 \times 10^{-5} \mathrm{deg}^{-1}$ until it reaches $7^{\circ} \mathrm{C}$. This agrees well with the linear thermal coefficient of expansion of porous glass evacuated with respect to water to a pressure of $1 \times 10^{-4} \mathrm{~mm}$ which was found to be 5 $\mathrm{x} 10^{-6} \mathrm{deg}^{-1}$ (Antoniou 1964).

Section B-C: at $-7^{\circ} \mathrm{C}$ a small expansion occurs which shows a hump in the results. This hump was said to be normal behaviour of partially saturated porous glass with respect to water. Following the small expansion the porous glass contracts with a higher linear coefficient of contraction of about three times the previous value.

Section C-D: The samples tend to expand in between temperatures $-20^{\circ} \mathrm{C}$ and $-26^{\circ} \mathrm{C}$. This behaviour is present because the liquid is in a super cooled state at this point.

Section D-E: The sample contracts below $-26^{\circ} \mathrm{C}$ with a linear coefficient of $15 \pm 1 \times 10^{-6}$ deg. ${ }^{-1}$.

Section E-F: Expansion occurs with increasing temperature from $-40^{\circ} \mathrm{C}$ to $-15^{\circ} \mathrm{C}$ with about the same linear coefficient as for contraction.

Section F-G: Contraction occurs from temperatures -15 and $-9^{\circ} \mathrm{C}$.

Section G-H: as the temperature increases, expansion was observed up to $-6^{\circ} \mathrm{C}$ with a slope of $21 \times 10^{-6}$ deg. $^{-1}$. 
Section H-K: with increase in temperature above $-5^{\circ} \mathrm{C}$, the sample expands further with a linear coefficient of expansion of $8 \times 10^{-6} \mathrm{deg} \cdot{ }^{-1}$.

Repetitive experiments have given the same results using the same glass under the same temperature range indicating that the behaviour of the porous glass under freezing will follow the same trend upon freezing and thawing. These results can be used to determine the expansion and the contraction of the PE sensor porous rod according to each temperature variation. Also the corresponding linear coefficient of expansion due to each temperature was used to determine the expansion of the PE sensor upon each increment of temperature under the freezing conditions. These results will be discussed in Chapter 3. 


\section{Chapter 3 METHODOLOGY AND THE MATERIALS USED}

\subsection{Assembly of the Poroelastic Suction Sensor (PE Sensor)}

This section describes the materials and the methodology of the PE sensor construction.

The PE sensor consists of 4 parts (the sensor cap, the porous rod, the strain gauges and the outer casing). The constructed sensor with the modifications are presented in the Figure 3-1 below,
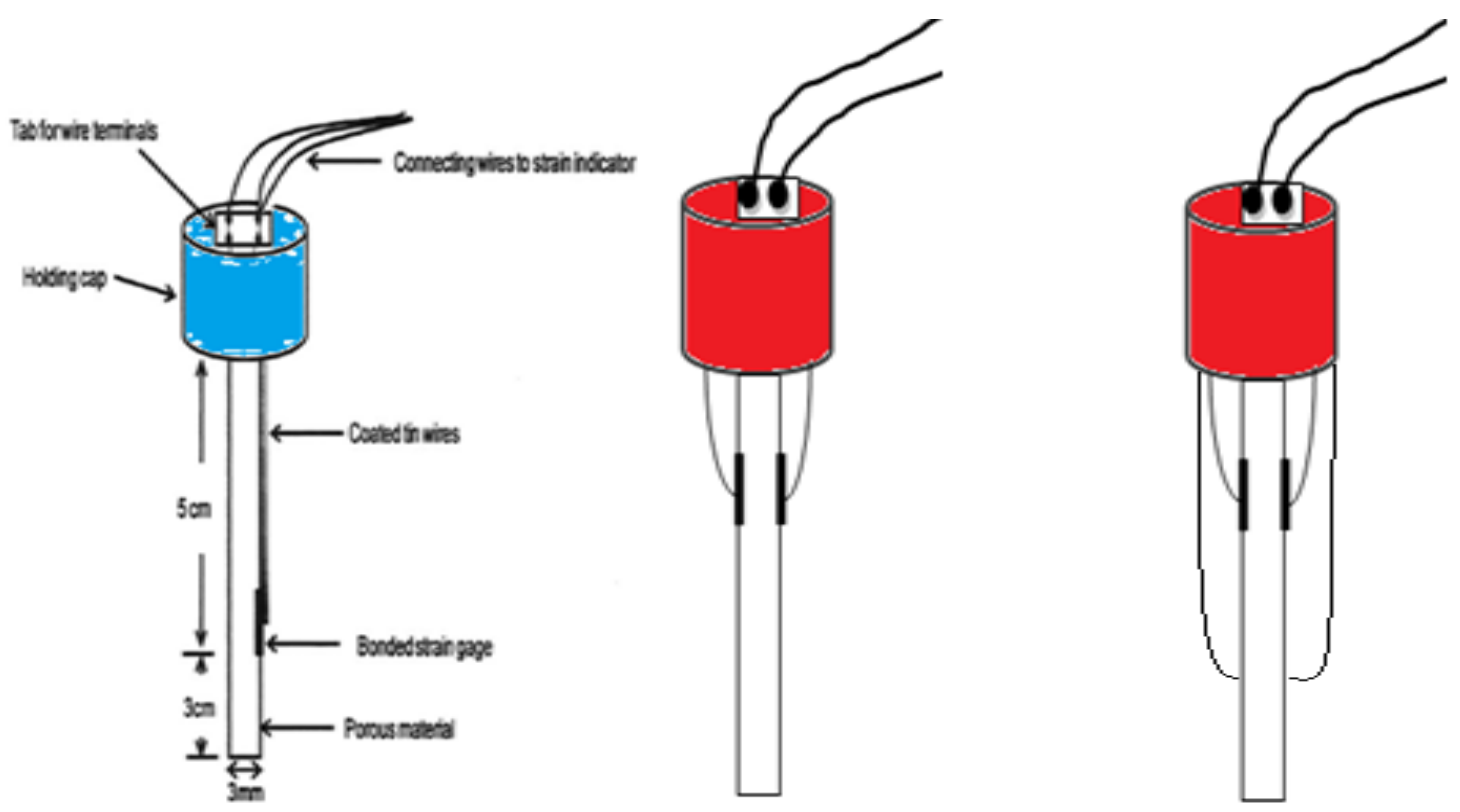

Figure 3-1: Previously Constructed Sensor (left, (Dunmola et al. 2009)), Added Strain Gauge (Middle), Newly Modified PE Sensor with Outer Cover (Right)

This diagram above illustrates the modifications that were made to the PE sensor to enhance its performance. The left diagram shows the original sensor design by Dunmola et al. (2009). The middle diagram represents the addition of the extra strain 
gauge to detect if the sensor bends one way or the other due to the soil interactions. In the diagram on the right, an outer casing is attached to avoid the outward interactions with the sensor body and limiting only the tip of the exposed porous rod for the outward interaction.

\subsubsection{Materials Employed in the Construction of the Poroelastic Suction}

\section{Sensor}

- Small plastic test tube cap ( height $=12 \mathrm{~mm}$, Diameter $=25 \mathrm{~mm}$ )

- Vycro nano amporphous porous rod (5mm, Diameter $3.4 \mathrm{~mm}$ )

- Note: Original length of the porous rod is $260 \mathrm{~mm}$ long. Therefore, it is cut into 4 pieces (approximately $65 \mathrm{~mm}$ ) to construct 4 poroelastic suction sensors.

- Two E clips ('E' Type Circlip DIN 6799 (D1500))

- Cork stopper ( Size 4, Catalogue No.: 07781G, Fisherbrand)

- A screw stopper (green)

- Plexiglass plate

- Epoxy glue

- HDPE (High Density Polyethylene) plastic tube (OD: $12.7 \mathrm{~mm}$, ID: $9.525 \mathrm{~mm}$, Length: $45 \mathrm{~mm}$ )

- Two general purpose electrical resistivity strain gauges (Vishay Micromeasurements, Raleigh, NC, gauge type: EA -06-060LZ-120, gauge factor: $120.0 \pm 0.5 \%$ at $75^{\circ} \mathrm{F}$, resistance in $\Omega$ of $120 \pm 0.3 \%$ ) 
- M- Line GC-6 Isopropyl alcohol ( control NO. 0866)

- M- Bond 200 Adhesive Kit (Vishay Micromeasurements, Raleigh, NC)

- M-Bond 200 Adhesive Catalyst C

- M-Bond 200 Adhesive

- PCT- 2M gauge installation tape ( Vishay Micromeasurements, Raleigh, NC, Control No.: 0013)

- M-Prep Conditioner A Part No. MCA-1 (Intertechnology, Don Mills, ON, Control No.: 001114)

- M-Prep Neutralizer 5A Part No, MN5A-1 (Intertechnology, Don Mills, ON, Control No.: 000887)

- M-Coat B Nitrile rubber coating ( Vishay Micromeasurements, Raleigh, NC, Control No.: 550)

- Non Sterile sponges

- M-Coat microcrystalline wax (Vishay Micromeasurments, Raleigh, NC)

- Soldering Iron

- Enamel coated tin wires

- Two bondable terminals (CEG - 100 D, Measurements Group, Inc., Raleigh, NC)

- Two sets of insulated strain gauge wires.

Figure 3-2 shows a collection of the materials used to construct the PE sensor, 


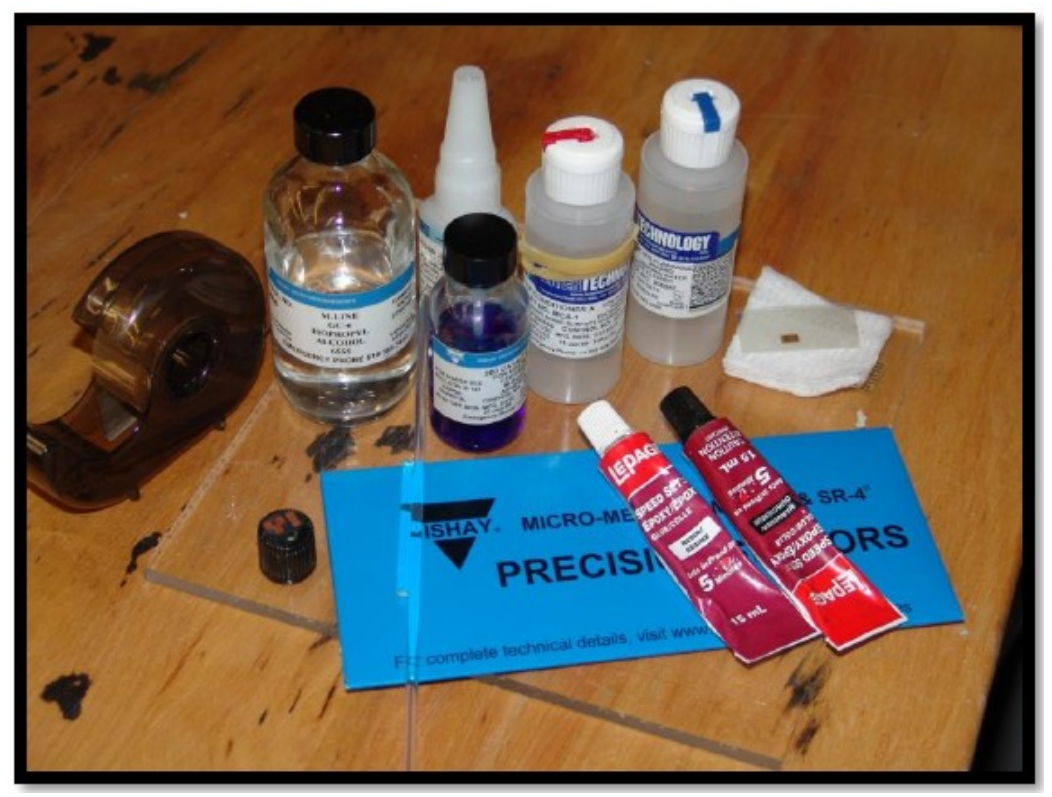

Figure 3-2: Illustration of the Materials Used to Construct the PE Sensor

\section{Step by Step Procedure for PE Sensor Preparation}

1. Using a flat surface, the porous rod $(65 \mathrm{~mm})$ was secured with a tape so that the porous rod is horizontal.

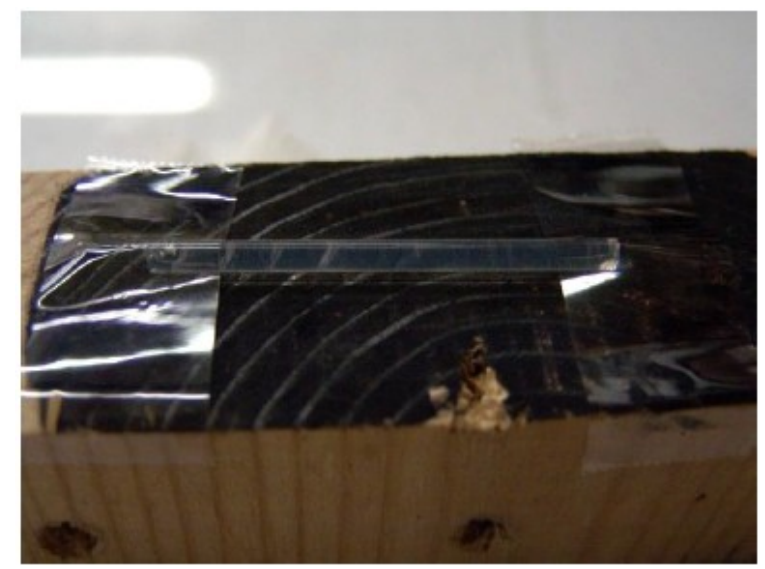

Figure 3-3: Horizontal Placement of the Porous Rod on a Flat Surface 
2. The area of the intended strain gauge placement was cleaned with Isopropyl alcohol using a clean piece of gauze by wiping the area in one direction repeatedly.
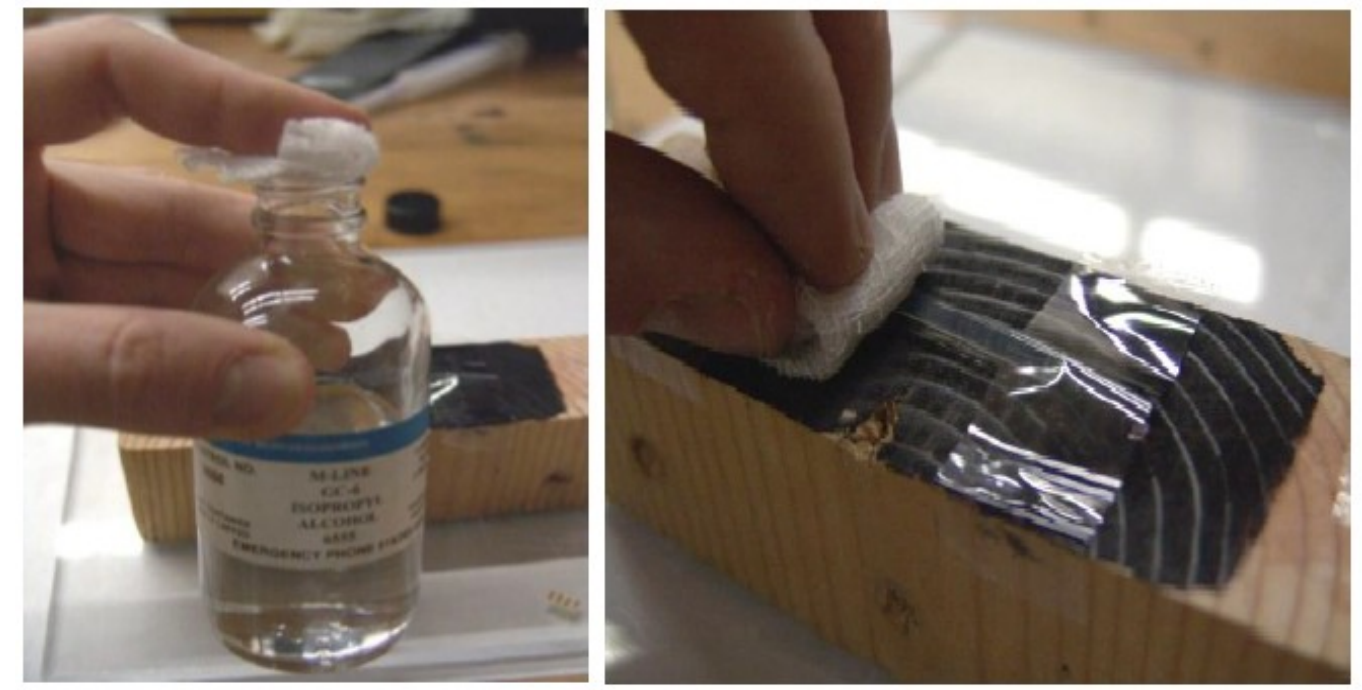

Figure 3-4: Obtaining Isopropyl Alcohol into Gauze, Applying the Isopropyl Alcohol on the Porous Rod in One Direction.

3. After the application of the isopropyl alcohol, the same area was wiped using a clean piece of gauze in one direction (same direction as before) with M-Prep conditioner in liberal amounts to the porous rod. Step 3 was repeated 2-3 times. 

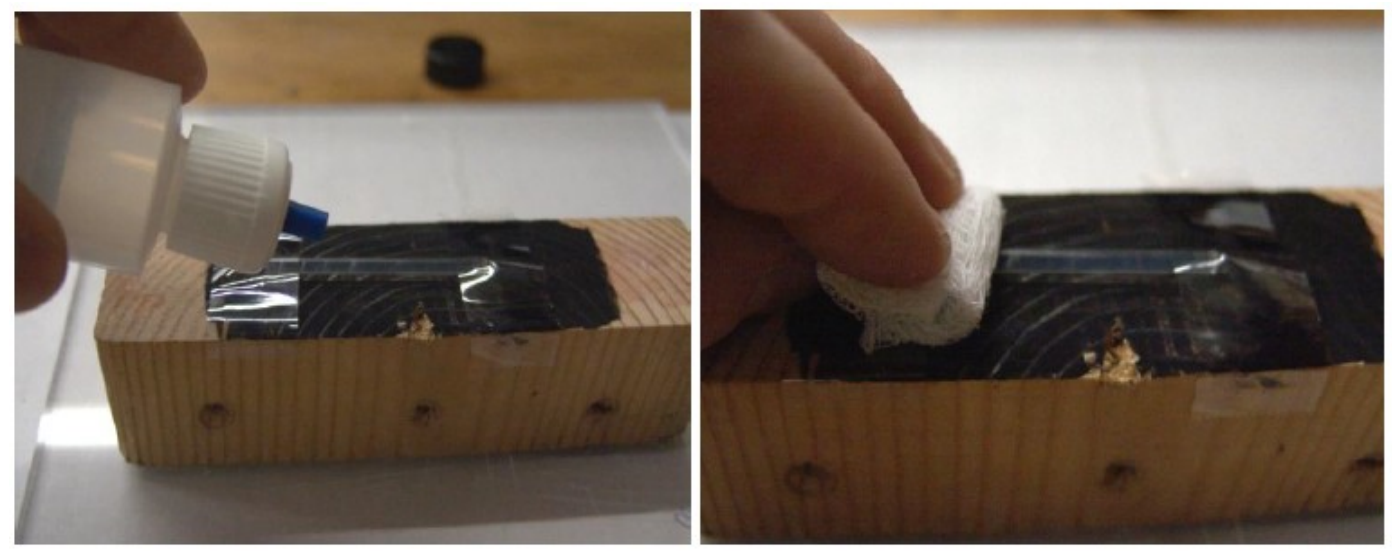

Figure 3-5: Application of the M-Prep Conditioner on to the Porous Rod and Wiping the Rod with Gauze in One Direction.

4. M- Prep Neutralizer was applied to the porous rod in liberal amount and wiped with a clean piece of gauze in one direction to restore the cleaned surface of the porous rod to its neutral $\mathrm{pH}$. After this step, the sensor rod was ready for the strain gauge placement.

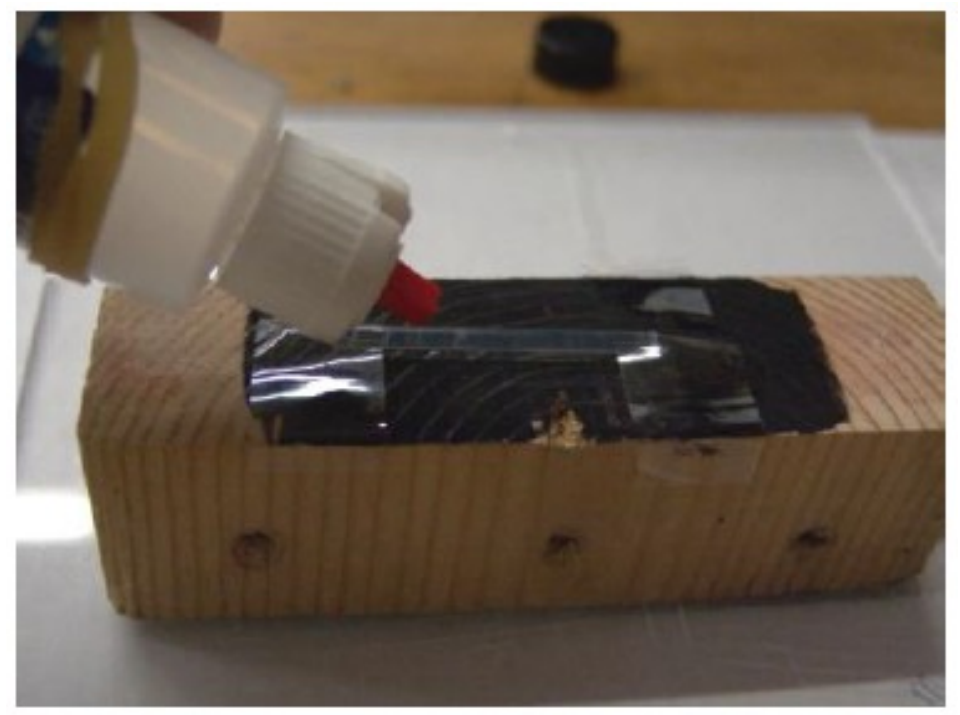

Figure 3-6: Neutralizer Application to Restore the Porous rod to its Neutral pH. 
5. The strain gauge was placed face up on the plexiglass. The strain gauge was adhered to PCT-2M installation tape, so it can be peeled off easily during placement on the porous rod.
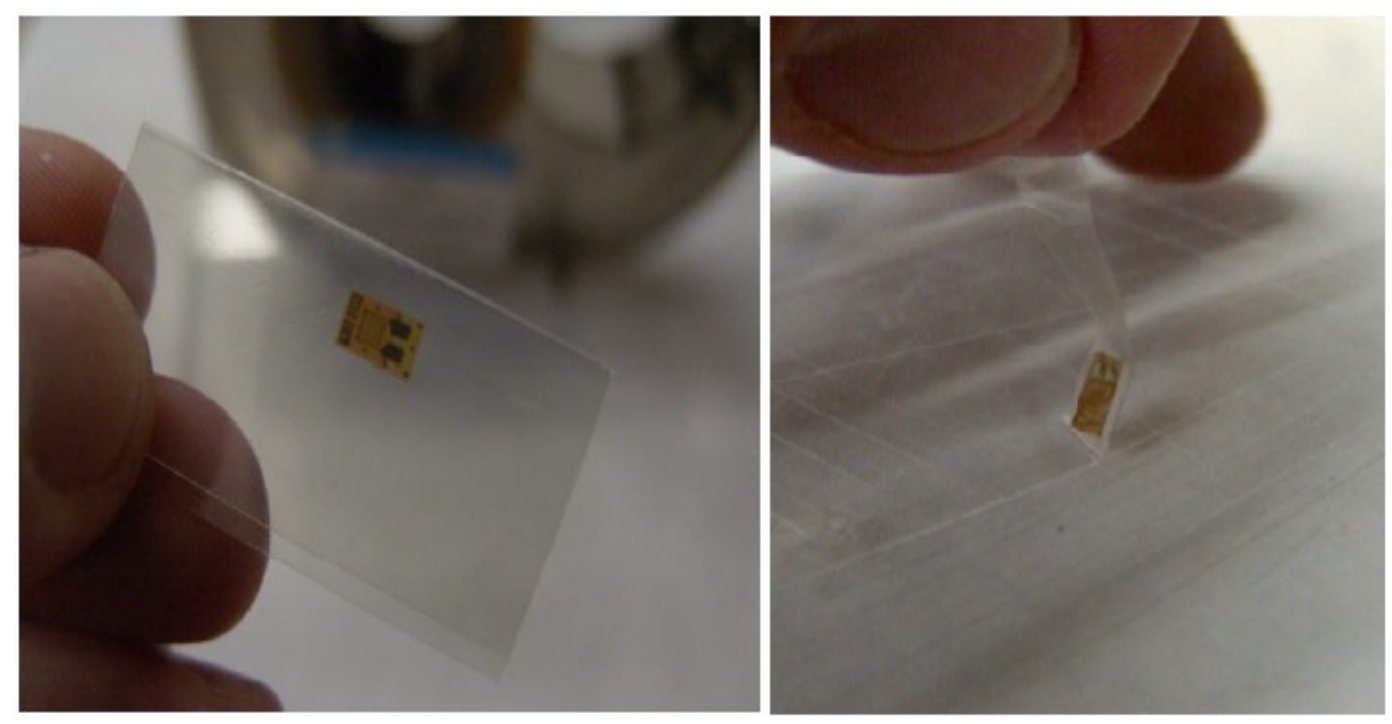

Figure 3-7: Placement of the Strain Gauge on to the Plexiglass and Pealing the Strain Gauge Face up Onto the PCT - 2M Installation Tape.

6. The tape was peeled off with the strain gauge stuck to it and placed on the porous rod so that the strain gauge was located approximately $3-4 \mathrm{~cm}$ away from the tip of the rod that would be exposed to the soil.

7. After sticking the tape to the porous rod, one end of the tape was peeled off so that the back of the strain gauge was exposed. 


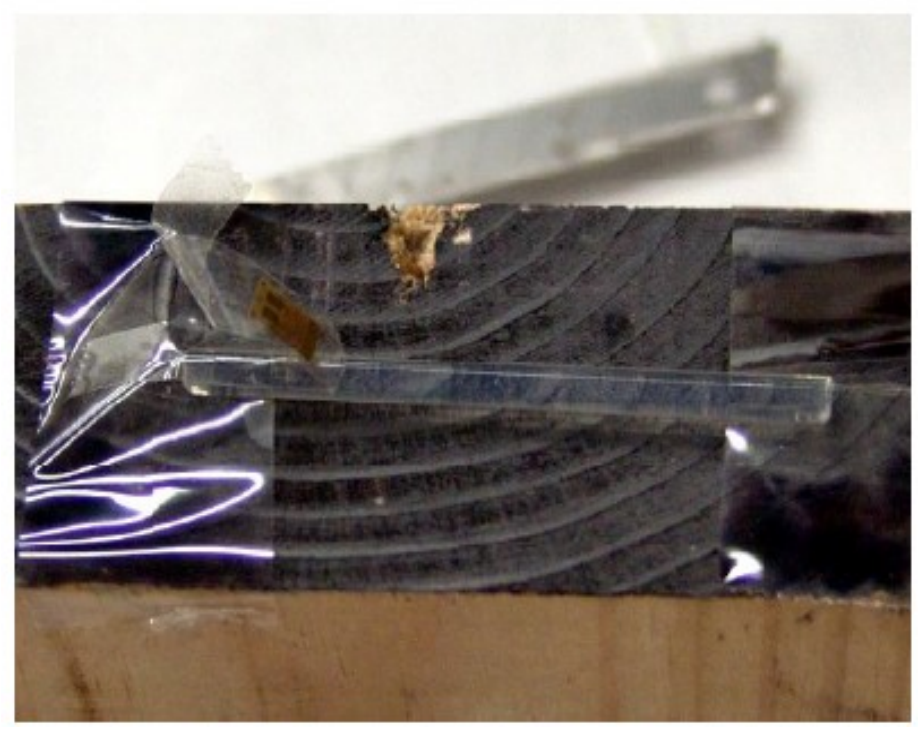

Figure 3-8: Placement of the Strain Gauge onto the Porous rod and pealing the Tape off so that the Bottom of the Strain Gauge was exposed.

8. The M-Bond adhesive catalyst was obtained and before applying the catalyst on to the back of the strain gauge, the brush was 'wiped' on the mouth of the bottle for about 7-8 times to protect the strain gauge from improperly mounting to the porous rod due to the decrease in the quality of the bond between the porous rod and the strain gauge.

9. After reducing the amount of catalyst present in the brush carefully the catalyst was applied using the bottle brush to the back of the strain gauge. 


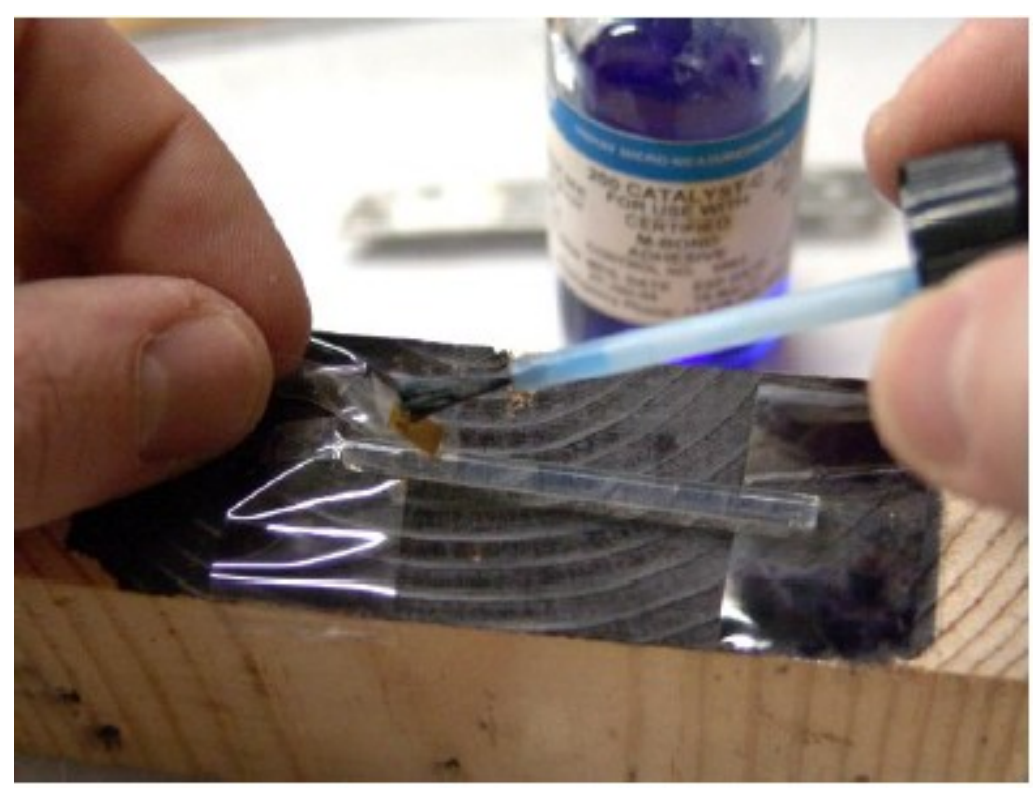

Figure 3-9: Careful Application of the M-Bond Catalyst to the Back of the Strain

Gauge.

10. After the application of the catalyst, one drop of the M-Bond adhesive was applied to the bottom of the strain gauge and the strain gauge was immediately pressed down over the porous rod. The index finger was slid in one direction until the adhesive spread throughout the bottom of the strain gauge so that it stuck well onto the porous rod. It was necessary to make sure that the strain gauge was mounted in the longitudinal direction to avoid errors to the data obtained.

11. The strain gauge and the rod were held together (cohered) using the index finger and the thumb for approximately $2-3$ minute, to ensure that the strain gauge was properly mounted to the porous rod with the pressure applied. 

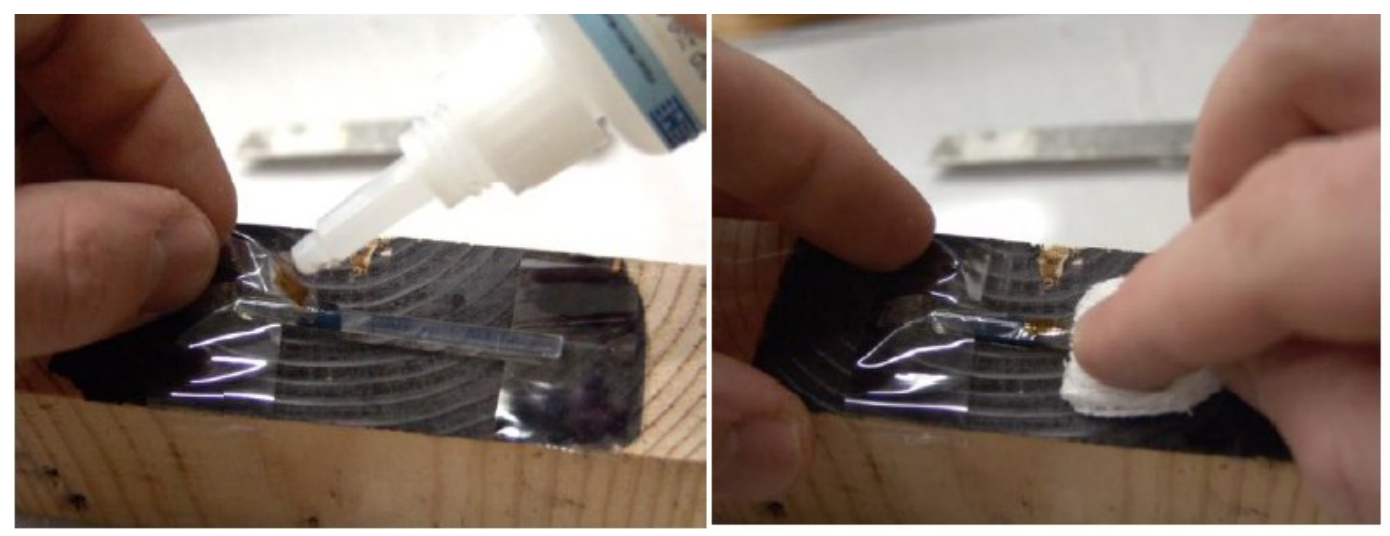

Figure 3-10: Application of the Adhesive on to the Strain Gauge and Mounting the Gauge on the Porous rod.

12. The porous rod was left undisturbed for at least 24 hours to make sure that the strain gauge was fully bonded to the surface of the rod.

13. Steps 5-12 were repeated to the opposite side of the porous rod. At the end two strain gauges were attached to the porous rod at opposite directions. After the appropriate time had elapsed, the porous rod was ready for the placement of the cap.

14. A plastic test tube cap was obtained upon which the terminal was to be attached. A hole, of approximately $2 \mathrm{~mm}$ in diameter, was drilled close to the edge so as to accommodate the passage of the wires from the strain gauge to the terminal.

15. Two bondable terminals were placed on the top of the plastic cap and affixed with epoxy glue close to the hole. 


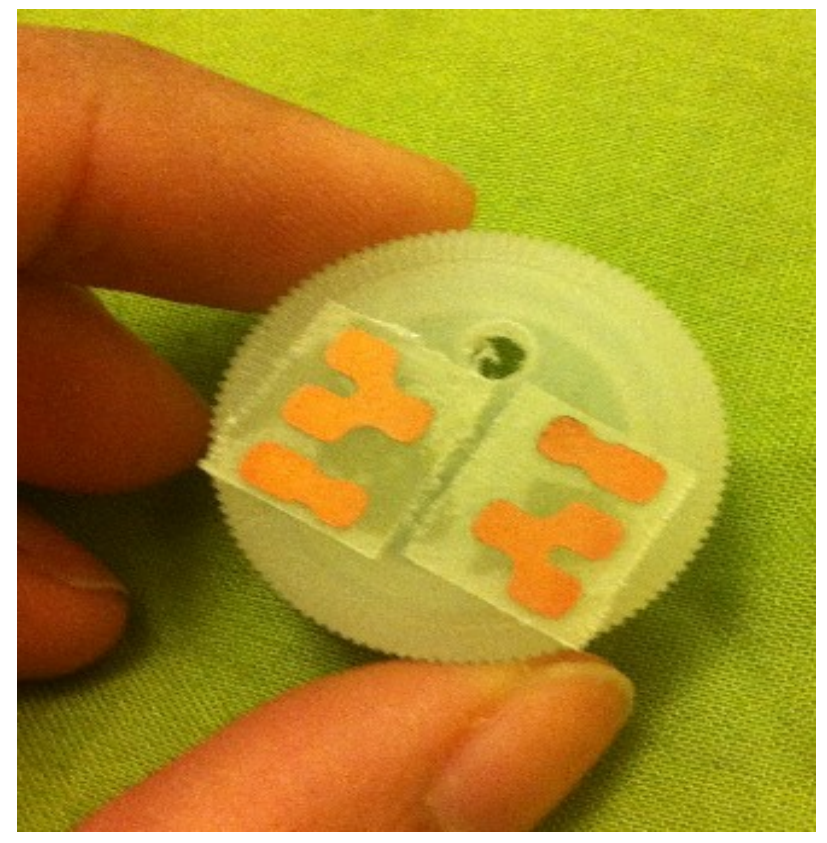

Figure 3-11: Affixing the Bondable Terminals to the Sensor cap

16. A size 4, cork stopper was obtained, and was cut in half to decrease the height. The end of the larger diameter of the cork stopper was affixed to the back of the sensor cap using the epoxy glue.

17. After making sure that the epoxy glue had set, a hole of $2 \mathrm{~mm}$ was drilled through the cork stopper to align with the sensor cap hole.

18. Another hole of $3 \mathrm{~mm}$ diameter was drilled half way through the cork stopper for the rod placement.

19. Epoxy was placed in the hole that was made for the porous rod and the sensor rod edge (the edge of the porous rod that is close to the strain gauge) was placed into the hole. 
20. To ensure the proper bondage of the porous rod to the cork, the sensor was left for about 10 hours. The sensor was now ready for the wires to be mounted.

21. 4 thin enamel coated tin wires were obtained, which were cut to the appropriate length so that they can be mounted from the terminal of each strain gauge to the bonded terminal of the sensor cap.

22. The ends of the 4 enamel coated tin wires were sanded to remove the enamel to allow good conductivity at the soldering junctions.

23. Each tin wire was mounted on to the sensor so that one of the ends was soldered to the strain gauge. The other end was put through the hole in the cap and soldered to the terminal on top of the cap. This step was repeated 4 times until all 4 wires were mounted to the sensor.

24. Two sets of insulated strain gauge wires were obtained and soldered to the terminals at the top of the cap at appropriate places. The red insulated wire was soldered to the single section of the terminal on the cap and the remaining two wires (white and black) were soldered to the double section.

25. The sensor was tested for the proper functionality by hooking the sensor to a Model 1300 gauge installation tester. 
26. To protect the strain gauge and the terminal, M-Coat microcrystalline wax was applied to the top of the strain gauge and the terminal to avoid structural damage to the strain gauge and the terminal.

27. A Thin layer of M-Coat B Nitrile rubber coating was applied on top of the wax and the whole sensor porous rod so that only the tip of the porous rod that was to be exposed to the soil would exposed. Application of the wax coating helps,

a. Protect the strain gauge from structural damage due to the moisture or damage that can be caused due to the soil during soil testing.

b. Prevents the de -saturation of the sensor body that is not exposed to the soil.

28. The sensor was then ready for the application of the protective casing.

29. 2 E-clips, a green screw stopper and a $45 \mathrm{~mm}$ HDPE plastic tube were obtained. 


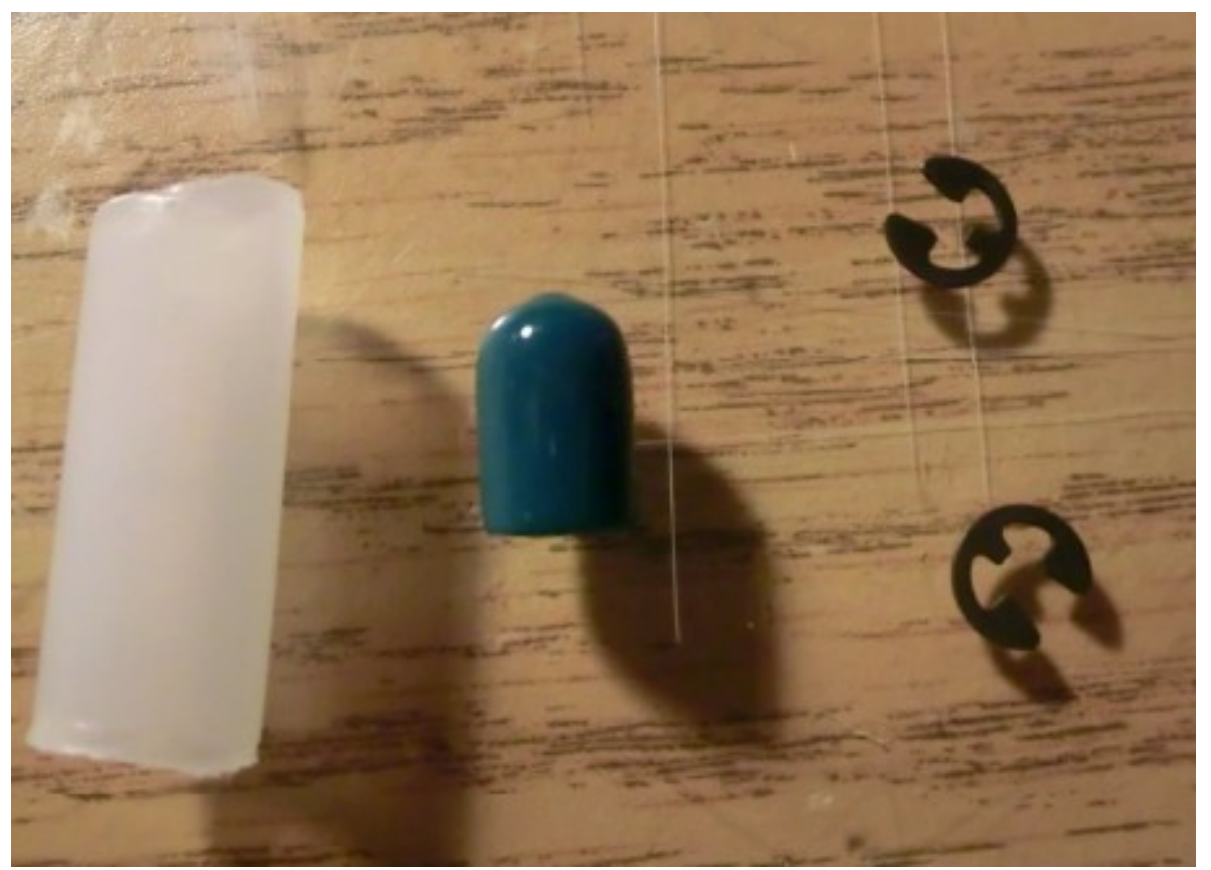

Figure 3-12: Materials Used to Apply the Protective Casing of the Sensor (Left: HDPE Tube, Middle: Green Screw Stopper, Right: 2 E- Clips).

30. Two E-Clips were placed (one closer to the strain gauge and the other close to the exposed tip) on to the sensor porous rod.

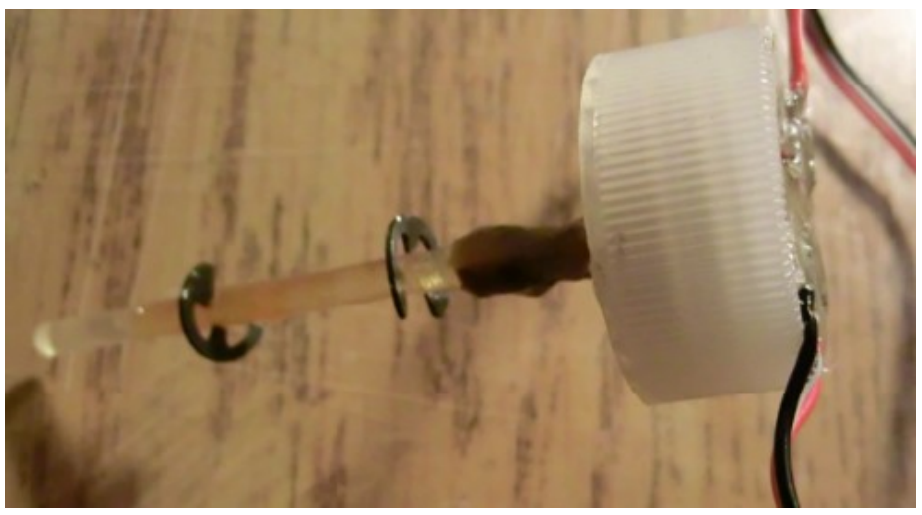

Figure 3-13: Placement of the two E- clips 
31. The HDPE plastic tube was passed through the sensor rod so that one end could touch the cork stopper. The tube was affixed to the cork stopper using epoxy glue.

32. A small hole was cut on the green screw stopper so that the porous rod could be passed through. The green screw stopper was inserted through the porous rod into the HDPE tube.

a. The outer casing of the sensor helps limit the porous rod to soil sensor interaction only to the exposed tip allowing the strain gage to only detect the strains caused by the change in volume of the porous rod and prevent the outward interactions (wind, $\mathrm{RH}$, temperature, external loads which can cause lateral compression) from directly influencing the strain values and giving erroneous results.

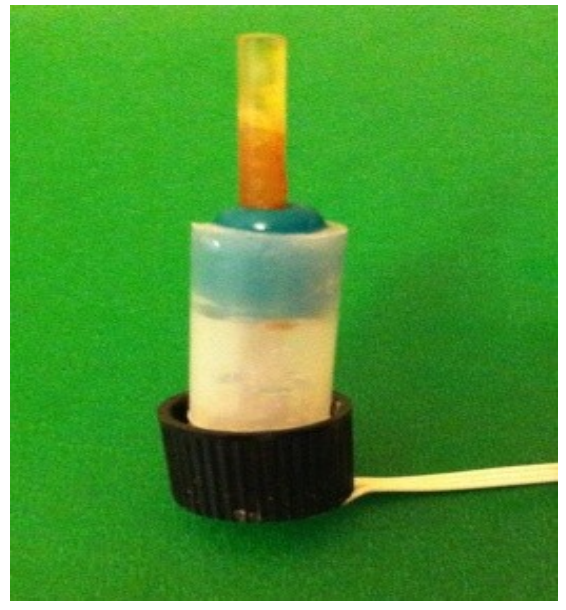

Figure 3-14: Finally Constructed PE Sensor Ready to be Tested and Used in Experiments. 


\subsection{Saturation Test of the Poroelastic Suction Sensor}

Saturation tests of the PE sensor were conducted to ensure that the sensor is working properly, where the deformation is elastic during saturation (tension). Therefore, the saturation test can be used to ensure the functionality of the newly mounted strain gauges. The method followed to conduct the saturation test of the PE sensor is presented below,

1. The PE sensor was connected to the strain meter; the strain measurements were obtained and monitored by the data acquisition system (NI DAS, data logger). The data logger allows the data to be monitored and stored by the computer.

2. In the computer, the channel measuring the strain from the two strain gauges of the sensor (strain1 and strain 2) in the data acquisition system was zeroed prior to the start of the experiment. The software used for the measurements was Lab View.

3. The data logger timer was set to 30 minutes to make sure readings were obtained every 30 minutes during the period of the experiment.

4. After setting the time, the data acquisition system was initiated by pressing on the green button.

5. A small beaker of $150 \mathrm{ml}$ capacity was filled with distilled water.

6. The exposed porous tip of the poroelastic suction sensor (PE sensor) was dipped into the distilled water filled beaker. 
7. The PE sensor was left in the water to be saturated for the period of time needed. (Approximately 48 hours).

8. The data obtained from the test was collected and plotted against time to evaluate the deformation range of the PE sensor.

9. The test was repeated to saturate the PE sensor prior to conducting tests on soil.

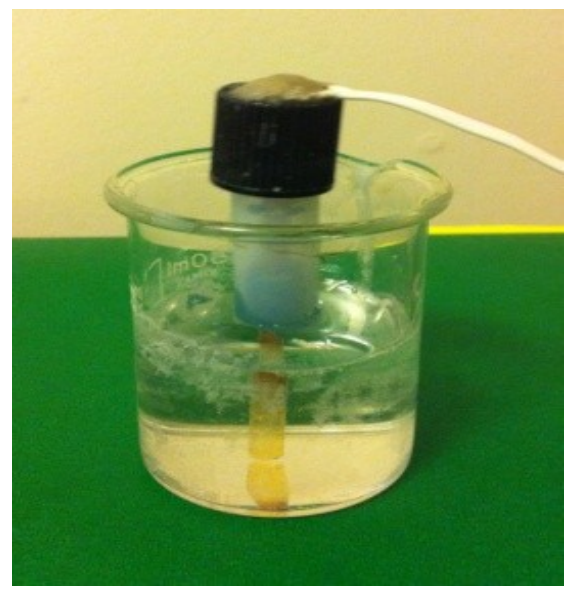

Figure 3-15: Saturation Test of the PE Sensor.

\subsection{Comparison of Total Suction and PE Sensor Using Silt under Drying Conditions}

The drying tests were conducted using Artificial Silt, which is an inert material. Therefore, the osmotic suction can be neglected when measuring the total suction values. The test was conducted for 26 hours by taking a reading every 1 hour. The initial gravimetric (mass of water divided by mass of soil) water content of the silt was $20 \%$. The purpose of this experiment was to determine the SWCC, comparing the total suction machine results to the PE sensor results. 


\subsubsection{Materials Used in the Drying Test}

1. Aluminium cups for the number of hours of readings (height $=2 \mathrm{~cm}$, diameter $7 \mathrm{~cm})$

2. Artificial Silt of $1000 \mathrm{~g}$

3. Distilled water $200 \mathrm{~g}$

4. Balance to measure the weight of the sample

5. PE sensor

6. Total suction machine (WP4 PotentiaMeter)

7. Oven to dry the samples to measure the water content

8. Total suction machine disposal sample cups for the appropriate amount of silt samples

9. $\mathrm{KCL}$ sample to measure the standard value of the total suction machine

10. Spatula

11. Computer to record the PE sensor data

\subsubsection{Procedure for the Drying Test Experiment}

1. The empty weights of all the Aluminium cups were recorded and the cups were numbered. One cup was utilized for sensor placement.

2. $200 \mathrm{~g}$ of water and $1000 \mathrm{~g}$ of silt were mixed together using the spatula so that initial water content of silt is $20 \%$. 
3. The mixed silt and water was placed into the cups so that all the cups have approximately the same weight (60g with the weight of the cup) of sample, with a height $2 \mathrm{~cm}$ of silt in the cup.

4. The wet weight of one of the samples was recorded and the PE sensor was inserted into the silt at a depth of $1 \mathrm{~cm}$.

5. The cup with the PE sensor was placed on the balance to measure weight and the time was recorded.

6. The software on the computer (Lab View) was initiated to record the PE sensor values.

7. The total suction machine was switched on and allowed to rest for at least 15 minutes prior to its use.

8. All the other cups filled with silt were placed closer to the sample with the PE sensor so that the outer interactions and the temperature of the samples were kept in the same environment.

9. A KCl sample was poured into a total suction machine sample cup and checked for the standard value of $2.19 \mathrm{MPa}\left(\right.$ at $20^{\circ} \mathrm{C}$ ) and $2.22 \mathrm{MPa}$ (at $25^{\circ} \mathrm{C}$ ). The vial with the $\mathrm{KCl}$ sample was placed into the total suction machine and checked for the corresponding value according to the temperature of the environment. If the values agreed, the total suction machine was ready to be used. If the values did not agree the total suction machine had to be cleaned. Refer to the manual of the WP4 PotentiaMeter (Decagon Devices Inc. 2007). 
10. After the first 20 minutes, a small scoop of silt was removed from the sample closest to PE sensor sample and placed in to a disposable cup to be used in the total suction machine using the spatula.

11. After obtaining the sample for the total suction machine, the wet weight of the cup with the silt was recorded and the cup was placed in the oven. After 24 hours, the dry weight of the sample was measured and used to determine the water content.

12. The disposable cup was placed in the total suction machine and the total suction reading was recorded.

13. After the first reading was done, steps $10-12$ were repeated every 1 hour for 20 hours until all the silt sample cups including the cup with the sensors were in the oven. At the end of the experiment, the total suction and the water content of the sample with the PE sensor was measured.

\subsection{Wetting and drying of the Silt in the Freezing Conditions}

Two PE sensors (saturated and dry) were placed inside a freezer at varying temperature conditions of $0^{\circ} \mathrm{C},-10^{\circ} \mathrm{C}$ and $-30^{\circ} \mathrm{C}$ for a period of time. The experiment was performed to see the behaviour of the sensor upon freezing, since the smaller pore sizes in the porous rod of the PE sensor can have the ability to have a higher freezing point depression hence performing well in the freezing conditions. Thermocouples were also placed in the freezer to accurately measure the temperature inside the freezer. 


\subsubsection{Materials Used for the Freezing Test}

1. $2 \mathrm{PE}$ sensors (saturated and dry)

2. Thermocouple

3. Freezer that has a temperature range up to $-40^{\circ} \mathrm{C}$

4. Distilled water

5. Tissue

6. Silt

7. 1-D column (Diameter: $7.5 \mathrm{~cm}$, Height: $10.5 \mathrm{~cm}$ ) with $50 \mathrm{~mm}$ Styrofoam insulation
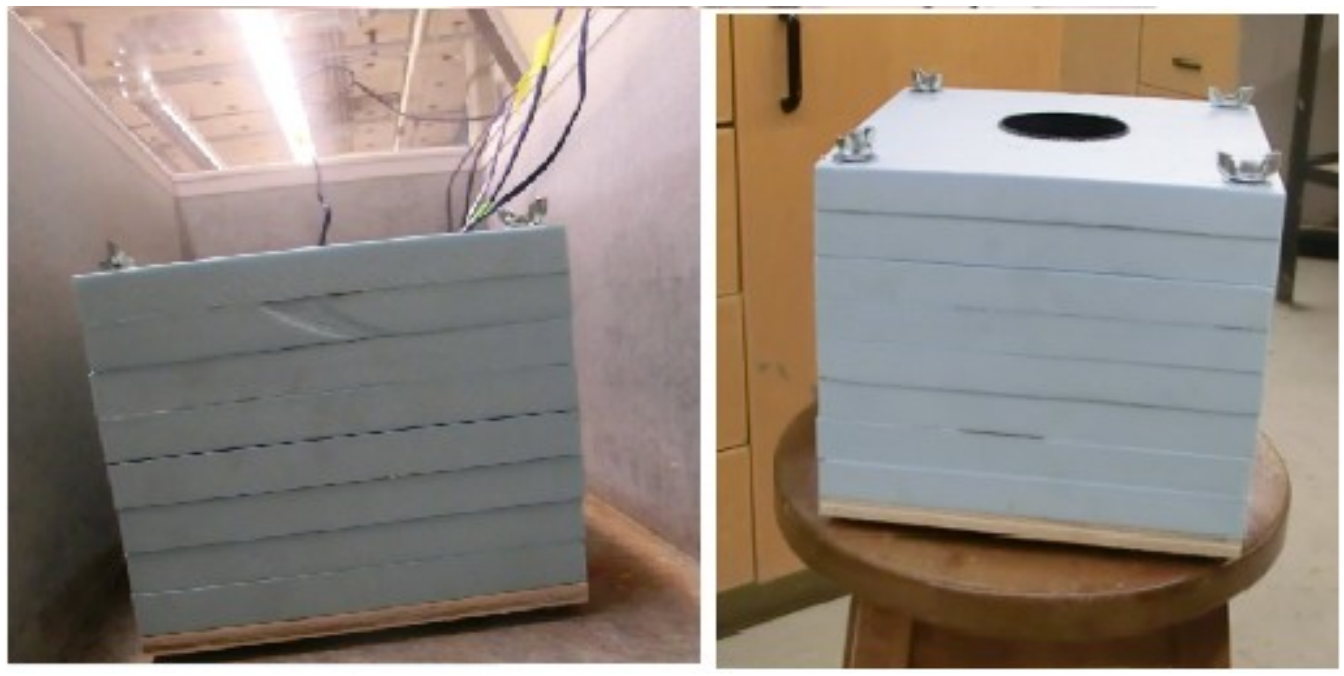

Figure 3-16: 1-D Columns Used in the PE Sensor Freezing with Silt Test

\subsubsection{Method Used in the Freezing Test}

1. A pre-saturated sensor was obtained that had been saturating for about a day (for saturated test), otherwise just the dry sensor. 
2. Thermocouple was obtained to determine the temperature inside the freezing chamber.

3. The PE sensors and the thermocouple were connected to the data logger for continues data readings.

4. The thermocouple and the PE sensors were put in the freezing chamber and the door was closed so that they are in close proximity of each other allowing more accurate measurements. The saturated PE sensor was wiped before the insertion into the freezing chamber to prevent crystallization of the surface water on the PE sensor

5. The temperature was decreased to $0,-10,-20$ and $-30^{\circ} \mathrm{C}$ at different time periods to determine the behaviour of the PE sensors during freezing.

\section{Further Instruction if the PE Sensor was tested in Silt (Follow after Step 3 above):}

6. For this test the saturated PE sensor was used.

7. Silt sample was prepared with a GWC of $20 \%$ and thermocouples were inserted into the 1-D column at three different depths at top, middle and bottom as shown in Figure 3-17.

8. Silt was filled into the column, while making sure to insert the PE sensor parallel to the middle thermocouple for accurate readings of the corresponding temperature change.

9. The temperature was lowered from 0 until $-30^{\circ} \mathrm{C}$ decrementing the temperature every $10^{\circ} \mathrm{C}$ at about every 5 hours. 
10. Upon completion of the test the thermocouple and the PE sensor data was acquired to be analysed.

Following Figure 3-17, shows the experimental set up and the depth of insertion of the PE sensor and the thermocouples in the 1-D freezing column.
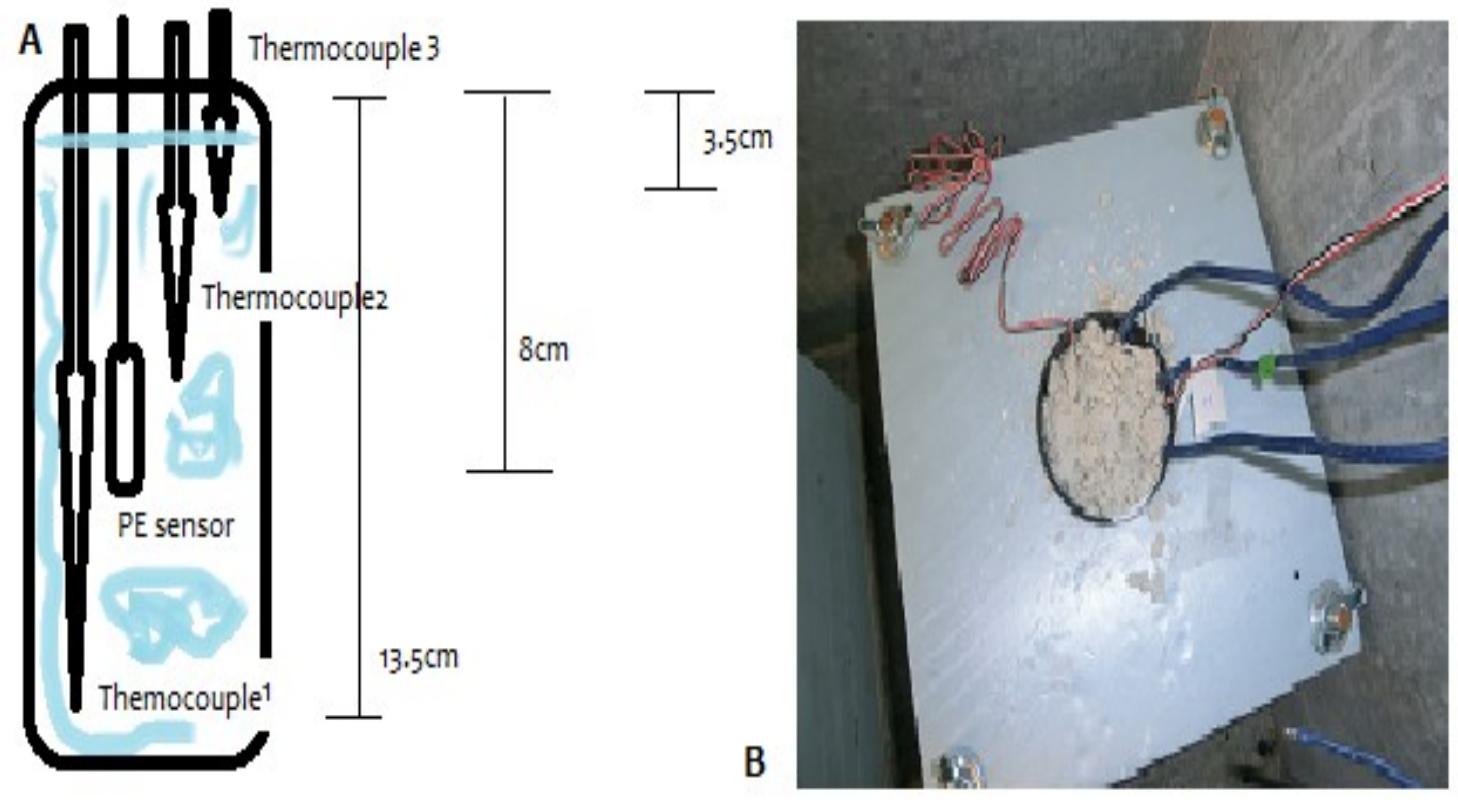

Figure 3-17: Experimental Setup of the Freezing Test of PE Sensor with Silt

\subsection{Function of Thermocouple Wires}

The voltage differences detected by the thermocouples are called the electro motive force (emf) which is created by twisting two wires together. The voltage difference created by the thermocouple wires that are homogeneous will be a function of the temperature difference between the measuring and the reference junctions (ASTM 
Committee, 1981). Homogeneity of the thermocouples will play an important role in the accuracy of the measurements.

Electric voltage of the thermocouples can be detected by connecting one end of the wire to a voltmeter or a data logger and placing the other end with the twisted wires on the system with a heat source to measure the temperature difference.

During the experiments the hot junction is in contact with the sample, where as cold junction is at room temperature. The resulting voltage can be calculated using the following formula,

$$
\Delta v=\int_{T_{0}}^{T} S \cdot d T
$$

This can also be represented as, $\Delta v=S_{A-B} \cdot \Delta T$ where $\mathrm{S}_{\mathrm{A}-\mathrm{B}}$ is the Seebeck coefficient difference between the two metals. 


\section{Chapter 4 RESULTS AND DISCUSSION}

The following section gives a detailed description of all the results of the experimental studies under taken in the thesis. These results include, the saturation and drying test of the PE sensor in distilled water to verify the validity of the sensor in reaching equilibrium, comparison of results obtained from the modified and the older version of the PE sensor, PE sensor results comparison to the WP4T PotentiaMeter using SWCC, the behaviour of the sensor upon construction with two strain gauges instead of one to measure the strain, the behaviour of the PE sensor in thickened oil sand tailings with comparison results using the WP4T PotentiaMeter and the PE sensor behaviour in freezing temperature conditions of $0^{\circ} \mathrm{C}$ to $-30^{\circ} \mathrm{C}$.

\subsection{Saturation Test and Drying of the PE Sensor in Water}

The saturation test was performed to determine the validity of the newly made poroelastic suction sensors. The strain obtained by the PE sensor was converted to matric suction. The negative pore water pressure or drying (matric suction) is indicated in positive and the saturation is indicated in negative values throughout the experimental results in the following section. A typical plot of this data is shown in Figure 4-1. 


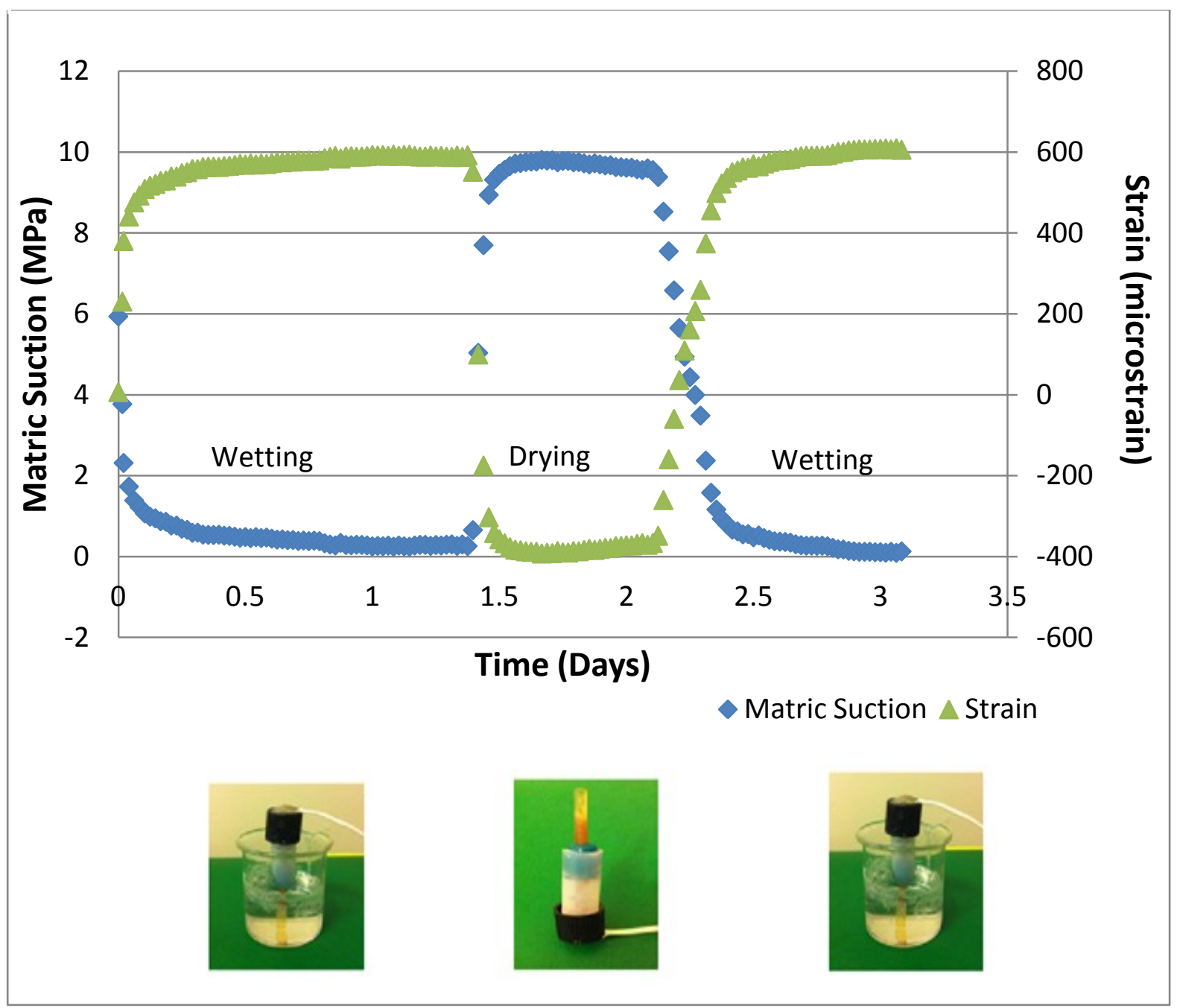

Figure 4-1: Wetting and Drying Test of the PE Sensor in Water

As the water filled into the pores of the porous rod in the PE sensor the sensor expanded indicating a positive microstrain, hence negative matric suction with a bulk modulus value of $1800 \mathrm{MPa}$. As the PE sensor reaches its maximum expansion (when all the pores are filled with water, $S \approx 100 \%$ ), the values reach equilibrium state at around $600 \mu \varepsilon$. When the PE sensor was left to air dry, the sensor reached a maximum equilibrium strain value of around $-400 \mu \varepsilon$. This equilibrium (the change in strain over 
time) values were reached only after the modifications were made to the PE sensor as shown in Figure 3-1, (right) diagram. Therefore, the drift problem observed by Apking (2010) in the previous experiments was not observed in the new results. Also the results of the drying and wetting test presented by Dunmola et al. (2010) does not show a clear representation of the equilibrium reached by the PE sensor at its maximum drying and wetting state.

\subsection{Comparison Test of the Old and the New PE Sensor in a Wetting Test}

The test was performed by submerging the dry sensors (PE sensor and modified PE sensor) in distilled water and allowing the PE sensors to attain the maximum rate of saturation over a period of about $20-30$ hours. The following Figure 4-2 shows the results obtained upon the completion of the saturation test.

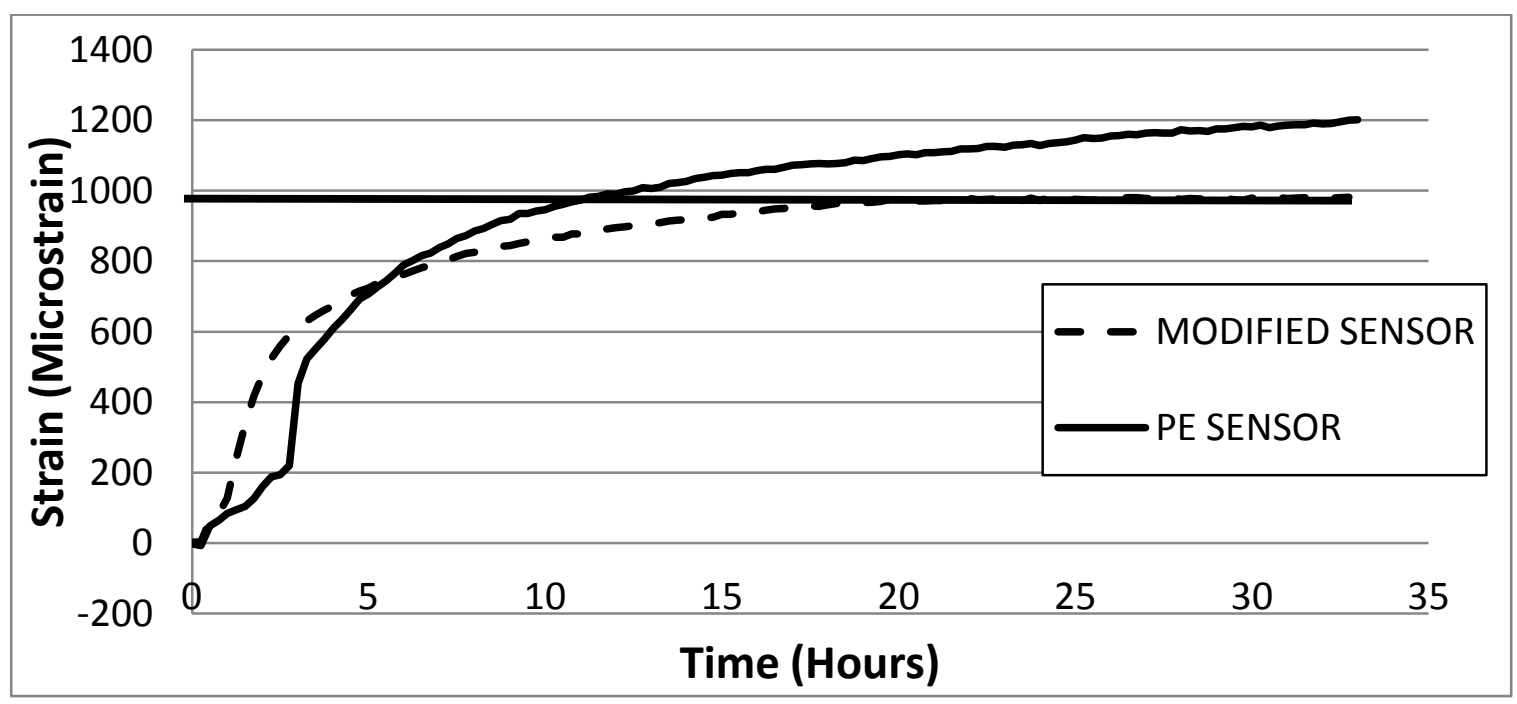

Figure 4-2: Comparison of the Old and the New PE Sensors during Saturation in Water. 
From the Figure 4-2 it is evident that the new sensor reached equilibrium upon maximum rate of saturation after around 20 hours, where as the old sensor tends to keep increasing in suction even after the point of maximum saturation. This may be due to the outer casing placement that supported the device and prevented the porous rod from bending when placed in soil or in a beaker. Therefore, the results presented shows that the previous problem that was faced by Apking (2010) was not apparent in this iteration of the sensor.

\subsection{New PE Sensor Results with the Two Strain Gauges}

Originally the PE sensor construction was done using one strain gauge to measure volume change. The new PE sensor was made with two strain gauges placed on opposite sides of the porous rod to see if the sensor experiences differential strain, such as when bending would occur. A PE sensor with two strain gauges was tested as shown in the Figure 4-3, which shows the results of initially saturated sensor in one of the experiments described in section 3-2. This and other tests show that the deformation of the porous rod is relatively consistent up to its AEV. The soil used in this experiment was silt. Upon reaching the AEV of the PE sensor the deviation in the results from one strain gauge to the other become apparent. This may be due to silt being near its residual water content, therefore even a slight deviation in the water content tend to give high variation in results causing a hysteresis effect. Another reason might be that as the 
water evaporates from the silt the volume of silt will decrease affecting the position of the PE sensor, changing its orientation. This can cause one strain gauge to detect a higher strain than the other depending on the side that each strain gauge was positioned.

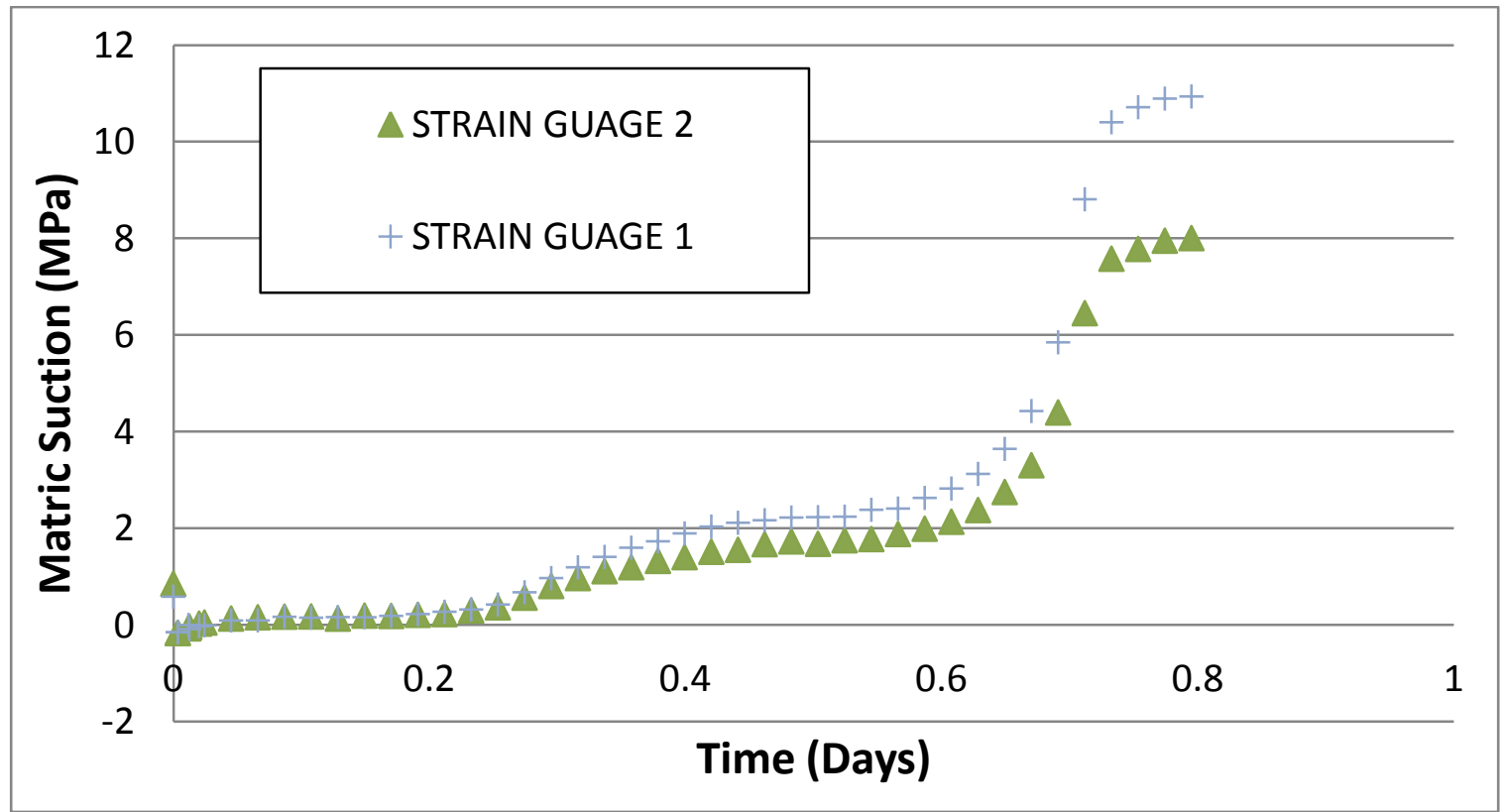

Figure 4-3: Representation of the Strain Values Obtained Using the two Strain Gauges Mounted to the PE Sensor in Silt at Drying.

\subsection{Comparison of Suction Readings of WPT4 Hygrometer to the PE Sensor}

Several tests were performed by drying artificial silt in duplicate samples to compare the measurements of the PE sensor to measurements of total suction by the WPT4 PotentiaMeter. These tests consisted of 20 hours (each measurement every hour or 
two hours) of reading of the total suction values and comparing the continuous readings of the matric suction values of the PE sensor. As the gravimetric water contents of the drying silt samples were determined after total suction measurement, a SWCC could be constructed for each test.

The results are compiled in two figures below, representing three different tests. The first figure (Figure 4-4) shows the SWCC as measured by the total suction sensor, fitted by the Fredlund and Xing SWCC equation. All three tests employed the same bulk modulus (K=1800MPa). The second figure (Figure 4-5) shows the SWCC using the PE sensor measurements, and the same theoretical SWCC equation shown in the previous figure. While there is considerable scatter in the apparent SWCC for values less than $1 \mathrm{MPa}$ for both the total suction measurements and the PE sensor, there is good agreement in the $1 \mathrm{MPa}$ to $10 \mathrm{MPa}$ range. Beyond $10 \mathrm{MPa}$, the $\mathrm{PE}$ sensor does not work as the AEV will have been substantially exceeded. The average absolute relative error and standard deviation of the error in this range is $0.5 \mathrm{MPa}$ and $0.5 \mathrm{MPa}$ between the two measurement techniques. Realizing that the PE sensor is a point measurement, while the total suction is an average value for the whole sample, and that suction may vary significantly with depth, and that measurements were made in replicate samples rather than the same sample, it is probable that these statistics represent an overestimate of the actual measurement error. 


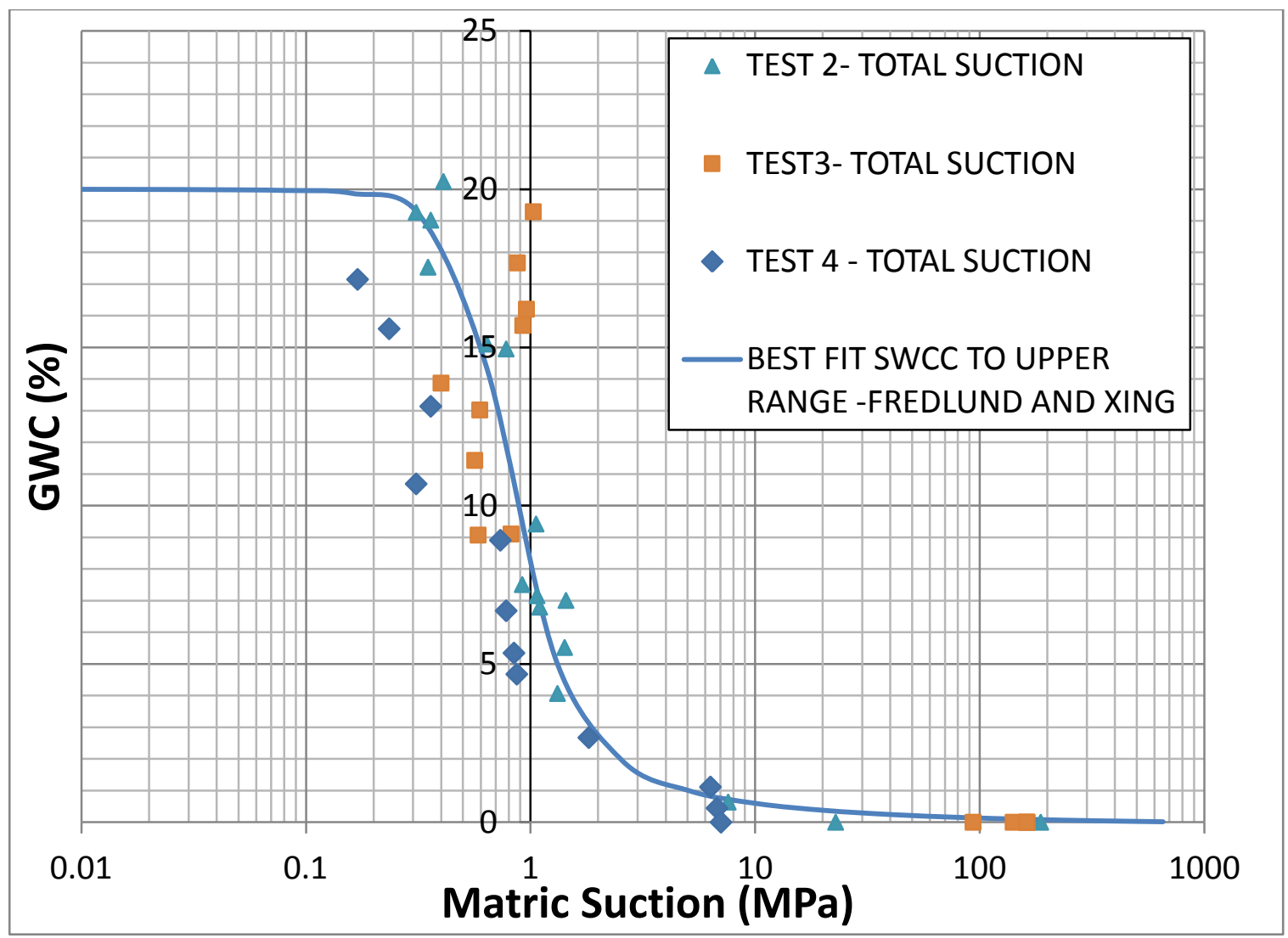

Figure 4-4: Total Suction Results for Drying Tests Presented as SWCC 


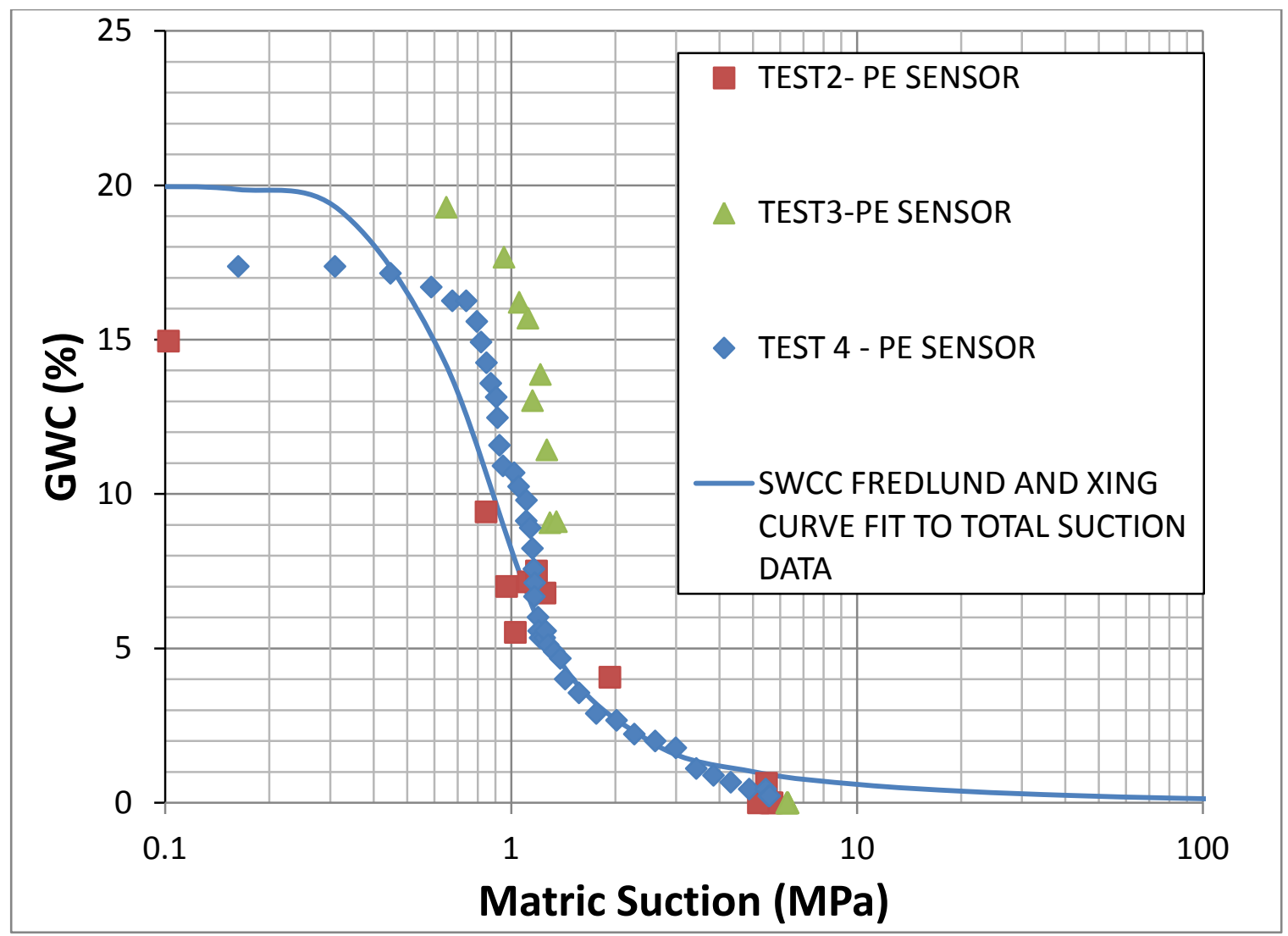

Figure 4-5: PE Sensor Results from Drying Test Presented as SWCC, Compared to Best fit SWCC Obtained by Fitting Total Suction Data in Figure 4-4

To better clarify the results obtained with the two measurements devices (WP4T PotentiaMeter and the modified PE sensor); following Figure 4-6 and Figure 4-7 are presented where the results are separated within the ranges of suction $0-1 \mathrm{MPa}$ and 1 - 10MPa. From this comparison it can be further validated that between the range of 1 $10 \mathrm{MPa}$ results tend to agree well. 


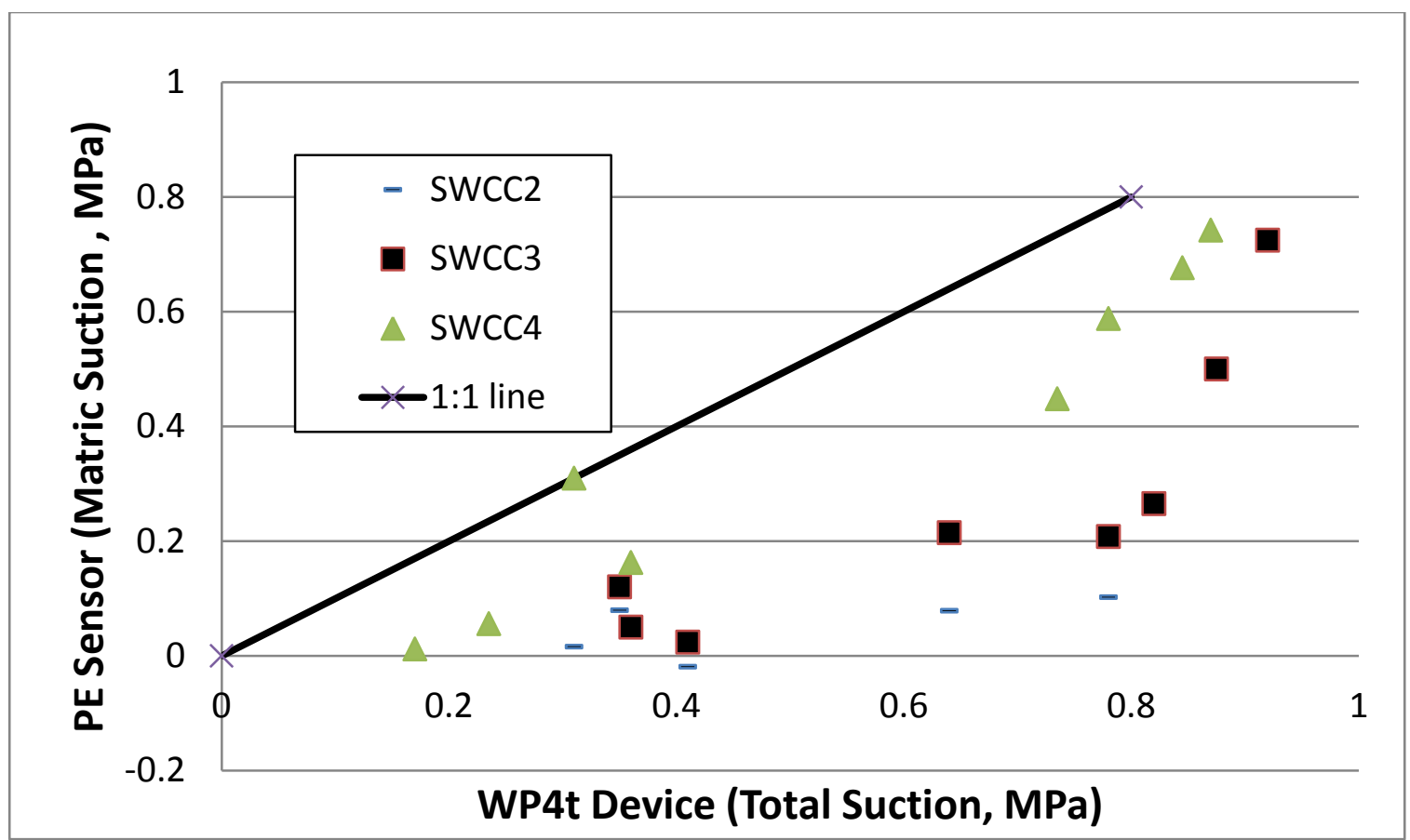

Figure 4-6: The Range of Suction from 0 - 1MPa for Both PE Sensor Results and the WP4T Device

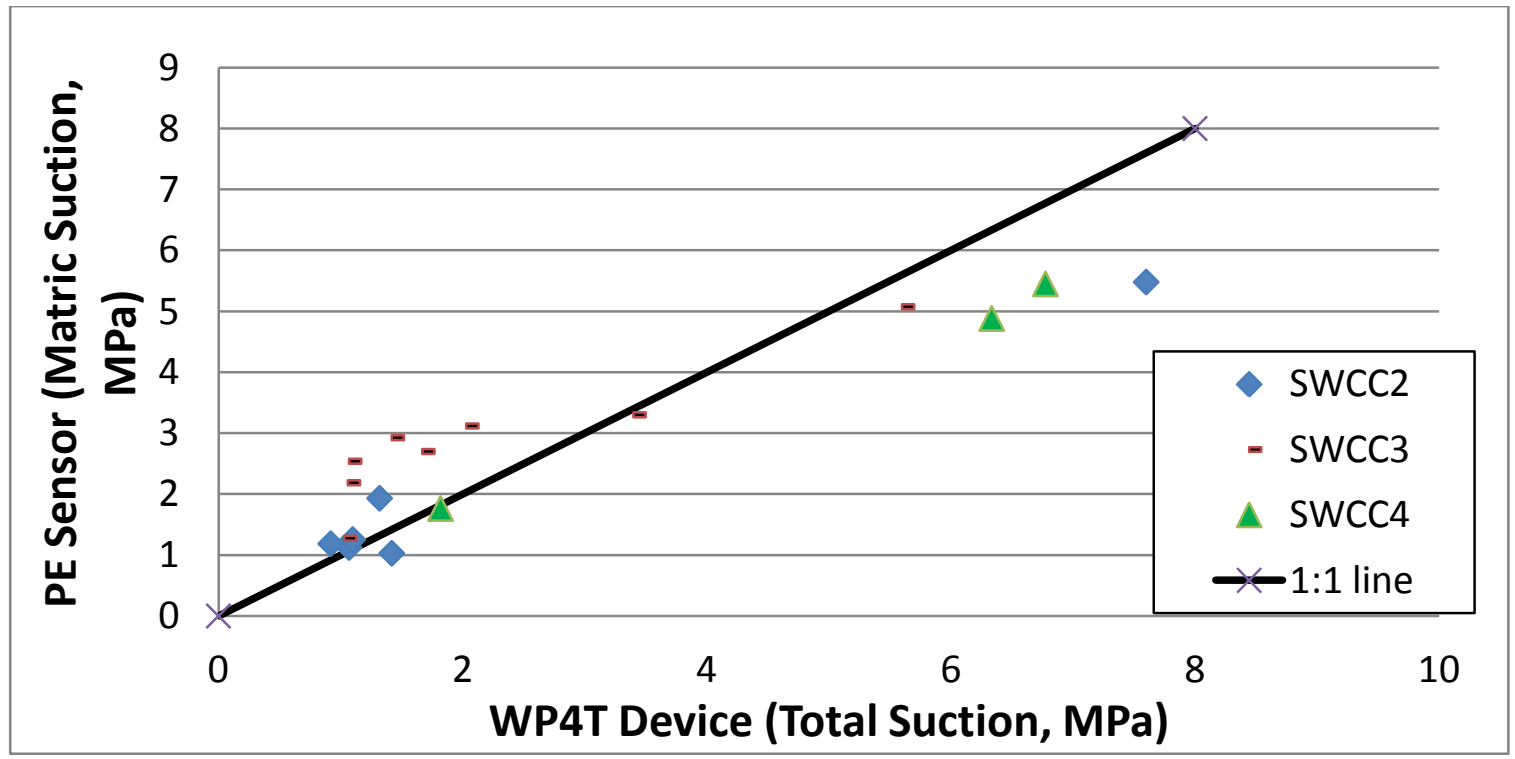

Figure 4-7: The Range of Suction from $0-10 \mathrm{MPa}$ for Both PE Sensor Results and the WP4T Device 
The data from these tests is also presented as time series in Figure 4-8. It is clear that the trends in suction are very similar between the two devices in all three tests.

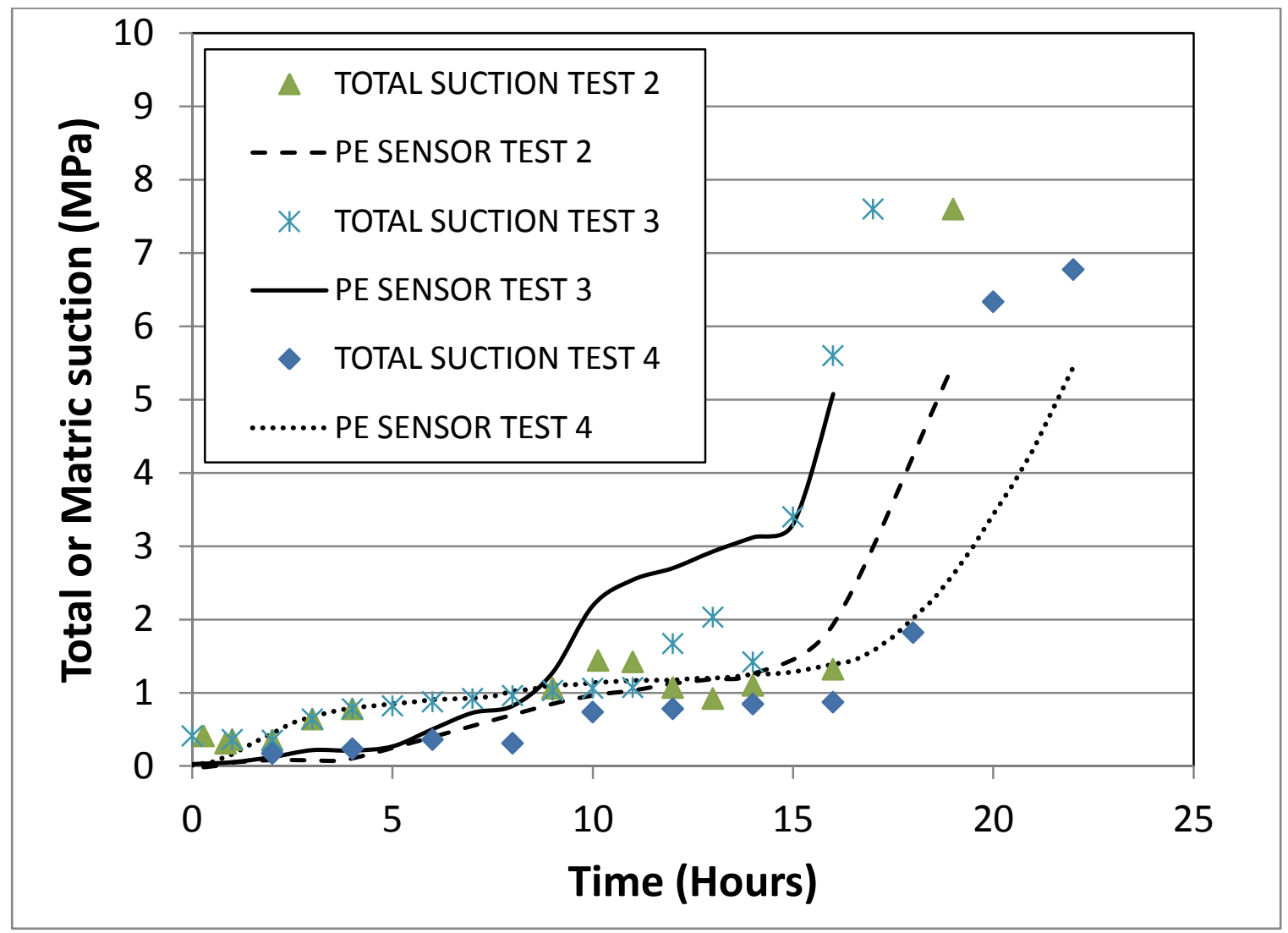

Figure 4-8: Suction Comparison of the WP4T PotentiaMeter Results to the PE Sensor Results versus the Time in Hours 


\subsection{PE Sensor Testing in the Total E\&P Pilot Plant Thickened Tailings, Alberta}

The PE sensor was tested in the thickened tailings provided by the Total E\&P from Alberta. The trend of the matric suction measured by the PE sensor was compared to the total suction values obtained using the WP4T PotentiaMeter. The thickened tailing properties consists of the following,

Table 4-1: Alberta, Total E\&P Thickened Tailings Properties

\begin{tabular}{|c|c|}
\hline Gravimetric Water Content & $94 \%$ \\
\hline Gs, Specific gravity & 2.7 \\
\hline LL, Liquid Limit & $25 \%$ \\
\hline SL, Shrinkage Limit & $17 \%$ \\
\hline PL, Plastic Limit & $20 \%$ \\
\hline$[\mathrm{Na}+]$ & $689 \mathrm{mg} / \mathrm{L}$ \\
\hline
\end{tabular}

The tailings were placed at an initial thickness of $0.20 \mathrm{~m}$. A figure presenting the PE sensor insertion in the drying box with the oil sand tailings is presented in the APPENDIX A-5. The experiment was performed by pouring oil sand tailings in to a box of $98.7 \mathrm{~cm}$ length $\times 69 \mathrm{~cm}$ width box as shown in the APPENDIX A-5. The temperature, $\mathrm{RH}$ and evaporation data are also shown in APPENDIX, Figure A-6 and Figure A-7 respectively. Additional details of tests can be found in Innocent-Bernard (2013). 
The PE sensor was inserted in a depth of $0-1 \mathrm{~cm}$ from the surface of the oil sands while the total suction samples were extracted from the top $1 \mathrm{~cm}$ of the surface of the drying oil sand tailings each day.

A plot comparing the total suction and the PE sensor matric suction results versus time is presented in Figure 4-9. These results show an under prediction of the results observed by the PE sensor to the WP4T PotentiaMeter. This variation maybe due to the fact that the WP4T PotentiaMeter gives total suction results while the PE sensor gives matric suction, therefore total suction results includes the osmotic suction component as well. The PE sensor was inserted at a depth (approximately $1-3 \mathrm{~cm}$ ); where as the total suction measuring samples were taken from the top surface. Therefore, the measurement variations can occur according to the place that the samples were extracted.

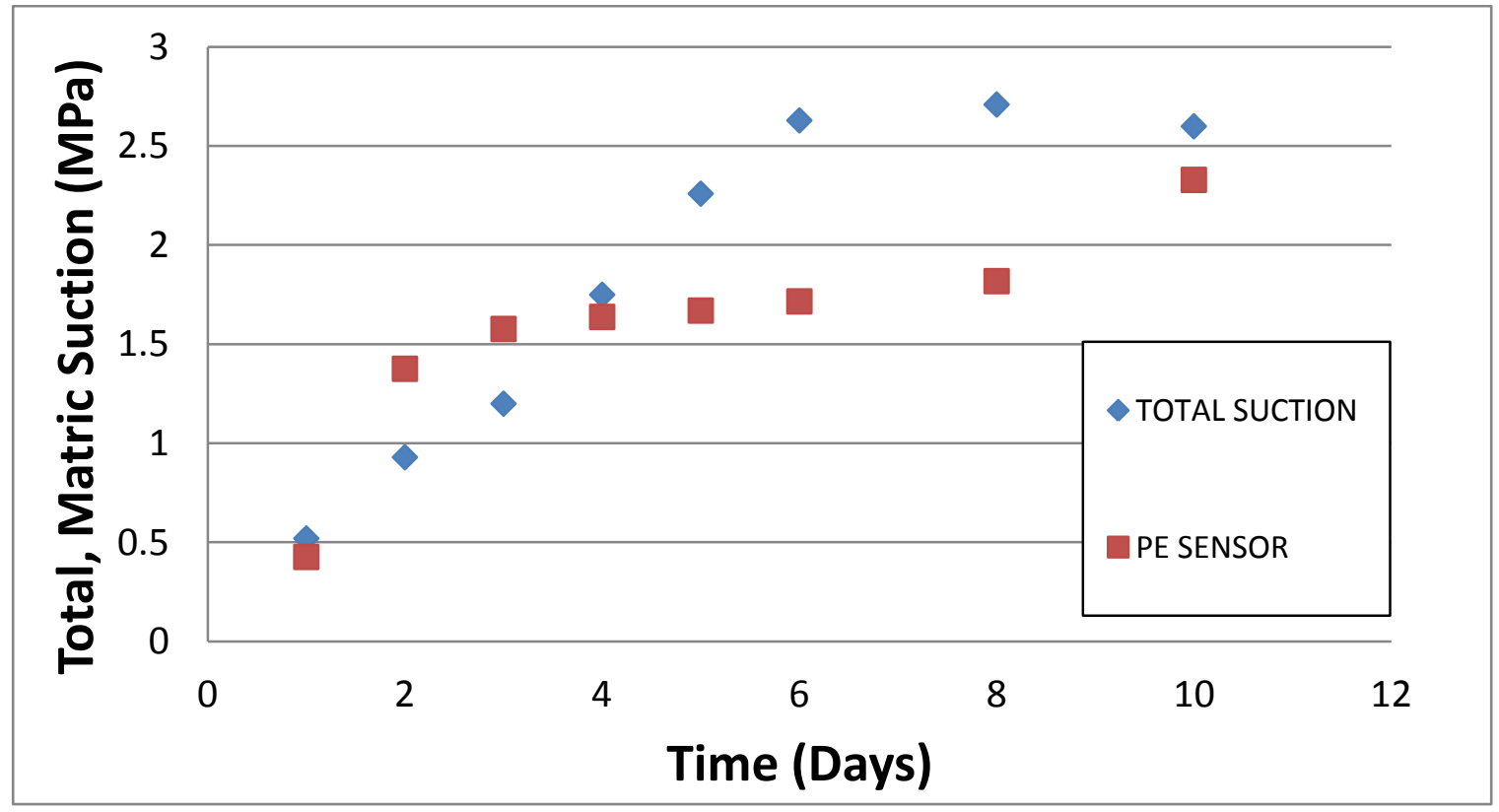

Figure 4-9: Comparison of Total Suction (WP4 Device) vz. Matric Suction (PE sensor) in Oil Sand Tailings 


\subsection{PE Sensor in Saturated and Dry Condition in the Freezing Conditions}

The porous rod of the PE sensor has very small pores (micro pores), therefore was thought that the PE sensor can withstand freezing below the $0^{\circ} \mathrm{C}$. As the pores get smaller, the freezing point depression tends to decrease, therefore allowing greater time before the water freezes inside the pores and for the sensor to cavitate, allowing matric suction to be measured at a lower range of temperatures. To test the theory the PE sensor was tested at dry and saturated conditions in the freezer to see if the porous rod can withstand the lower temperatures. The temperature ranges that the PE sensor was tested, for the dry and the wet conditions were: $0,-10,-20$ and $-30^{\circ} \mathrm{C}$.

\subsubsection{Dry PE Sensor in the Freezing Temperatures of $0,-10,-20$ and - $30^{\circ} \mathrm{C}$}

The following Figure 4-10 represents the PE sensor results that were observed when the sensor was placed inside a freezer at freezing conditions. A thermocouple was placed inside the freezer to detect the temperature right at the position of the PE sensor. Please note that in the sensor freezing results, the increase in strain is due to contraction of the sensor upon freezing. 


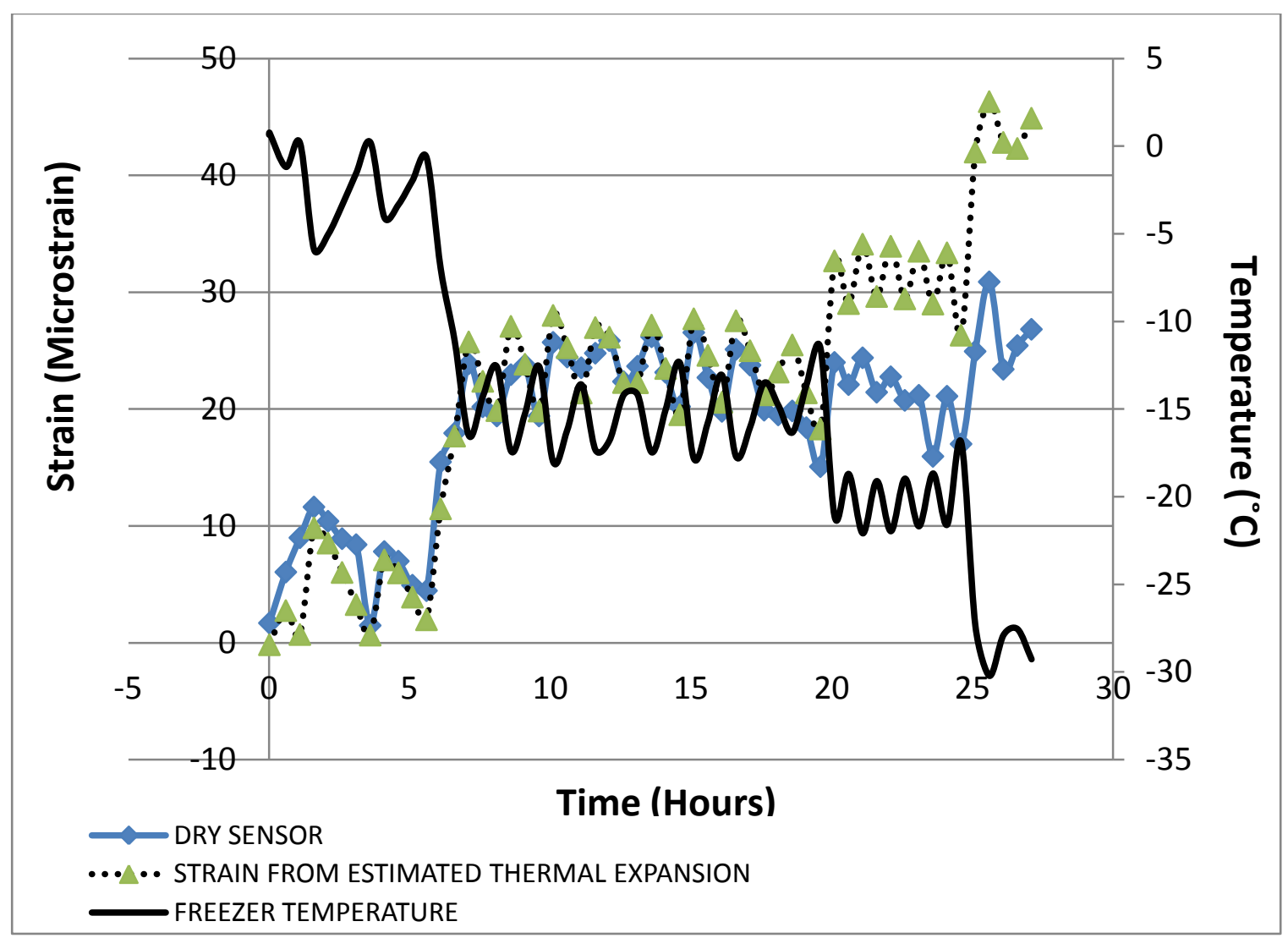

Figure 4-10: Behaviour of the dry PE Sensor in Freezing Conditions

The average thermal expansion of vycor porous glass of the PE sensor at its dry state due to freezing was estimated using an average value of $1.5 /{ }^{\circ} \mathrm{C}$ for different kinds of glass reported in the literature. The results clearly show that variation in temperature explains the observed variations in strain. However, these strain values are small compared to the strains that would be expected from changes in suction.

\subsubsection{Saturated PE Sensor in the Freezing Temperatures of 0, -10, -20 and $-30^{\circ} \mathrm{C}$}

The PE sensor was also tested at saturation in the freezing conditions to see how the porous rod reacts to expansion / contraction of cooling water, and to see if it indeed 
freezes. The strain determined at freezing temperatures of $0,-10,-20$ and $-30^{\circ} \mathrm{C}$ when the PE sensor is at saturation is presented in the Figure 4-11 below,

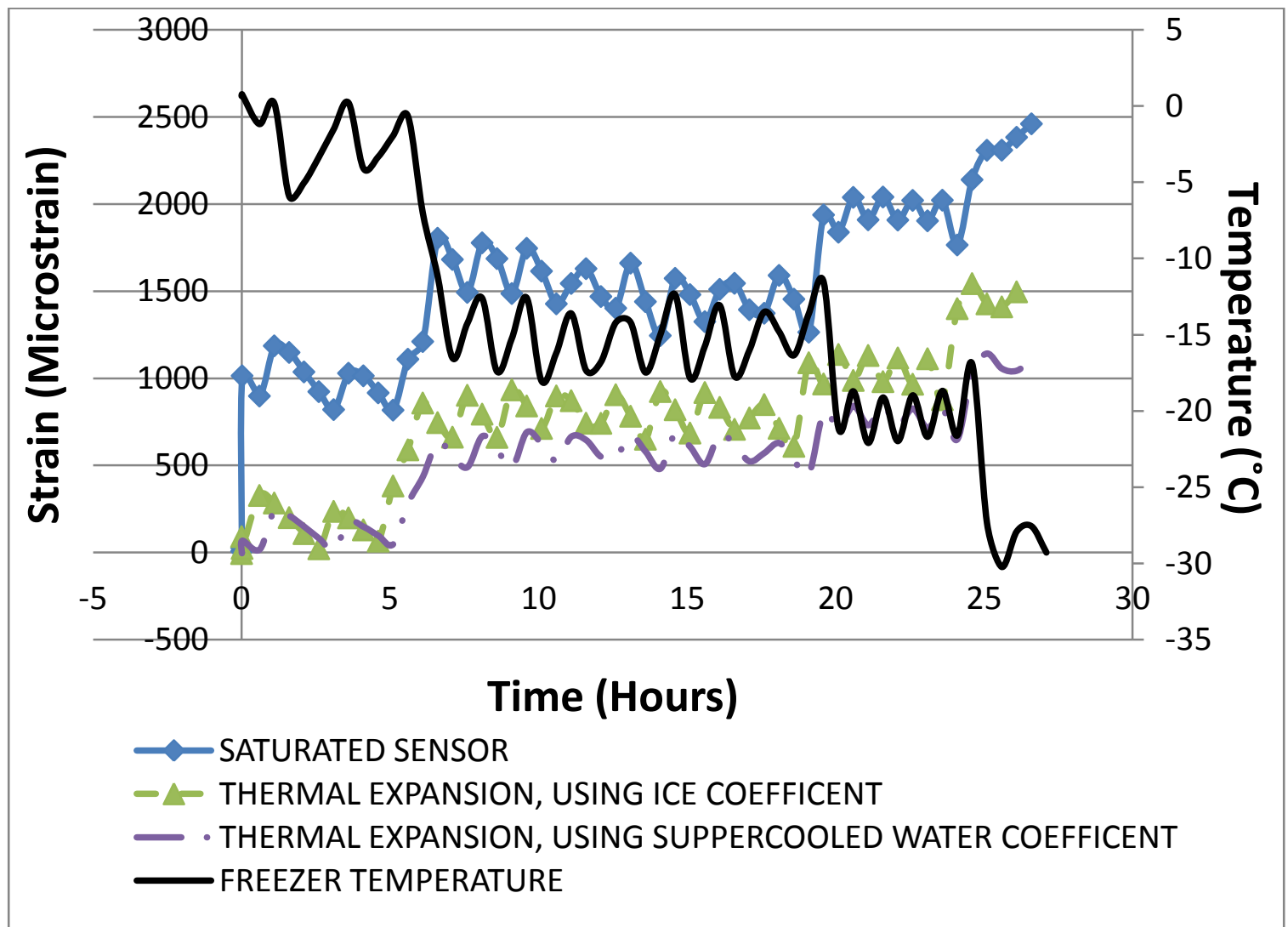

Figure 4-11: Saturated PE Sensor at Temperatures $0,-10,-20$ and $-30^{\circ} \mathrm{C}$ 
From the Figure 4-11 it can be seen that as the temperature decreases the strain tends to increase. The temperature change and the PE sensor behaviour tend to correlate with each other. It can also be observed that compared to the matric suction obtained from the dry sensor at freezing to the saturated sensor at freezing, the saturated PE sensor has a higher strain compared to the dry PE sensor. The strain values obtained by the PE sensor show that when the PE sensor is at its saturation, accurate results can be

obtained. The results are compared to both expected thermal expansion of ice $\left(50 /{ }^{\circ} \mathrm{C}\right)$ and the thermal expansion of super cooled water $\left(37 /{ }^{\circ} \mathrm{C}\right)$.

Both thermal volume change of super cooled water and ice could largely explain the observed changes in the sensor, therefore it was not possible to determine when the pores inside the sensor were frozen or not. Whether or not the pores were frozen, the strains produced by temperature change are the same order as would be expected from suction changes. Therefore, the use of the sensor in freezing conditions remains problematic.

\subsubsection{PE Sensor in Freezing Conditions in Silt at Saturation}

An additional experiment was conducted using the PE sensor under the same freezing conditions while inserted in to the silt with a gravimetric water content of $20 \%$. The behaviour of the change in matric suction due to the change in temperature from $0^{\circ} \mathrm{C}$, $10^{\circ} \mathrm{C},-20^{\circ} \mathrm{C}$ and $-30^{\circ} \mathrm{C}$ is presented in the Figure $4-12$ below, 


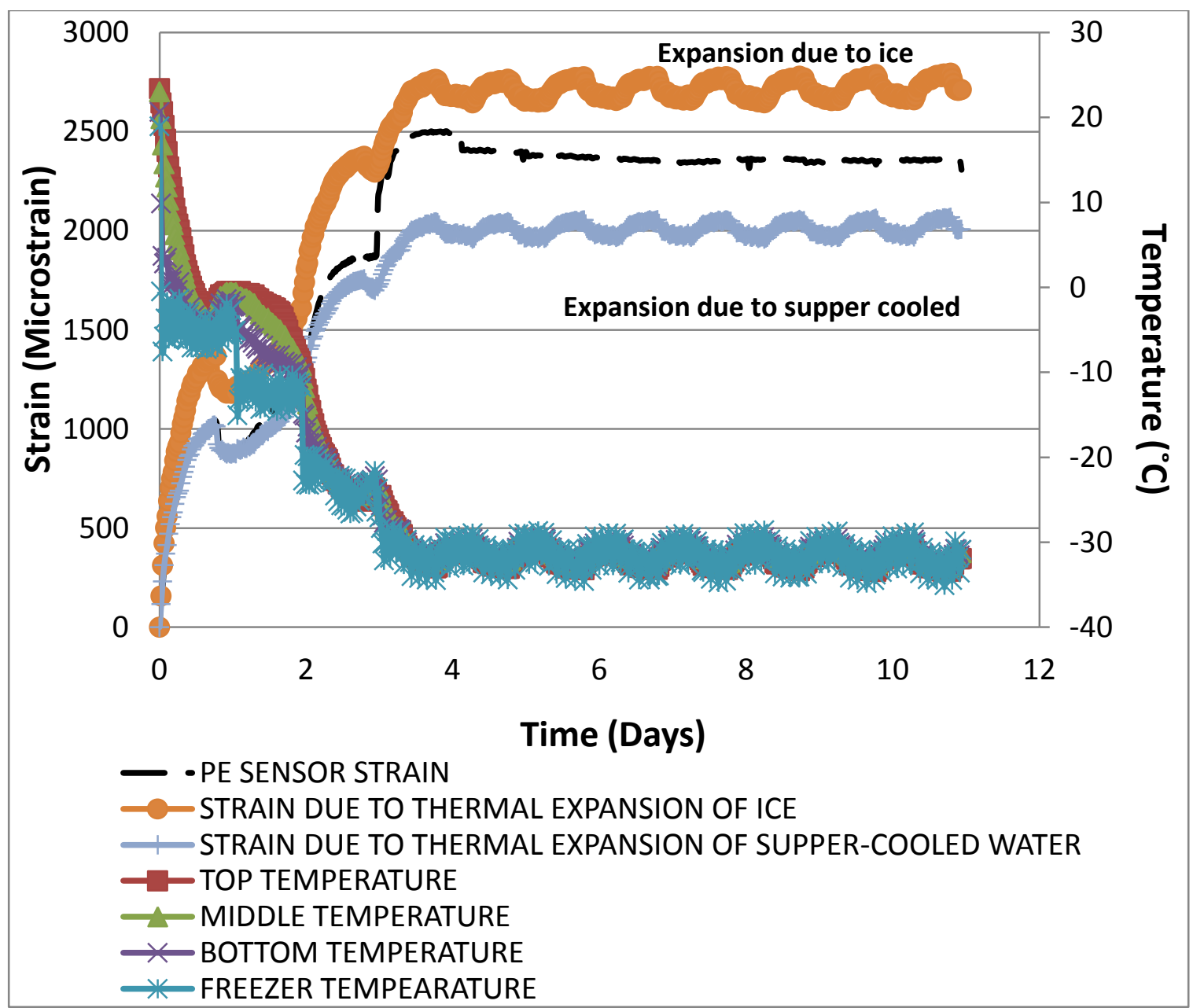

Figure 4-12: Freezing of Silt at 0, -10, -20 and -30 Degrees Centigrade

From the Figure 4-12 it is evident that the PE sensor strain values vary with the changing temperatures. As shown at each temperature change the values tend to go into equilibrium with time as the maximum capacity of volume change was reached in the PE sensor due to the freezing of the silt. The strain results obtained from the PE sensor in Figure 4-12 does not show accurate results due to the fact that strain tends to increase very rapidly as the temperature decreases. It can be seen, whether or not the volume change is due to the presence of ice or super cooled water, the temperature effects 
controls the response of the sensor, and the suction values cannot be determined without further research.

At the end of the experiment, samples of different depths were taken to determine the total suction using the WP4 PotentiaMeter as shown in Table 4-2. Unfortunately, due the influence of temperature on the PE sensor, the total suction results cannot be compared with sensor predictions at this time.

Table 4-2: Total Suction and the Water Content Results after the Freezing Conditions PE Sensor Test with Silt

\begin{tabular}{|c|c|c|c|}
\hline & & & \\
Day & Depth $(\mathrm{cm})$ & Total Suction (MPa) & WC\% \\
\hline 10.5 & $0-1$ & 5.6 & 10.3 \\
\hline 10.5 & $1.0-3.0$ & 1.78 & 9.6 \\
\hline 10.5 & $3.0-5.0$ & 2.33 & 6.6 \\
\hline 10.5 & $5.0-6.0$ & 1.98 & 6.2 \\
\hline 10.5 & $6.0-7.0$ & 2.03 & 6.7 \\
\hline 10.5 & $7.0-9$ & 2.26 & 6.6 \\
\hline
\end{tabular}




\section{Chapter 5: CONCLUSION}

Experiment studies were undertaken to determine the reliability and the functionality of the modified PE sensor. The experiments were conducted mainly using silt. The material chosen for the study was silt which was an inert substance with no chemical composition facilitating it easier to compare the results obtained to other acceptable methods such as the WP4Potentiameter (which measures total suction). The water used in the experiments was distilled water to make sure no other chemicals were present in the water. Oil sand tailings were used in the experimentation to further validate the PE sensor by obtaining matric suction results that corresponds to other acceptable methods. The oil sand tailings used in the experiments were obtained from Total E\&P, and was taken from a mine in Alberta. The applicability of the PE sensor to measure suction under freezing conditions was also investigated.

The experimental results obtained in this thesis yield the following conclusions:

- Valid measurement of the PE sensor requires that the porous rod of the sensor is saturated to $>0.8$ saturation. Given that the AEV (Air Entry Value) of the PE sensor is about $8 \mathrm{MPa}$, the range of suction of the sensor can give reliable measurements of matric suction within the range of $0-8 \mathrm{MPa}$.

- The previous experiments that were done by other researches Dunmola et al. (2010) and Apking (2010) showed a drift in the data obtained. The drift was eliminated by incorporating an outer cover to the sensor to minimize the stress transfer from the 
soil. This allowed the sensor to only interact with the test sample with the exposed tip and give matric suction values that are more accurate with no drift.

- The modification of mounting 2 strain gauges on opposite sides instead of one on the side was proven to be desirable but not fundamental since differential strain in the porous rod tends to be minimal in the operating range of the sensor, as shown in Figure 4-3.

- The comparison tests that were done using the PE sensor and the WP4T potentiaMeter show that the results agree with each other with an average relative error of $0.5 \mathrm{MPa}$ with a standard deviation of $0.5 \mathrm{MPa}$. Given the challenges to perform comparative testing at this suction range, the accuracy is likely even better. This is promising for future development of the Sensor.

- The measurements obtained using the PE sensor in the oil sand tailings was plausible, though conformations of the exact readings were difficult due to the role of osmotic suction, and the high variation of suction with depth.

- The presence of smaller pore diameter $(4 \mathrm{~nm})$ present in the porous rod of the PE sensor was expected to facilitate use of the PE sensor in the freezing conditions as well. The results, however, showed that while the strain occurring in a dry sensor due to the temperature, was small, the strain generated in a saturated sensor was in the same order as would be due to changes in suction. These measurements could either have occurred due to ice formation, or simply by thermal contraction of super cooled water. Therefore, further research is required to determine whether or not 
ice actually formed in the pores, and whether a temperature correction could be used to facilitate suction measurements. 


\section{REFERENCES}

Agus, S. S., \& Schanz, T. (2005). Comparison of four methods for measuring total suction. Vadose Zone Journal,4, No.4, 1087-1095.

Antoniou, A. A. (1964, October). Phase transformations of water in porous glass. The Jounal of Physical Chemistry, 68 (10), pp 2754-2763.

Apking, R. (2010). Research and testing of a poroelastic matric suction sensor. Ottawa: Department of Civil and Environmnetal Engineering, Carleton University.

ASTM Committee. (1981). Manual on the use of thermocouples in temperature measurment. ASTM International, 119.

Beddoe, R. A., Take, W. A., \& Rowe, R. K. (2010). Development of suction measurement techniques to quantify the water retention behaviour of GCLs. Geosynthetic International, 17, 301-312.

Bentz, D. P., Garboczi, E. J., \& Quenard, D. A. (1998). Modelling drying shrinkage in reconstructed porous materials: application to porous Vycor glass. Modelling and Simulation in Material Science and Engineering, 6, 211-236.

Brooks, R. H., \& Corey, A. T. (1964, March). Hydraulic properties of porous media. colorado State University, No.3, 1-27. Fort Collins, Colorado, United States of America: Hydrology Paper

Campbell, J. D. (1973). Pore pressures and volume changes in unsaturated soils. UrbanaChampaign, IL: Ph.D Thesis, Univesity of Illinois.

Cardoso, R., Romero, E., Lima, A., \& Ferrari, A. (2007). A comparative study of soil suction measurement using two different high-range psychrometers. Springer Proceedings in Physics, 112, pp 79-93.

Chesworth, W. (2008). Encycopedia of soil sciences. Springer.

Chin, D. A. (2006). Water resources engineering (second edition ed.). Prentice Hall.

Darcy, H. (1856). Les fontaines publiques de lu Ville de Dijon. Victor Dalmont,Paris.

Davidson, J. M., Stone, L. R., Nielson, D. R., \& Larue, M. E. (1969). Field measurement and use of soil-water properties. Water Resources Research, 5,1312-1321.

Decagon Devices Inc. (2007). WP4 DewPoint PotentiaMeter operators manual. Pullman, WA: Decagon Devices Inc. 
Dunmola, A., Simms, P., \& Padilla, M. (2009). Conception, design, and preliminary testing of a poroelastic matric suction sensor.In Proceedings of GeoHalifax 2009, 65 ${ }^{\text {nd }}$ Canadian Geotechnical conference, Sept $20-24^{\text {th }} 2009$, Halifax, N.S., Canada, Electronic Proceedings.

Dunmola, A., Simms, P., \& Padilla, M. (2010). Princicle and Prototye Testing of a New Matric Suction Sensor. Geotechnical Testing Journal, 33, No.5, 1-7.

Fredlund, D. G., \& Houston, S. L. (2013). Interpretation of soil-water characteristic curves when volume change occurs as soil suction is changed. In Proceedings of the First Pan-Am Conference on Unsaturated Soils, UNSAT 2013, "Advances in Unsaturated Soils", Editor: Bernardo Caicedo, February 20-22 2013, 15-31.

Fredlund, D. G., \& Morgenstern, N. R. (1977). Stress state variables for unsaturated soils. Journal of the Geotechnical Engineering Division, 103, ASCE 12919, 447-466.

Fredlund, D. G., \& Rahardjo, H. (1988). State-of-development in the measurement of soil suction. Proceedings of the First International Conference of Engineering Problems of Regional Soils. 47, pp. 582-588. Beijing, China: NRC Research Press.

Fredlund, D. G., \& Rahardjo, H. (1993). Soil mechanics for unsatuarted soils. John Wiley \& Sons.

Fredlund, D. G., \& Rahardjo, H. (2007). Appendix B: theoretical justification for stress state variables, in soil mechcanics for unsaturated soils. Hoboken, NJ, USA: John Willey \& Sons, Inc. doi:10.1002/9780470172759.app2

Fredlund, D. G., \& Xing, A. (1994). Equations for the soil-water characteristic curve. Can.Geotech,31(3), 1-12.

Fredlund, D. G., Fredlund, M. D., \& Zakerzadeh, N. (2001). Predicting the permeability fuction for unsaturated soils. In Proceedings of the International Symposium on Suction, Swelling, Permeability and Structured Clays, January $11-13^{\text {th }} 2001$, IS-Shizuoka, Shizuoka, Japan, Electronic Proceedings.

Fredlund, D. G., Wilson, G. W., Gan, J. K.-M., \& Barbour, S. L. (1995). Moisture movement in highway subgrade soils - prediction and measurement. In Proceedings of the $45^{\text {th }}$ Canadian Geotechnical Conference 1992, October 26-28, 1992, Toronto, Canada, 21-40.

Gardner, W. R. (1958). Laboratory studies of evaporation from soil columns in the presence of a water-table. Soil Sci., 85(5),244-249.

Green, A. E., \& Corey, J. C. (1971). Calculation of hydraulic conductivity: a further evaluation of some predictive methods. Soil Sci Soc.,35, 3-8.

Hosford, W. F. (2005). Mechanical behavior of materials. Cambridge, New York, United States: Cambridge University Press. 
Huat, B. B., Ali, F. H., \& Mariappan, S. (2005). Effect of surface cover on water infiltration rate and stability of cut slope in residual soils. Electronic J Geotech Eng, 10. Retrieved from www.ejge.com/2005/Ppr0614/Ppr0614.htm

Innocent-Bernard. (2013). Evaporation, cracking, and salinity in a thickened oil sands tailings. MSc Thesis. Ottawa: Carleton University.

James, C. M. (2000). Damping of water infiltrated nanoporous glass. Journal of Alloys and Compounds,310,24-28.

Kagawa, Y. (1994). Effect of thermally induced stress on fracture toughness of SiC figure-glass matrix composites. Material Transactions, Vol.35, No. 5, 363-369.

Krahn, J., \& Fredlund, D. G. (1972). On total, matric and osmotic suction. Soil Science,114, No. 5, 339-348.

Laloui, L., Klubetranz, G., \& Vulliet, L. (2003). Solid-liquid-air coupling in multiphase porous media. John Wiley \& Sons, Ltd.

Li, J. C., Ross, D. K., \& Benham, M. J. (1991). Small-angle Neutron scattering studies of water and ice in porous vycor glass. Birmingham: Journal of Applied Crystallography. 21 (2), 794802.

Lu, N., \& Likos, W. J. (2004). Unsaturated Soil Mechanics. John Wiley \& Sons.

Micro-Measurment Division. (n.d.). General infomation series EA strain sages. Releigh: Measurment Group, INC.

National Instruments Corporation. (1998). Strain gauge measurement - A. National Instruments, 1-12.Retrieved from www.ni.com

Pan, H., Qing, Y., \& Pei-yong, L. (2010). Direct and indirect measurment of soil suction in the laboratory. Electronic Journal of Geotechnical Engineering, vol. 15, 1-14.

Patzek, T. (2005, December 5). Biot Theory . Seminar at the University of Houston, 32. Houston: University of Houston.

Rahardjo, H., \& Fredlund, D. G. (2007). Measurment of soil suction. In Soil Mechanics for Unsaturated Soils (p. chapter 4). Hoboken, NJ, USA.: John Wiley \& Sons, Inc.

Rault, J., Neffati, N., \& Judeinstein, P. (2003). Melting of ice in porous glass:why water and solvents confined in small pores do not crystallize. The European Physical Journal , B 36, 627-637.

Richards, L. A. (1931). Capillary conduction of liquids though porous medium. Journal of physics, 1, 318-333. 
Ridley, A. M., \& Burland, J. B. (1999). Use of the tensile strength of water for the direct measurement of high soil suction: discussion. Can. Geotech Journal, 36, 178-180.

Ridley, A. M., \& Wray, W. K. (1995). Suction measurement: a review of current theory and practices. In proceeding of the 1st International Conference on Unsaturated Soils. Unsaturated soilds, 3, pp. 1293-1322. Paris: Transport Research Laboratory.

Schiller, P., Bier, T., Wahab, M., \& Mogel, H. J. (2008, September 15). Mesoscopic model of volume change due to mosture variations in porous material. Elsevier, 327(1-3), 34-43.

Sotomayor, P. T., Raimundo Jr., I. M., Zarbin, A. J., Rohwedder, J. J., Neto, G. O., \& Alves, O. L. (2001). Constrauction and elvaluation of an optical pH sensor based on Polyanilineporous Vycor glass nanocomposite. Elsevier Science, B 74, 157-162.

Tarantino, A., Romero, E., \& Cui, Y.-J. (2009). Laboratory and field testing of unsaturated soils. New York, NY, United States of America: Springer Netherlands. doi:10.1007/978-1-40208819-3_1

Tokyo Sokki Kenkyujo Co.Ltd. (n.d.). Precise \& flexible strain gauges. Tokyo: TML.

UMS. (2009). Manual: T5/T5x pressure transducer tensiometer. 1-48. Retrieved from http://www.ums-muc.de/fileadmin/produkt_downloads/Tensiometer/T5_Manual.pdf

van Genuchten, M. T. (1980, September- Octorber). A closed-form equation for predicting the hydraulic conductivity of unsaturated soils. Journals of the Soil Sciences Soc., 44, No. 5, 892-898.

Vanapalli, S. K., \& Fredlund, D. G. (2000). Comparison of different procedures to predict unsaturated soil shear strength. In Proceedings of the GeoDenvor Conference 2000, August 5-8 2000 Colorado: GeoDenver. (pp. 195-209).Geotechnical Special Publication

Vanapalli, S. K., Nicoteria, M. V., \& Sharma, R. S. (2008). Axis translation and negative water column techniques for suction control. Geotechnical and Geological Engineering, 26, 645-660.

Wilson, G. W., Clifton, A. W., \& Barbour, G. L. (1999). The emergence of unsaturated soil mechanics. NRC (Natural Research Council), 75,735.

Wind, G. P. (1955). Field experiment concerning of rise of moisture in heavy clay soil. Netherlands Journals of Agricultural Science, 3, 60-69. 


\section{APPENDIX A}

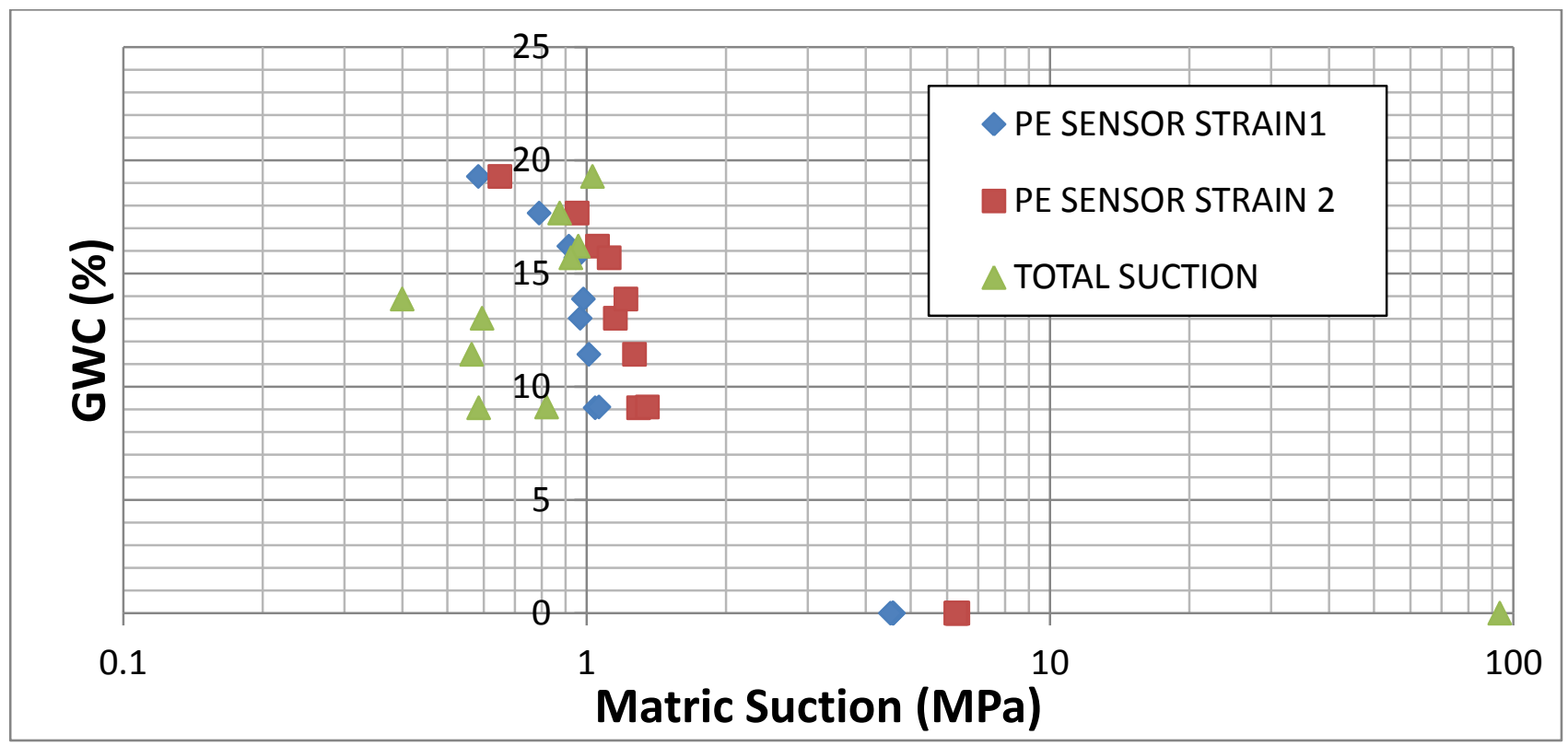

Figure A -1: Comparison Results of Total Suction Machine Results vs. PE sensor Results in SWCC1 - Test1

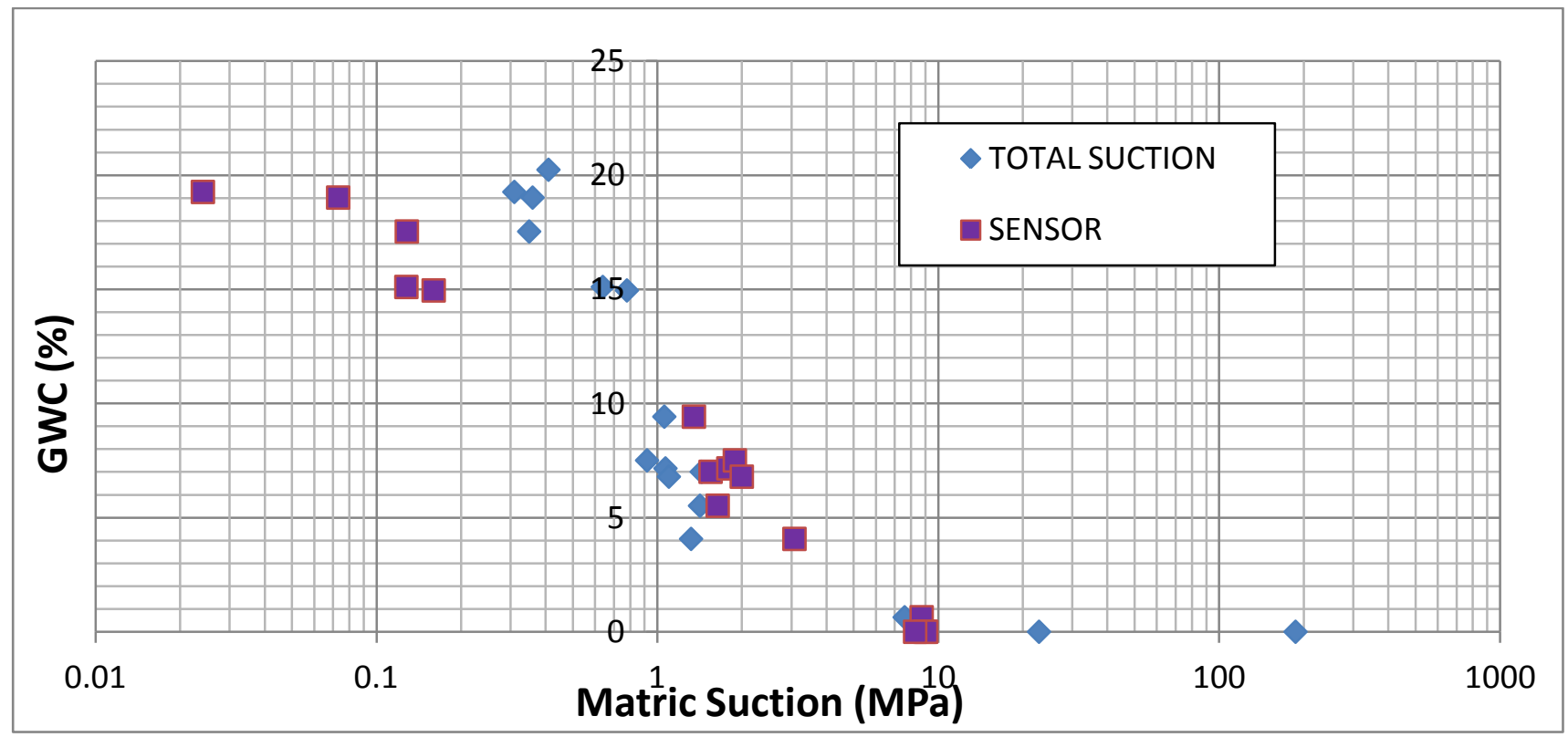

Figure A -2: Comparison Results of Total Suction Machine Results vs. PE sensor Results in SWCC2 - Test2 


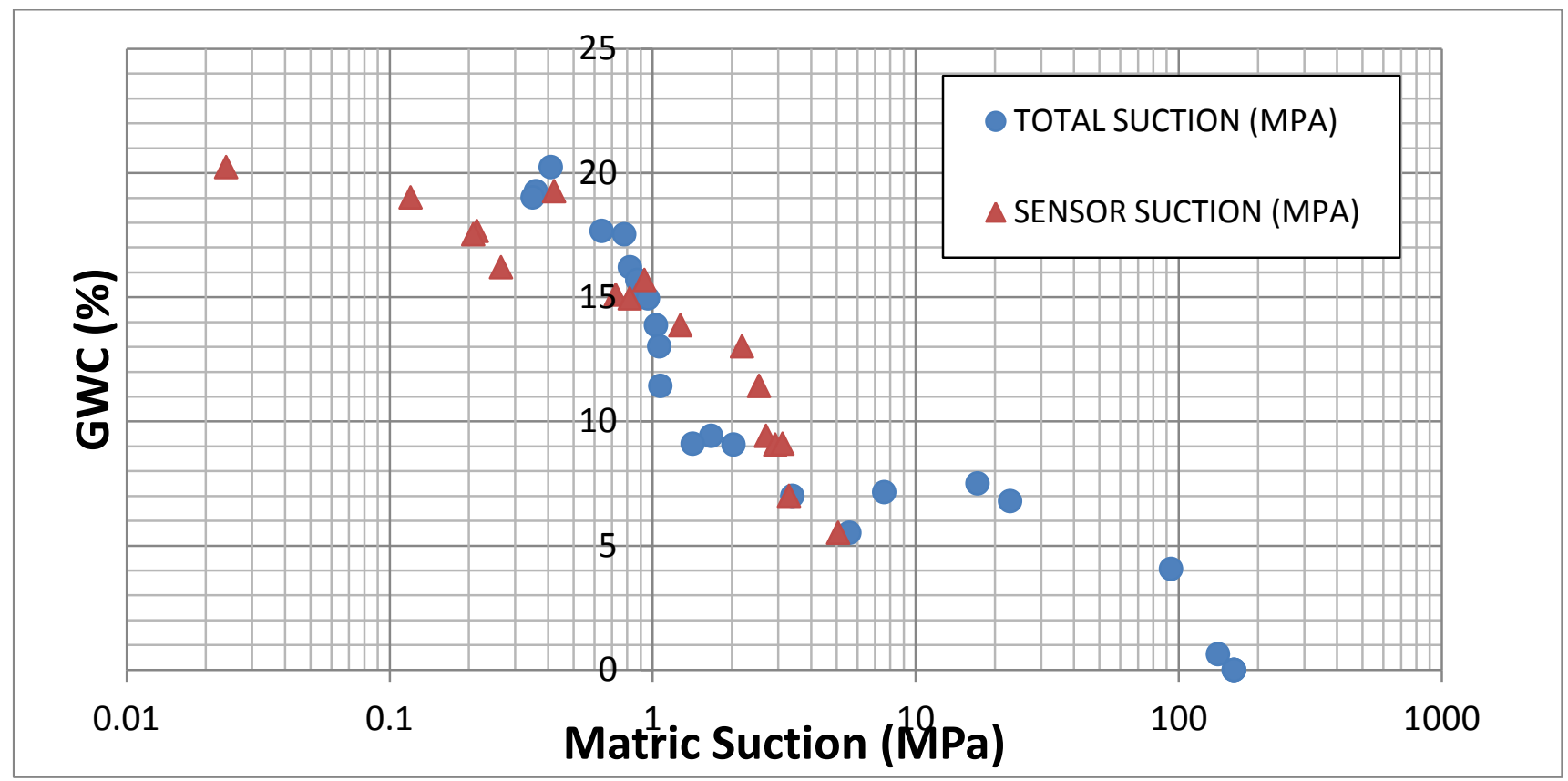

Figure A-3: Comparison Results of Total Suction Machine Results vs. PE sensor Results in SWCC3 - Test3 


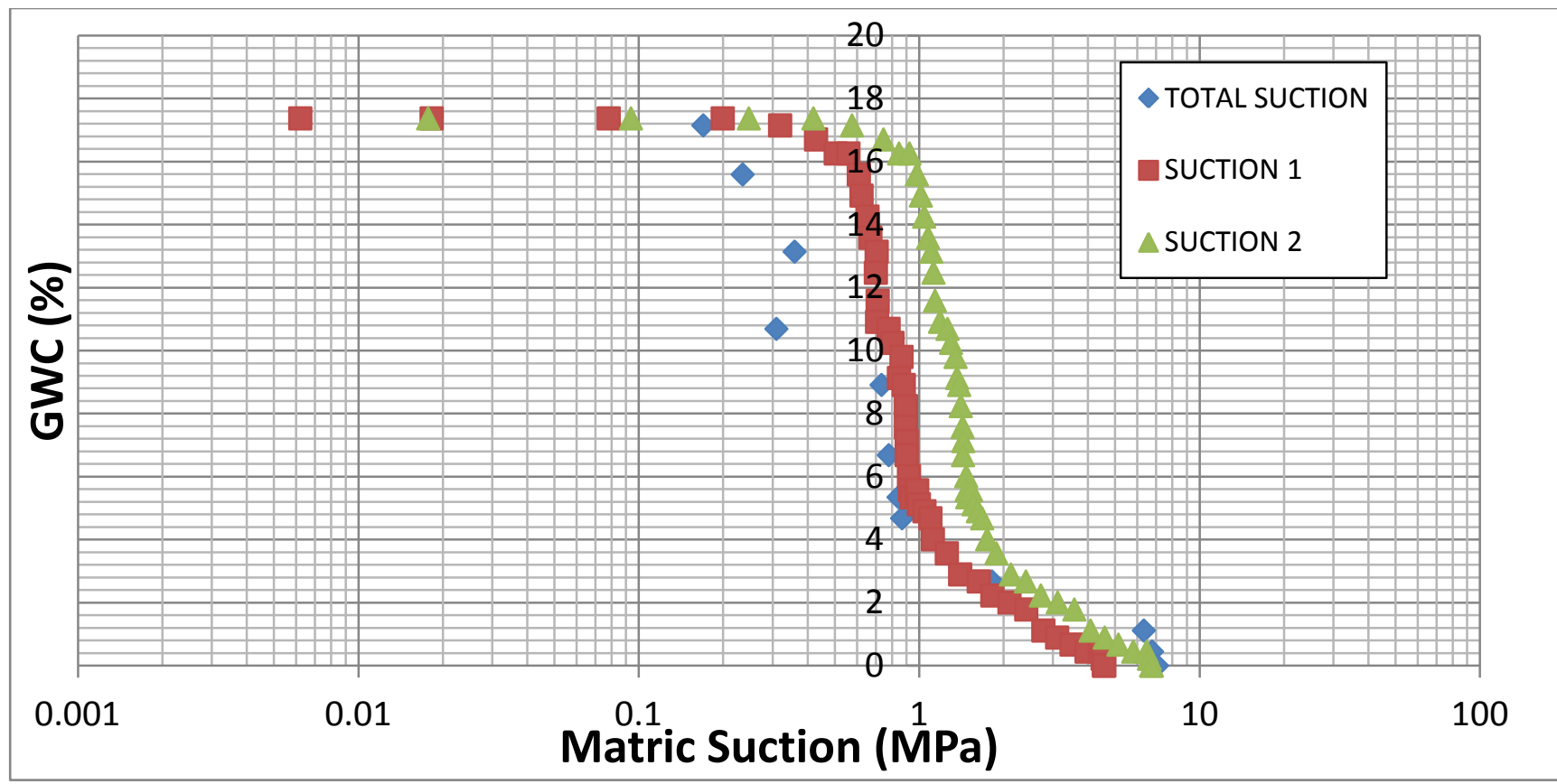

Figure A-4: Comparison Results of Total Suction Machine Results vs. PE sensor Results in SWCC4 - Test4

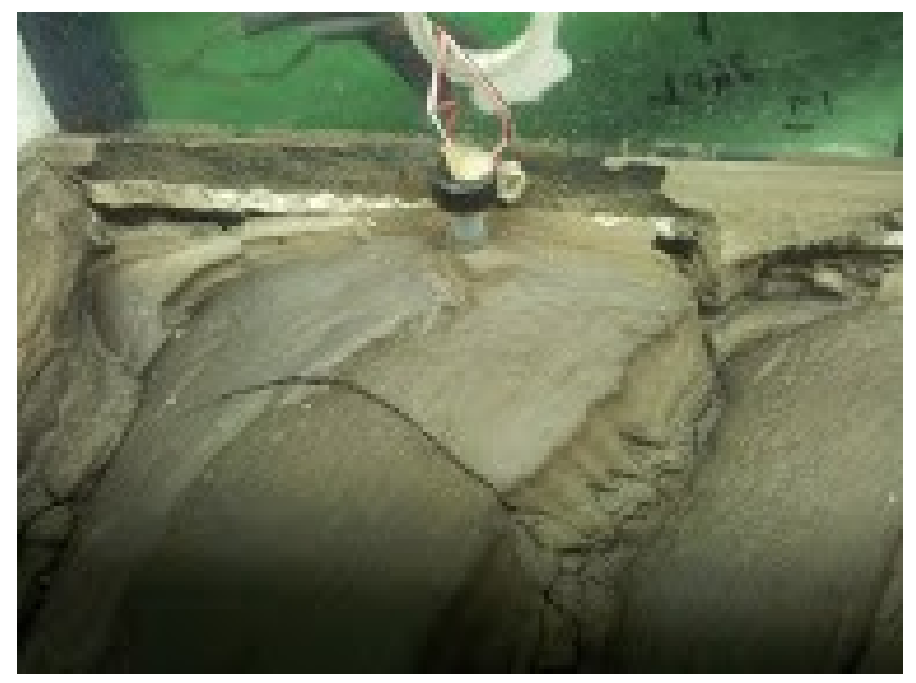

Figure A-5: Photograph of the PE Sensor Inserted into the Drying box of the oil Sand Tailings 


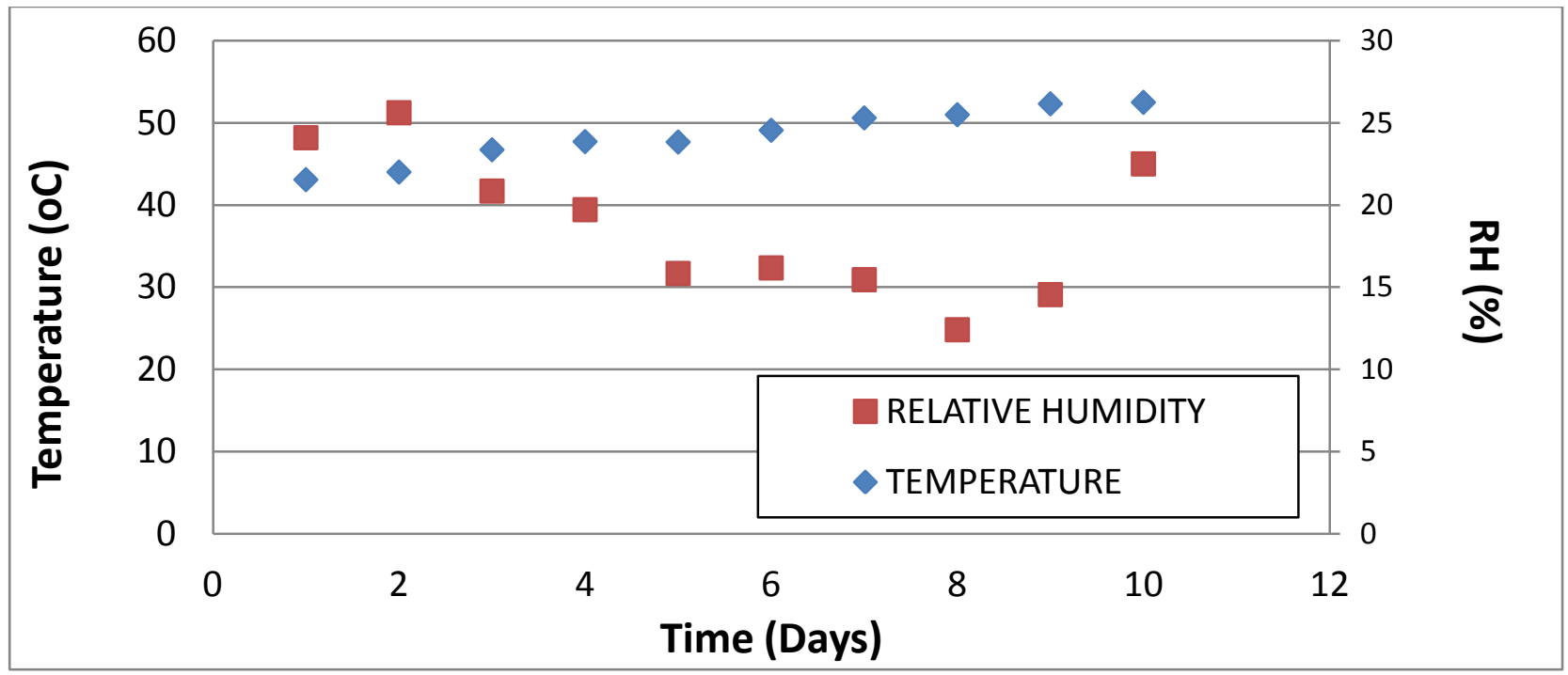

Figure A-6: Temperature, RH versus Time Plot for the oil Sand Tailings

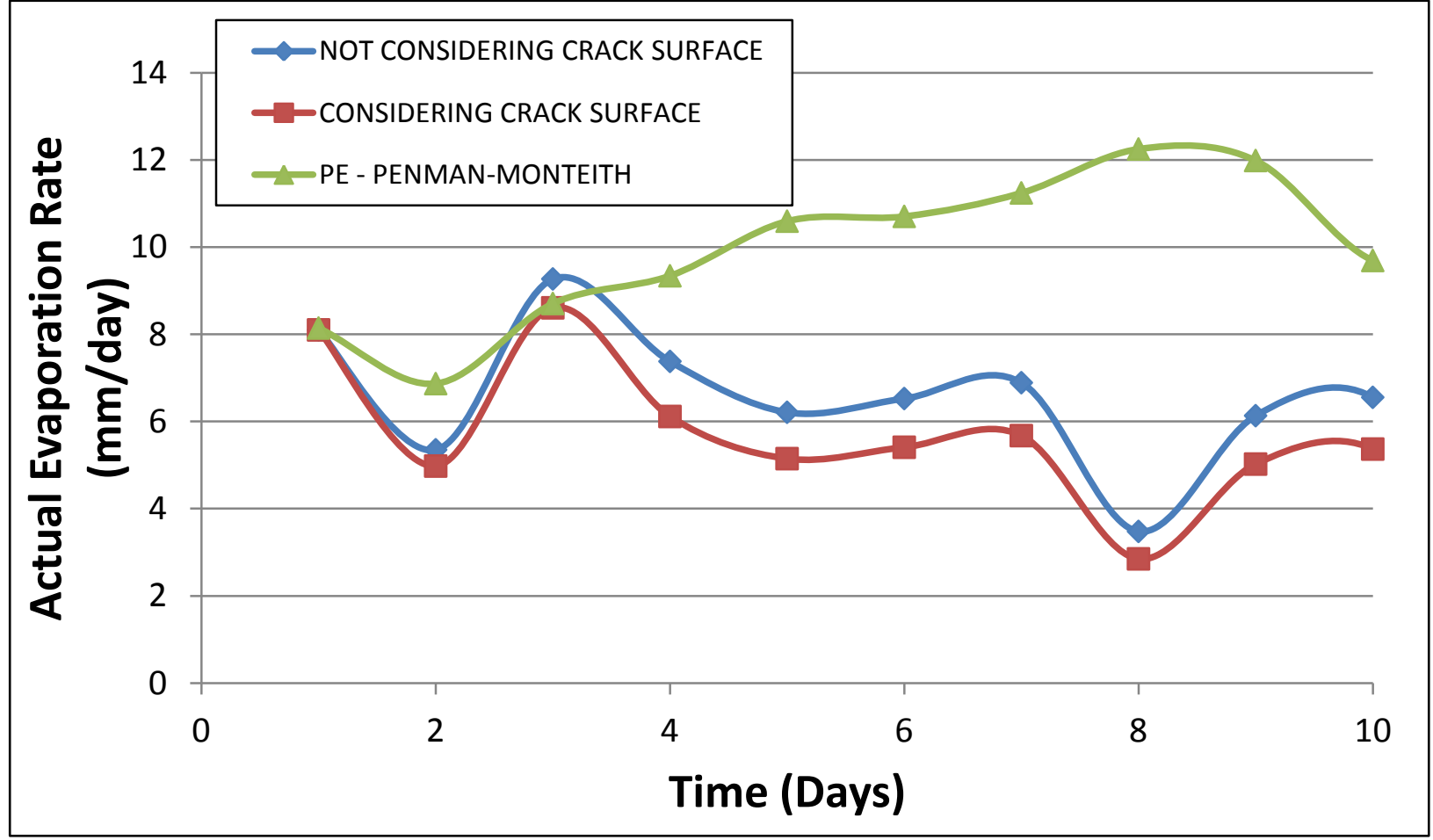

Figure A-7: Evaporation Rates of the oil Sand Tailings with and without Cracked Surface 